WALTER DE PAULA LIMA

ENGENHEIRO-AGRÓNOMO

"MASTER OF SCIENCE"

Professor Assistente do Departamento

de Silvicultura. ESALQ-USP

\title{
ESTUDO DE ALGUNS ASPECTOS QUANTITATIVOS E QUALITATIVOS DO BALANÇO HIDRICO EM PLANTAÇÕES DE EUCALIPTOS E DE PINOS
}

Orientador: Prof. Dr. Octavio Freire

Tese apresentada a Escola Superior de Agricultura "Luiz de Queiroz" da Universidade de São Paulo para a obtenção do titulo de Doutor 
ERRATA

Na capa e na contracapa, onde se lê PINOS leia-se PINUS 
AOS MEUS PAIS,

A MINHA ESPOSA,

E A MINHA FILHA,

ofereço 


\section{AGRADECIMENTOS}

O autor deseja manifestar seus mais sinceros agrade cimentos as seguintes pessoas e instituições, as quais foram de inestimável valor na elaboração do presente trabalho:

Ao Prof. Dr. Octavio Freire, pela orientação.

Ao Prof. Dr. Helládio do Amaral Mello, pelo constan te estímulo e apoio.

Ao Prof. Dr. Klaus Reichardt, pela colaboração, pelas sugestões apresentadas, e pela permissão para uso da sonda de neutrons.

Ao Prof. Dr. Décio Barbin, pela orientação nas análises estatísticas.

Ao Prof. Dr. Jesus Marden dos Santos, pelas sugestões e pelo empréstimo dos interceptômetros.

Ao Prof. Dr. Zilmar Ziller Marcos, pela colaboração na análise das amostras do solo.

Ao Sr. Pedro Brancalion, pela análise textural do solo.

A Srta. Mariluce Pitta Villar, pelo cuidado e dedi cação com que executou as análises de laboratório, a computação dos dados, a confeção dos gráficos e a datilografia do manuscrito.

Ao Centro de Energia Nuclear na Agricultura (CENA), pelo empréstimo da sonda de neutrons.

A Fundação de Amparo à Pesquisa do Estado de São Paulo, pela doação do veículo.

Ao Conselho Nacional de Pesquisas, pelo auxílio financeiro que possibilitou a compra dos instrumentos de laboratório e dos reagentes necessários para parte das análises desenvolvidas. 
CONTEO DO

IISTA DAS TABELAS • • • • . • • • • • v

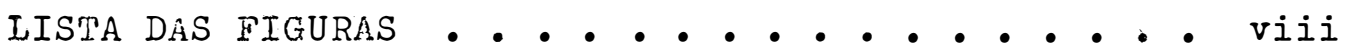

1. InTRODUÇAO . . . . . . . . . . . • 1

2. OBJETIVOS ...................... 4

3. REVISÃo da LITERATURA

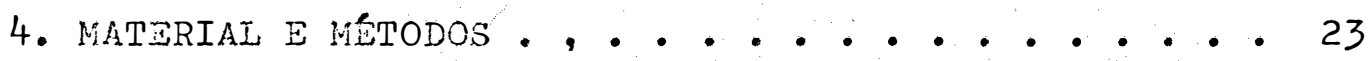

4.1. A Area Experimental . . . . . . . 23

4.2. Plano Experimental . . . . . . 25

4.3. Metodologia .............. 27

5. RESULTADOS E DISCUSSTO . . . . • . . . 32

5.1. Caracteristicas Fisicas do Solo... . . . 32

5.2. Interceptação . . . . . . . . . 34

5.3. Regime da Água do Solo . . . . . . . 44

5.4. Crescimento em Área Basal . . . . . . 68

5.5. Efeitos Sobre a Qualidade da Água . . . . 72

6. RESUMO $\mathrm{E}$ CONCLUSOES

7. SUMMARY •................ 95

8. LITERATURA CITADA • • • • • • • • • 99 
1 Características Tísicas do solo ............ 33

2 Frequências das várias classes de tamanho de chuvas ocorridas durante o periodo experimen tal, e respectivos valores médios de PI e Tit registrados nos povoamentos de Eucaliptos e

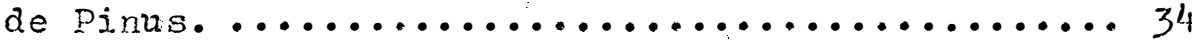

3 Equações para a Estimativa da Precipitação Interna (PI), siscoamento pelo tronco( $\Xi t)$ e Precipitação Ifetiva $(\mathrm{P})$, a partir da medi-

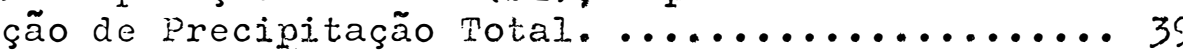

4 Valores de Precipitação Interna (PI), Lscoamento pelo tronco (Lt), Precipitação Bietiva (PE) e Perda por Interceptação (I) em $\mathrm{mm} \mathrm{e}$ em porcentagem sobre Precipitação Total (PT) para o povoamento de Eucalipto.............41

5 Valores de Precipitação Interna (PI), Escoamento pelo tronco ( It), Precipitação Efetiva (PE) e Perda por Interceptação (I) em mm e em porcentagem sobre Precipitação Total (PT) para o povoamento de Pinus................ 42

6 Valores Máximos e Mínimos de Agua do solo Observados durante o Período Experimental....... 51

7 Depleção da Água do Solo, Precipitação e Eva poração de Tanque Classe A medidas em Períodos Isolados da Pstação Seca de 1973, 1974 e 1975. Eucalipto.......................63

8 Depleção da Ácua do Solo, Precipitação e iva poração de Tanque Classe A medidas em Períodos Isolados da Istação Seca de 1973, 1974 e 1975. Pinus. ........................... 64

9 Depleção da Agua do Solo, Precipitação e Tiva poração de Tanque Classe A medidas em Períodos Isolados da Estação Seca de 1973, 1974 e 1975. Vesetação Ierbácea.................. 65 
10 Consumo de Áçua e Taxa de Evapotranspiração por iucalyptus salina, por pinus caribaea e por Vegetação ITerbacea Hatural, durante as estações secas de 1974 e parte das estações secas de 1973 e 1975, e Valores da Razão ET/

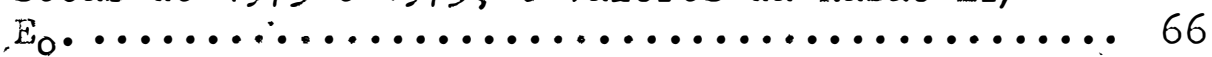

11 Valores de DAP médio e de Area Basal do Povoamento de Eucalipto e de Pinus, durante o Período ixperimental................... 68

12 Valores de pif para Chuva, Precipitação Inter na de Lucalipto (E-PI), Pinus (P-PI) e escoa mento pelo tronco em eucalipto ( $\mathrm{E}-\mathrm{Et}$ ) e em

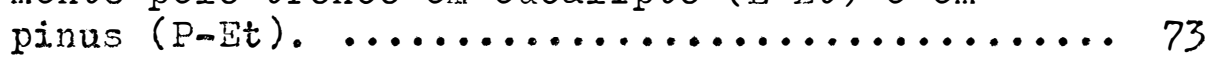

13 Análise da Variância para os Dados de ply...... 74

14 Análise da Variância para os Dados de pH. ..... 75

15 Valores de Turbidez para Chuva, Precipitação Interna em eucalipto ( $\mathrm{E}-\mathrm{PI}$ ), pinus (P-PI) e escoamento pelo tronco em eucalipto (E-Et) e

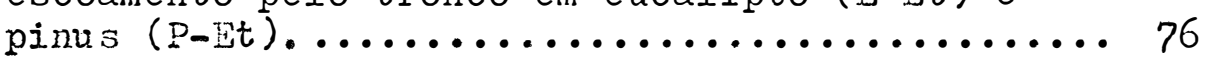

16 Análise da Variância para os dados de Turbidez. ........................... 77

17 Valores de Condutividade Especifica para Chu va, Precipitação Interna em eucalipto (E-PI), pinus (P-PI), e escoamento pelo tronco em eucalipto $(\mathrm{E}-\mathrm{E} t)$ e pinus $(\mathrm{P}-\mathrm{E} t) \ldots \ldots \ldots \ldots \ldots \ldots, 78$

18 Análise dáa Variância para os Dados de Condutividade ispecífica................... 79

19 Valores de Sólj.dos Totais Dissolvidos para Chuva, Precipitação Interna em Eucalipto ( $\mathrm{E}-\mathrm{PI}$ ), Pinus (P-PI) e escoamento pelo tronco em euca-

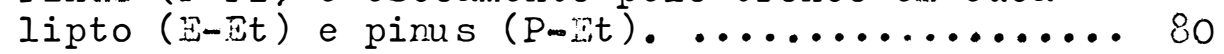


20 Análise da Variância para os dados de sólidos Totais Dissolvidos ........................ 81

21 Valoṛes de Cor para chuva, precipitação interna em eucalipto (E-PI), pinus (P-PI), e escoamento pelo tronco em eucalipto ( $\mathrm{s}-\mathrm{Tt}$ ) e pinus

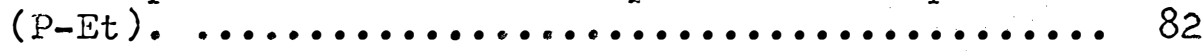

22 Análise da Variância para os dados de Cor...... 83

23 Análise da variância para os dados de Cor...... 84

24 Valores de Alcalinidade para a chuva, precipitação interna em eucalipto (E-PI), pinus (P-PI), e escoarento pelo tronco em eucalipto (E-Et) e pinus $(P-E t) . \ldots \ldots \ldots \ldots \ldots \ldots \ldots \ldots \ldots \ldots . \ldots \ldots$

25 Análise da Variância para os dados de Alcalinidade. ............................... 86

26 Comparação dos aspectos qualitativos entre chuva, precipitação interna em eucalipto (E-PI), pirus (P-PI), e escoamento pelo tronco em eucalipto $(\mathrm{E}-\mathrm{Et})$ e pinus $(\mathrm{P}-\mathrm{Et})$................ 87 
1 Localização da Area Experimental em Relação ao Estado de São Paulo, ao Município de Piracicaba, e ao Campus da BSAIQ-USP.

2 Representação esquemática dos componentes do balanģo hídrico em um povoamento flores-

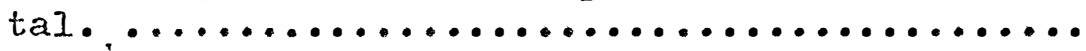

3 Vista interna do povoamento de eucalipto e dos dispositivos de medição da precipitação interna e do escoamento pelo tronco...........

4. Detalhe da medição da água do solo, vendo-se a sonda de neutrons sobre o tubo de alumínio e o aparelho medidor de neutrons moderados......

5 Relação entre Precipitação Interna (PI) e Precipitação Total (PT) em Eucalipto e Pinus...... 36

6 Relação entre Escoamento pelo tronco (Et) e Precipitação Total (PT). en Eucalipto e Pinus.... 37

7 Relação entre Precipitação Efetiva (PE) e Precipitação Total (PT) em Eucalipto e Pinus. .... 38

8 Variação do Armazenamento de água no perfil

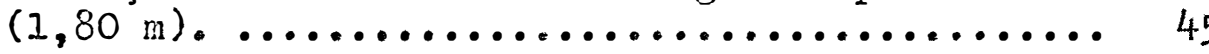

9 Regime Anual da Água do Solo $(1,80 \mathrm{~m})$. Média de dados de 2 anos. .................... 47

10 Variação Anual da Água do Solo em Diferentes Profundidades

11 Valores Máximos e Míninos de Ågua no Solo, nas diferentes camadas, observados em dois anos de

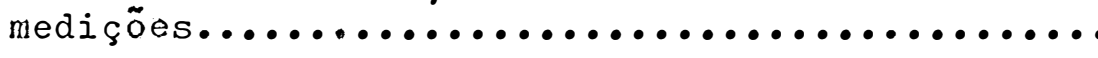

12 Distribuição da Ågua no Perfil do Solo......... 53

13 Distribuição da Agua no Perfil do Solo ........ 54 
14 Distribuição da $\AA_{\text {gua no }}$ Perfil do Solo ...... 55

15 Depleção da Agua do Solo................ 56

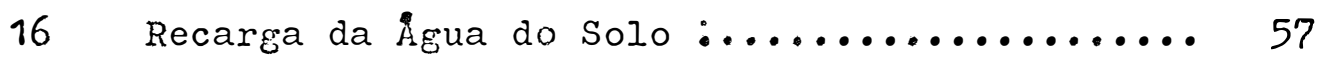

17 Comparação do Total de Ánua Armazenada no Perfil de 1,80 metros (S) entre Eucalipto e V'écetação Herbácea

18 Comparação do Total de Água Armazenada no Perfil de 1,80 metros (S) entre Pinus e Vegetação पrerbácea

19 Comparação do Totaj de Agua Armazenada no Perfil de 1,80 metros (S) entre Eucalipto

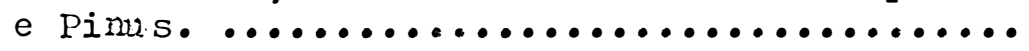

20 Crescimento da Área Basal Estacional dos Povoamentos de Eucaliptos e de Pinus. ....... 69

21 Crescimento Acumulado de Area Basal, Incremento do DAP e Agua Armazenada no Perfil do Solo durante o periodo experimental 


\section{INTRODUÇÃO}

Várias espécies de eucaliptos e de pinus encontraram condições de crescimento bastante favoráveis no Brasil, e a cultura destas espécies rapidamente adquiriu elevada importância econômica. Somente com o estabelecimento dos incentivos fiscais, no Estado de São Paulo foram reflorestados, de 1967 a 1973, cerca de 380 mil hectares, correspondendo a aproximadamente 822 milhões de árvores plantadas, sen do $72,6 \%$ com espécies de eucaliptos e $21,2 \%$ com espécies de pinus. Para o país todo, no mesmo período foram reflorestados 1.206 .715 hectares, correspondendo a cerca de 2,7 bilhões de árvores plantadas, sendo $70 \%$ de eucaliptos e $25 \%$ de pinus (ASSOC. PAUL. FABRIC. CELULOSE E PAPEL, 1973): No Estado de São Paulo, 85\% do consumo de madeira de eucaliptos e 60\% do consumo de madeira de pinus são destinados à fabrica ção de celulose e papel (SECRETARIA DA AGRICULTURA, 1974).

Com relação to eucalipto, existe uma opinião popular generalizada de que esta essência florestal, além de outros efeitos, é responsável por um consumo exagerado de água, e que o reflorestamento com esta espécie poderia, portanto, ser prejudicial aos recursos hídricos. Estas especulações, correntes não apenas no Brasil (FERRI, 1957), como também em outros países (KARSCHON e HETH, 1967), (DORST, 1973), podem ser consideradas sob dois aspectos: um lado positivo, que reflete o fortalecimento de uma preocupação geral para com os chamados problemas ambientais; e um lado negativo, pois podem forçar uma mudança de política em relação ao reflorestamento com estas es pécies exóticas, mesmo considerando sua atual expressão econômica.

O conhecimento das relações de água em eucaliptos

e em pinus se reveste, portanto, de importância prática imediata. Primeiro, pelo fato de que tais dados experimentais são essenciais para o estabelecimento de políticas sadias de uso do solo e da água (KARSCHON e HETH, 1967). Segundo, porque são imprescindíveis para a elaboração de normas de manejo destas essências florestais exóticas compatíveis com a manutenção de condições ambientais desejadas. Isto, ao que parece, seria um dos requisitos básicos para se ajustar as atividades de explotação econômica destes recursos naturais às necessidades atuais de planejamento adequado do uso da terra, pois, como afirma VON ARX $(1974)$ : 
"In recent centuries we have learned a great deal about the earth but not much about our relationship to it. It is becoming clear that we now have to learn to live with the earth and not just on it..."

Antes que se possam estabelecer normas adequadas de manejo de um recurso natural qualquer, é necessário proceder-se a um in ventário deste recurso. Um inventário completo deve conter também a aná lise detalhada de todas as fases do ciclo hidrológico, incluindo as per das de água por interceptação, evapotranspiração e escoamento superfici al, o regime da água no solo, os efeitos sobre a qualidade da água, além de outros. A caracterização destes processos individuais é fundamental para o conhecimento do recurso em si mesmo, de seu comportamento local e de suas possíveis influências ambientais, conforme esclarece WITrICH, citado por GEIGER (1966):

\footnotetext{
"... it is only when the complicated (water) relations are broken doun into individual processes, and these processes are studied in typical limited areas, that advances can be made and the tendency avoided to transfer correct results incorrectly in to other contexts."
}

A literatura, todavia, mostra muito pouco, ou quase nada a respeito de estudos de balanço hídrico com estas essências florestais no Brasil. FRANCO e INFORZATO (1950) e MELLO (1960) procuraram determinar as taxas de transpiração de Eucalyptus saligna e de E. alba, respectivamente, através do método de pesagens rápidas de folhas destacadas. Esta metodologia tem sido usada para a verificação da taxa de transpiração de essências florestais, mas é passivel de críticas(RUTTER 1968), (DECKER e WIEN 1960). Segundo RULTER (1968), a taxa de transpiraçâo pode ser alterada a partir do exato momento em que se cortou a fo Tha para a pesagem; além disto, fica muito dificil, a partir dos dados obticos pelo método de pesagens rápidas, estimar-se o consumo de água de unoamento durante um período de tempo. Como lembra RUTTER ainda, ao se referir ao consumo de água em florestas, é preciso não esquecer que este inclui não apenas a transpiração, mas também a evaporação da precipitação que é interceptada pelas copas, assim como a evaporação da água do solo. Já em 1961, por ocasião da Segunda Conferência Mundial do Eucalipto, realizada em São Paulo, KAPLAN (1961), após revisar a literatura, sobre estudos das relações de água em eucalipto, concluia que "os dados existentes eram limitados e insuficientes para servir de sub- 
sídio ao planejamento adequado do uso da terra", e recomendava que a FAO coordenasse o desenvolvimento de pesquisas principalmente envolvendo estudos da variação anual da água do solo, da depleção da água do solo, das relações com o crescimento dos povoamentos e da evapotranspiração.

O presente trabalho compreende o estudo de vários parâmetros quantitativos e qualitativos do ciclo hidrológico em povoamentos de ęucaliptos e de pinus. O experimento foi instalado no início de 1973 em plantações localizadas na área experimental do Departamento de Silvicultura, no campus da Escola Superior de Agricultura "Luiz de Queiroz". A coleta de dados prolongou-se de junho de 1973 a junho de 1975, e incluiu medições da precipitação total, da precipitação interna nos povoamentos, do escoamento pelo tronco, das variações da água do solo, do crescimento radial das árvores, e dos seguintes aspectos qualitativos em amostras de água da chuva, da precipitação interna, e do escoamento pelo tronco: pH, turbidez, alcalinidade, condutividade especifica, cor e sólidos totais dissolvidos.

A partir da análise de cada um destes componentes individualmente, e da análise conjunta dentro do contexto do balanço hídrico, é intenção do presente trabalho fornecer al gum subsidio para - melhor conhecimento dos aspectos hidrológicos associados com as plantações homogêneas de eucaliptos e de pinus nas nossas condições. 


\section{OBJETIVOS}

o presente estudo foi orientado para alcançar os seguintes objetivos gerais:

a) caracterizar, para as condições dos povoamentos e do local, os processos de interceptação de água da chuva, incluindo a precí pitação interna, o escoamento pelo tronco, e a quantificação das perdas de água por interceptação nos dois ecossistemas;

b) medir as variações mensal, estacional e anual da água do solo nos dois povoamentos e comparar estas variações com idênticas medições realizadas em parcela revestida por vegetação herbácea natural;

c) estimar, na medida que permite a metodologia seguida, os valores de evapotranspiração em cada um dos três tipos de cobertura vegetal estudada, ou seja, eucaliptos, pinus e vegetação herbácea natural;

d) correlacionar as medições do crescimento radial dos povoamentos de eucaliptos e de pinus com as variações do total de água armazenada no solo;

e) verificar os efeitos que as florestas de eucaliptos e de pinus podem causar à qualidade da água da chuva que penetra por suas copas;

f) inferir, com base nas informações obtidas, medidas práticas de manejo destas essências florestais com vistas à conservação dos recursos hidricos. 


\section{RIEVISTO DA I.ITERATURA}

A Hidrologia Florestal, ou seja o estudo das relações de água em florestas, é um dos ramos da ciência florestal que apresenta literatura relativamente rica. O reconhecimento já antigo da intima associação existente entre a floresta e a água na natureza, e a reconhecida dificuldade de medição precisa dos processos envolvidos são alguns dọs fatores responsáveis pelo grande número de trabalhos já realizados.

De modo geral, a preocupação do homem para com o problema pode ser resumida na seguinte pergunta: como alterar favoravelmente o ciclo hidrológico através de diferentes práticas de manejo ou de uso do solo? A resposta, obviamente, necessita do conhecimento aprofundado da natureza do ciclo da água nos ecossistemas florestais, ou seja, do papel real desempenhado pelas florestas no recebinento, re distribuição, consumo e alteração qualitativa da áşua da chuva.

Até a pouco tempo, não se conhecia método preciso para medir o consumo de água de superfícies vegetadas. A partir da década de 60 , todavia, muita informação nova tem contribuido significati vamente para o aperfeiçoamento da medição do processo. WARD (1971) apresenta análise crítica dos vários métodos existentes para a medição da evapotranspiração. Segundo este autor, no caso de áreas florestadas, devido a inadequação do uso de lisímetros, o balanço hídrico do perfil do solo parece ser a mais realistica tentativa de medição da evapotranspiração em florestas. Ista conclusão é também compartilhada por FEDERER (1970). Este autor afirma, ainda, que outra metodologia que pode oferecer alguma precisão consiste na medição do balanço de energia de uma dada superfície florestada, conforme mostram os trabaIhos de BAUMGARTNER (1967), THOMAS et al (1972), HORNBECK (1970), MCNAUGHTON e BLACK (1973), PENMAN (1967), THORNTHWATTE e MATHER (1955). O balanço hídrico do solo pode ser representado pela seguinte equação geral (REICHARDT, 1973), (TANNER, 1968), (FEDERER, 1970), ( $/ A R D, 1971)$, (DREIBELBIS, 1962), (BURROUGHS, Jr. e SCHULTZ, 1964), (KITCHING, 1967), (JOHNSTON et al, 1969): 
onde:

$E T$ = evapotranspiração

$\mathrm{P}=$ precipitação

$R$ = escoamento superficial (runoff, enxurrada)

$G=$ percolação profunda

$S$ = armazenamento da água do solo.

Desta equação, os quatro termos da direita devem usualmente ser medidos, o que possibilita o cálculo da evapotranspiracão. Sob determinadas condições, alguns deles podem, eventualmente, ser desprezados. Por exemplo, em condições semi-áridas, o valor de ET é simplesmente o balanço de $S$, ou seja, a diferença entre duas leitum ras consecutivas da umidade do solo (BURROUGHS e SCHULTZ, 1964). Já pa ra regiões, ou para períodos de alta pluviosidade, o não controle de $R$ e de G torna praticamente impossível a obtenção de estimativas razoáve is de ET através desta metodologia (TANNER, 1968).

A medição da percolação profunda (G) é, em geral, mais controvertida. Na maioria dos trabalhos de balanço hídrico, o ter mo G é desprezado. Mesmo em condições de solo seco, todavia, a hipótese de não ocorrência de percolação profunda pode conduzir a erros (FEDERER, 1970). Alguns autores utilizam uma estimativa de G obtida a partir de dados de tensão e condutividade do solo e pela aplicação da lei de Darcy (BURROUGHS e SCHULTZ, 1964), (KITCHING, 1967), (FERRAZ, 1972), (LIGON e WILSON, 1972). Em recente publicação, STAMMERS et al. (1973) fizeram um estudo de balanço hídrico para verificar a magnitude dos erros cometidos ao se considerar e ao se desprezar os valores de G. De acordo com os resultados obtidos, STAMMERS et al. afirmam que pa ra a área estudada as estimativas de ET obtidas quando se levou em con ta a percolação profunda não foram diferentes daquelas obtidas quando se desprezou o valor de G na equação do balanço hídrico. Afirmam ainda que mesmo em condições úmidas os erros encontrados em consequência do desprezo de G não foram maiores que os erros comumente associados com a medição da água do solo.

Já a medição da água do solo ( $S$ ) é menos problemática, e o advento da técnica de moderação de neutrons facilitou sobremodo a avaliação periódica das variações do conteúdo de umidade do so- 
10, principalmente no caso de áreas florestadas. De acordo com KITCHIHG (1967) e TANNLR (1968), a técnica de moderação de neutrons apresenta, dentre outras, as seguintes vantagens: a) perturbação mínima do solo; b) determinação direta das variações volumétricas da água do solo; c) medições repetidas podem ser feitas no mesmo local; d) amostragem de um volume relativamente grande de solo em cada ponto. HII LETT et al. (1964), SCHULTZ (1967) e SARTZ (1972) discutem alguns problemas relativos a emprego desta técnica, principalmente no que diz respeito aos possíveis erros inerentes ao método. SARTZ, por exemplo, argumenta a respeito dos erros que podem resultar quando as parcelas nas quais se efetuam as medições não são planas. Para o caso de áreas florestadas, frequentemente localizadas em terrenos declivosos, as tentativas de se evitar tais possíveis discrepancias pela escolha judiciosa de parcelas em locais planos não parecem ser solução aceitável. Seria mais conveniente, segundo o autor, aumentar tanto quanto possível a anostragem, a fim de satisfazer o grau de variabilidade.

As medições periódicas da água do solo através da técnica de moderação de neutrons, além de fornecerem dados suficientes para a estimativa da evapotranspiração, conforme a equação do balanço hídrico já apresentada (FERRAZ, 1972), possibilitam ainda a caracteriza ৎão do regime da áçua do solo sob diferentes condições de cobertura vegetal (DREIBELBIS, 1962). Por exemplo, BABALOLA e SAMIE (1972) estudaram o regime da água de um mesmo solo mas sob dois tipos de vegetação - vegetação natural de savana, e plantação de Eucalyptus citriodora, com 10 anos de idade - através da técnica de moderação de neutrons. Pa ra um período seco, os autores determinaram evapotranspiração de 13,7 $\mathrm{mm}$ para o eucalipto, e de $17,5 \mathrm{~mm}$ para a vegetação natural. Verificaram ainda que durante o período experimental a amplitude máxima de variação da água do solo foi maior para a vegetação natural do que para o eucalipto. Com base nos resultados obtidos, concluíram que a substituicão da savana por eucalipto seria recomendável, pois este apresentou me Ihor aproveitamento da aǵua disponível concomitantemente com melhor ren dimento econômico.

FLETCHER e LULL (1963) verificaram que para os 3 me ses de verão de um ano relativamente seco havia cerca de $75 \mathrm{~mm}$ a mais de água no solo de uma parcela desprovida de vegetação do que numa parcela florestada. Já GINDEL (1964), fazendo observações da água do solo 
em parcelas desprovidas de vegetação e em parcelas revestidas por espé cies arbóreas xerófitas, em regiōes subtropicais, semi-desérticas, e desérticas em Israel, verificou que em todas as condições havia quanti dade significativamente maior de água em solos sob xerófitas do que nas parcelas sem vegetação.

SHPAK (1971), com base em inúmeros trabalhos desen volvidos principalmente na Rússia, apresenta algumas conclusões gerais no que diz respeito às variações da áqua do solo sob diferentes tipos de vegetação. Afirma, por exemplo, que na estação de crescimento as ca madas superficiais em áreas abertas secam mais rapidamente do que em áreas florestadas, ao passo que no outono as camadas mais profundas do solo são mais secas sob florestas do que em áreas abertas. Conclui ain da que tais variações dependem do tipo de solo; em solos arenosos, os regimes da água do solo em floresta e em área não florestada não são diferentes.

MIKHOVICH et al. (1970) mediram a água do solo sob florestas de folhosas e sob culturas agrícolas. Verificaram que no per fil de $3 \mathrm{~m}$ estudado havia menor conteúdo de água sob floresta do que sob culturas. Todavia, durante a primavera não houve diferença de água armazenada nos dois casos.

CERVंRLIINI et al. (1972) realizaram observações do regime da água do solo em cerrado, comparando parcelas com vegetação e parcelas cuja vegetação havia sido eliminada. Verificaram maior variacão de umidade na parcela sem vegetação do que na vegetada. Durante o período experimental de um ano, verificaram ainda que sempre houve água disponível no solo nos dois casos. FRRRI (1961) já observara que as plantas do cerrado transpiram o ano todo, e que a curva de transpiração destas plantas é muito parecida com a curva da evaporação de uma superfície Iíquida.

GIFFORD e SHAW (1973) estudaram a água do solo em parcelas com vegetação arbórea natural e em parcelas nas quais a mesma vegetação havia sido eliminada com o uso de correntão, verificando que estas últimas apresentaram maior conteúdo de água do que as primeiras. Resultados semelhantes foram obtidos por REPNEVSKAJA (1969), estudando a água do solo em parcelas com floresta de pinus e em parcelas nas quais as árvores haviam sido cortadas. Durante a estação de crescimen- 
to na qual efetuou as mediçōes, o autor verificou que o solo da parcela deflorestada apresentou, nos vários horizontes observados, maior te or de umidade do que o solo da parcela com floresta.

BALDY et al. (1970) estudaram o regime da água do solo sob plantações de pinus ( $\mathrm{P}$. radiata e $\underline{\mathrm{P} \text {. pinea) }}$ e sob plantações

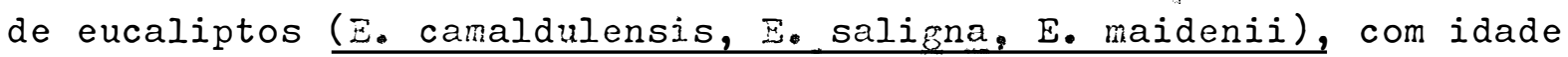
aproximada de 10 anos, verificando que os eucaliptos, de modo geral, apresentaram demanda maior da água do solo do que os pinus. Por outro lado, BUBLINEC (1972) estudou o regime da água do solo durante dois anos em plantações de pinus, concluindo que tais plantios homogêneos de florestas de pinus não exibem, em geral, efeitos adversos sobre a água do solo.

Estudando a umidade do solo em um povoamento de pi nus antes e depois de um desbaste, ORR (1968) verificou que havia maior quantidade de água armazenada no solo no povoamento desbastado do que antes do desbaste.

TROENDLE (1970) observa que o conhecimento do comportamento da água do solo sob vários tipos de cobertura florestal é de grande valia no entendimento de como o manejo florestal pode influir sobre o rendimento hídrico, ou sobre a conservação dos recursos hidricos de um modo geral: Im um estudo conduzido em floresta de folhosas mistas da região dos Apalaches, este autor verificou que as perdas de água do solo (balanço anual entre ganho e perda) foram significativamente maiores sob floresta do que sob solo nu. Conclui ainda que para as condições do experimento a maior parte da água consumida pelas florestas é retirada dos $60 \mathrm{~cm}$ superficiais do perfil do solo. PATRIC et al. (1965), num estudo conduzido também na região dos Apalaches, de alta pluviosidade, concluiram que onde as condições são tais que o potencial matricial do solo é mantido baixo, a maior parte da água trans pirada é retirada da camada superficial, de alta densidade de raízes.

$$
\text { METZ e DOUGLASS (1959) verificaram que os regimes }
$$

da água do solo em povoamento misto de coníferas e folhosas e em povoa mento homogêneo de coníferas foram similares, sendo que o solo no primeiro caso apresentou-se, em geral, pouco mais úmido que no segundo. HERRING (1970), por sua vez, comparou os regimes da água do solo em po voamento de Pinus ponderosa e em parcela com vegetação herbácea natu- 
ral, não notando diferença marcante entre ambos. DREBELBIS (1963) observou que durante os meses de verão havia maior conteúdo de umidade em solo sob floresta do que em solo sob pastagens, sendo que o reverso se verificou nos demais mêses do ano. HILL (1972) relata resultados de estudos da água do solo conduzidos em diferentes tipos de solo e sob diferentes vegetações, afirmando que o conteúdo de água no solo sob florestas foi usualmente maior que sob outros tipos de vegetação.

- BYRNES (1967), comparando os regimes de água de so lo nu e de solo sob vegetação herbácea natural, afirma que não houve diferença marcante entre os dois casos para os $30 \mathrm{~cm}$ superficiais do solo. Já para as camadas mais profundas (até $1,50 \mathrm{~m}$ ) o solo vegetado apresentou-se significativamente mais seco do que o solo nu.

Através do método de balanço hídrico do solo, como já comentado, muitos autores têm chegado a estimativas razoáveis do consumo de água de diferentes tipos de vegetação. SHACHORI et al. (1967), comparando vegetação arbustiva natural, plantações de pinus

(Pinus halepensis), vegetação herbácea natural e área de solo nu, chegaram as seguintes estimativas anuais de ET: $452 \mathrm{~mm}, 410 \mathrm{~mm}, 327 \mathrm{~mm}$ e $265 \mathrm{~mm}$, respectivamente.

SARTZ (1972̉) mediu a depleção da água do solo em parcela com floresta de' folhosas mistas e parcela adjacente da qual as árvores haviam sido cortadas, chegando aos seguintes resultados para uma estação de crescimento: $188 \mathrm{~mm}$ na parcela florestada, e $87 \mathrm{~mm} \mathrm{na}$ parcela cortada.

BANERJEE (1973) estimou o consumo de água de uma plantação de Alstonia scholaris, de 20 anos de idade, através da medição periódica da água do solo, chegando aos seguintes resultados anuais de transpiração, interceptação e evaporaçãọ da água do solo: 736 $\mathrm{mm}, 345 \mathrm{~mm}$ e $568 \mathrm{~mm}$, respectivamente.

KARSCHON e HETH (1967) estudaram o balanço hídrico de uma plantação de Eucalyptus camaldulensis, desde os nove até os 12 anos de idade, em Israel, comparando-o com o obtido em uma parcela adjacente contendo veģetação herbácea natural, através do método da equação do balanço hídrico já referida. O termo $R$ foi computado entre cada duas leituras consecutivas da água do solo, como sendo a água em excesso à capacidade de campo do solo, alternativa esta possível de 
șer usada para as condições semi-áridas da região. Os resultados médios dos quatro anos do período experimental deram valores anuais médios de evapotranspiração para eucalipto e para a vegetação herbácea de 466 $\mathrm{mm}$ e $322 \mathrm{~mm}$, respectivamente. Por outro lado, as perdas de água por es coamento superficial foram de $237 \mathrm{~mm}$ a mais na parcela de vegetação herbácea do que na de eucaliptos. Os autores observam que o consumo mé dio anual tanto do eucalipto como da vegetação herbácea depende primariamente da recarga anual da água do solo pelas precipitações, e concluem, pelos resultados obtidos, que as plantações de eucaliptos naque la região não causam efeitos adversos sobre os recursos hídricos.

Este mesmo poroamento de eucalipto foi explotado posteriormente em corte raso, e KARSCHON (1971) relata os resultados do balanço hídrico obtidos 4 anos após o corte, obtendo, de um modo ge ral, as mesmas conclusões do trabalho anterior. Verificou ainda que a evapotranspiração começa a se igualar aos valores de antes do corte ma is ou menos a partir do 30 ano de desenvolvimento da brotação das cepas.

Também em Israel, COHEN et al. (1966) não notaram diferenças marcantes de balanço hídrico entre uma plantação de pinus (P. halepensis e P. brutia), com cerca de 15 anos de idade, e vegetação herbácea natural.

CRUCIANI (1972) estimou, pela mesma métodologia de balanço hídrico, o consumo de água de uma cultura de cana-de-açúcar em Piracicaba, durante os 16 meses de seu ciclo, obtendo um total de $1.076 \mathrm{~mm}$ de evapotranspiração real durante o período.

CROFT e MONNINGER (1953) e posteriormente JONNSTON (1970) relatam sobre um mesmo experimento de estimativa de ET em diferentes vegetações, no qual encontraram as seguintes médias anuais de evapotranspiração: $287 \mathrm{~mm}$ para parcelas de solo nu, $389 \mathrm{~mm}$ para parcelas com vegetação herbácea, e $533 \mathrm{~mm}$ para parcelas com cobertura florestal (Populus sp.).

COSTIN (1961) estudou, com blocos de gesso, a água do solo em diferentes comunidades vegetais na Australia, não notando diferenças significativas de evapotranspiração entre elas. Afirma, com base nos resultados, que em condições de água à vontade no solo, ET é mais governada por fatores meteorológicos do que biológicos. 
Pela análise dos dados de balanço hídrico de bacias hidrográficas pequenas, BILI e GATENBY (1969) não notaram diferencas no rendimento hídrico entre bacias reflorestadas com eucalipto e bacias reflorestadas com pinus. Observaram ainda que o consumo da água do solo (consumo entre a capacidade de campo e o PMP) foi praticamente idêntico nos dois casos.

Através da medição dos parâmetros da equação de ba lanço hídrico em plantaçōes de pinus, de idade variando entre 20 a 40 anos, KITCIING (1967) determinou que a evapotranspiração média para pe ríodo de 4 meses de verão era de $247 \mathrm{~mm}$; calculando, ainda, a evapotranspixação potencial pela fórmula de Penman, obteve relação ET/PET de 0,69 .

Na França, AUSSENAC (1972) estimou a evapotranspiração de várias parcelas com coníferas e várias com folhosas, através da medição da precipitação, da infiltração, do escoamento superficial e da flutuação do lençol freático, concluindo que, para as condições do experimento, e sob mesmas condições de solo, diferentes espécies, mas com idade e estrutura idênticas, apresentam idênticas taxas de eva potranspiração.

Analisando dados de lisimetros e de bacias hidrográficas pequenas, em Coshocton, Ohio, DRETBELBIS e AMBRMAN (1964) observaram que cultura de milho e pastagem apresentaram taxa de evapotranspiração naior que floresta nos primeiros $40 \mathrm{~cm}$ do solo; abaixo dos $60 \mathrm{~cm}$ do perfil, todavia, ET foi maior em floresta, depois em milho, depois en pastagem, o que reflete, segundo os autores, diferenças de penetração dos sistemas radiculares.

Outro componente importante do ciclo da água em um ecossistema florestal é o processo de interceptação da água da chuva. De fato, dentro do contexto do balaņ̧o hídrico; durante períodos secos a transpiração e a evaporação da água do solo compõem o consumo de água de uma superficie vegetada. Durante periodos chuvosos, todavia, a interceptação também passa a fazer parte das perdas de água pelo ecossis tema (RUTTER, 1968).

Pela interceptação, a cobertura florestal causa uma diminuição no total de chuva que atinge o solo. Conforme o tipo de floresta, esta redução pode atingir cerca de $25 \%$ da precipitação anual 
(LIHSLEY et al., 1949). Im regiões úmidas dos Lstados Unidos, por exem plo, as perdas por interceptação chegam a alcançar $254 \mathrm{~mm}$ por ano (HLL VEY e PATRIC, $1965^{\mathrm{b}}$ ). Os aspectos físicos do processo de interceptação podem ser encontrados com detalhes em várias publicações, como por exemplo em LINSLEY et al. (1949), LEONARD (1967), e em CZARINOWSKI e OLSZEWSKI (I968).

A interceptação vem sendo estudada desde a muito tempo em diversos países. Há quase meio século atrás, ZON (1927) apresentava uma revisão sobre alsuns trabalhos que já haviam sido realizados sobre interceptação da chuva pelas florestas na Europa. De acordo com HELVEY e PATRIC ( $1965^{a}$ ), o primeiro trabalho de interceptação nos Estados Unidos foi desenvolvid em 1919.

A fim de tornar mais fácil o entendimento dos aspectos relacionados com a interceptação, principalmente para aqueles ainda não familiarizados com esta fase do ciclo hidrológico, será útil rever alguns conceitos e definições mais comumente usados em estudos. de interceptação. De acordo com HELVEY e PATRIC $\left(1965^{\mathrm{b}}\right)$ tem-se:

INTERCEPTAÇÃ: é o processo pelo qual a água da chuva é temporariamente retida pelas copas das árvores, sendo subsequentemente redistribuída em: a) água que respinga ao solo; b) água que escoa pelo tron co; c) água que volta à atmosfera por evaporação.

PRECIPITAÇÃO TOTAL (PT): quantidade total de chuva que é medida em terreno aberto, ou acima das copas das árvores.

PRECIPITAÇÃO INTLRNA (PI): chuva que atinge o piso florestal, incluindo gotas que passam diretamente pelas aberturas existentes entre as copas e gotas que respingam das copas.

ESCOAMENTO PILO TRONCO (Et): água da chuva que, após retida pelas copas, atinge o solo escoando pelos troncos das árvores.

PRECIPITAÇÃO EFETIVA (PE): chuva que efetivamente chega ao solo florestal: $P E=P I+E t$.

PERDA POR INTERCEPTAÇÃO (I): parte da água interceptada que evapo ra diretamente das copas, não atingindo, portanto, o solo. Este componente, como pode ser deduzido, não é medido diretamente, mas sim calcu lado por diferença, conforme a equação:

$$
I=P T-(P I+E t)
$$


O trabalho de HELVEY e PATRIC $\left(1965^{\mathrm{b}}\right)$ se constitui; ainda, em excelente tratado sobre a metodoloğia de medição da intercę tação em povoamentos florestais. Segundo estes autores, o coeficiente de variação associado com as medições dos parâmetros da equação acima é, em Eeral, pequeno quando o total de água medida aumenta, mantendo-se praticamente constante $(10-15 \%)$ parà medições maiores que $10 \mathrm{~mm}$. A medição de PT em postos meteorológicos convencionais apresenta, em geral, coeficiente de variação de 5\%. Para estudos de interceptação, tem sido verificado que PT pode ser medida com precisão adequada usando-se de 2 a 4 pluviômetxos instalados próximo ao local do experimento.

A medição de PI apresenta, geralmente, maior varia bilidade, e maior número de pluviômetros é necessário para sua medição. De acordo com HELVEY e PATRIC, o uso de 18 pJuviômetros pequenos, com diâmetro ao redor de $12,7 \mathrm{~cm}$, também referidos como interceptômetros, são suficientes para igualar em preciã̃o com a medição de PT por 2 plü viômetros convencionais, desde que sejam periodicamente relocados dentro do povoamento florestal.

No que diz respeito ao escoamento pelo tronco, o método mais usado para sua medição tem sido o uso de dispositivos cole tores cuidadosamente colocados ao redor do tronco de árvores seleciona das ao acaso. HELVEY e PATRIC, todavia, argumentam que este não seria o método mais preciso, afirmando que o uso de parcelas, das quais se mediria o It de todas as árvores, daria menor coeficiente de variação.

Os problemas relativos aos métodos experimentais em estudos de interceptação são discutidos também em vários outros trabaIhos, como os de REYHOLDS e LEYTON (1963), LFONARD (1961) e IINKE (1967). Este último autor apresenta análise geral com base na revisão de cerca de 80 trabalhos sobre interceptação em diferentes tipos de florestas.

KITTPPDGI et al. (1941) mediram, durante 6 anos, a interceptação em uma plantação de pinus (p. canariensis), de idade aproximada de 28 anos, determinando que as perdas por interceptação do povoamento estudado variaram de 17 a $28 \%$. Verificaram ainda que a proporção do componente at foi de apenas $1 \%$ da precipitação medida no aberto.

VOIGT (1960) realizou observações durante 2 anos 
numa área florestada em Connecticut, istados Unidos, encontrando valores de interceptação de $39 \%$ em pinus e $25 \%$ em floresta de espécie foIhosa (Fagus grandifolia).

Na Inglaterra, RUTTER (1963) mediu a interceptação em uma plantação de Pinus sylvestris, de 19 anos de idade, encontrando valor de 32\% de perda por interceptação nas condições do estudo. Verificou ainda que existe correlação positiva entre o componente escoamen to pelo tronco (Et) e o DAP (diâmetro a $1,30 \mathrm{~m}$ do solo) das árvores. DEALLE e PAÚSELL (1969), medindo a interceptação em floresta natural de folhosas mistas, não encontraram correlação entre Bt e DAP, sendo que o valor da interceptação determinada foi de $12 \%$.

De modo geral, sempre existe uma defasagem entre o início da chuva e o início dos componentes precipitação interna e esco amento pelo tronco. Numa floresta de folhosas na Nova Zelândia, por exemplo, ALDRIDGE e JACKSON (1973) verificaram que PI inicia-se após a precipitação total ultrapassar $0,5 \mathrm{~mm}$, ao passo que Et iniciamse após $1,3 \mathrm{~mm}$ de precipitação total. A quantidade de água que fica retida nas copas até o início de PI e Et é referida como "capacidade de retenção" (LEONARD, 1967).

Para alguns tipos de florestas, a interceptação po de ser determinada apenas pela medição do componente PI, uma vez que Et não se verifica, ou ocorre em proporções desprezíveis (ROTHACHER, 1963), (SKAU, 1964).

De modo geral, de acordo com os resultados de inúmeros trabalhos já realizados, pode-se afirmar que as florestas de coniferas interceptam mais do que as florestas de folhosas (RAPP e ROMANE, 1968), (FRECHETTE, 1969), (DELFS, 1967), (S:AANK et al., 1972), (RO GERSON e BYRNES, 1968), (NIHLGARD, 1969), (SIITH, 1973), (MOLCHANON, 1963). Tem sido verificado, também, que as perdas por interceptação tendem a aumentar com a idade do povoamento florestal (HELVEY, 1967), (DELFS, 1967).

Através da interceptação, as florestas diminuem a quantidade da chuva que chega ao solo, mas TRIMBLE e VITZMAN (1954) verificaram que também a intensidade das chuvas que penetram pelas copas das árvores é diminuida, numa proporção máxima de até 20\% de redução. 
Alguns autores têm tentado relacionar as diferenças de comportamento no que diz respeito ao processo de escoamento pelo tronco com a distribuição e o conteúdo da água do solo ao redor das árvores (ESCHNER, 1967), (BROWN e BOURN, 1973), (WEIHE, 1973). Este úl timo autor, por exemplo, estudando a interceptação em povoamentos de folhosa (Fagus sp.) e de coniferas (Picea $\mathrm{sp}_{.}$) verificou que $\mathrm{Et}$ atinEiu cerca de $20 \%$ da precipitação total no primeiro caso, mas permaneceu zero no povoainento de conífera. Com base nestas observações, sugeriu que a alta taxa de interceptação seria um dos fatores responsáveis pelo pobre crescimento da conífera (Picea sp.) em locais de baixa precipitação e em terreno relativamente plano.

A perda por interceptação de uma cobertura florestal pode ser separada em dois componentes: evaporação das copas e evaporação do piso ("litter", serapilheira). Este último componente, bem menor, geralmente não é considerado nos estudos. HELVEY (1964) mostrou que em florestas naturais de folhosas a interceptação pelo piso pode. atingir cerca de $50 \mathrm{~mm}$ anuais. Outros trabalhos relativos a intercepto ção do piso e também por vegetação de gramineas são, por exemplo, os de KERENSKI (1970), BURGY e POMEROY (1958), CROUSE et al. (1966).

Dențe as características da vegetação, a densidade do povoamento é um dos fatores que afetam a interceptação. ROGIRSO: (1967) analisou os dados de um estudo aplicando regressão múltipla para a determinação de uma equação de regressão para a estimativa de PI a partir de 9 variáveis. Considerando apenas uma variável por vez, a única que deu correlação significativa foi a quantidade (mm) de PT, cu.. ja equação respondia por $98,6 \%$ da variação de PI. Com o acréscimo de outras variáveis, a equação que deu melhor resultado $(99,3 \%$ da variaçäo) foi a que incluia, além de PT, o valor da.área basal do povoamento. ROGERSON (1968) afirma que a redução de $4,5 \mathrm{~m}^{2} /$ ha de área basal do povoamento pode aumentar a precipitação interna de cerca de 2,0\%. THORUD (2963), por outro lado, verificou que a desrama artificial não causou variação significativa nas proporções de PI e de $\Xi t$, em um pove amento de pinus resinosa de 31 anos de idade. THOMPSON (1970), trabaIhando com folhosas (carvalho), observou que a interceptação foi maior quando as árvores se encontravam com as folhas do que quando haviam si do desfolhadas por produtos químicos. 
Muito pouco tem sido feito a respeito da medição da interceptação em florestas tropicais. JACKSON (1971) estimou que se ria necessário um número muito grande de interceptômetros a fim de que se pudesse medir a precipitação interna com precisão razoável. LOW (1972) sugere que as perdas por interceptação são responsáveis pela re dução de 50\% na precipitação total em florestas da Malásia. De fato, SIM (1972) observou que nesta mesma região as perdas por interceptação variaram de 25 a $80 \%$. No Brasil, a única referência encontrada foi a de um trabalho realizado em 1936, em condições de floresta subtropical, citado por GEIGER(1966). Segundo esta citação, considerando $\mathrm{PT}=100 \%$, as medições de PI, Et e I deram, respectivamente, os segui II tes valores: $34 \%$, $28 \%$ e $38 \%$.

Em Israel, KARSCHON e HITH (1967) hediram a interced tação em plantações homogêneas de eucalipto (E. camaldulensis), obtendo as seguintes equações de regressão, de acordo com as diferentes idades do povoamento:

$$
\begin{aligned}
& \text { aos } 7 \text { anos: } \mathrm{PE}=0,857(\mathrm{PT})-0,04 \\
& \text { aos } 8 \text { anos: } \mathrm{PE}=0,851(\mathrm{PT})-0,03 \\
& \text { aos } 9 \text { anos: } \mathrm{PI}=0,889(\mathrm{PT})-0,33 \\
& \text { aos } 10 \text { anos: } \mathrm{PE}=0,904(\mathrm{PT})-0,75
\end{aligned}
$$

Em termos médios, as proporções de PI, Et e I deram os seguintes resultados: $80,8 \%, 4,5 \%$ e $24,6 \%$, respectivamente.

Para as florestas de folhosas mistas de toda a região leste dos Estados Unidos, HELVEY e PATRIC $\left(1965^{\circ}\right.$ ) afirmam que as equações

$$
\begin{aligned}
& \mathrm{PI}=0,901(\mathrm{PT})-0,031 \\
& E t=0,041(\mathrm{PT})-0,005
\end{aligned}
$$

podem ser usadas para as estimativas de PI e de Et a partir da medição da precipitação em área aberta.

Para completar esta revisão sobre a interceptação, será interessante discutir um aspecto ainda controvertido na literatura, qual seja o de se saber se o processo representa ou não uma perda real de água para o ecossistera (GOODEY, 1963), (I IYYON et al., 1967). Pelo fato de que a evaporação é um processo que depende do fornecimento de energia, e considerando que a quantidade de energia disponivel para a evaporação em um dado ambiente é uma quantia limitada, alguns 
autores têm sugerido que a energia utilizada para a evaporação da água interceptada deve necessariamente ser parte do total que seria utiliza da para a evapotranspiração. A partir desta idéia básica, duas linhas de pensamento se desenvolveram no que diz respeito ao papel da interceptação no ciclo hidrolósico. Uma delas sugere que se a energia utilizada para a evaporação da água interceptada é "retirada" do total que seria disponível para a transpiração, então a perda por intercepta ção é compensada pela concomitante diminuição da transpiração (THORITHWITE e MATHER, 1955), (RAKHMANOV, 1958), (NICOLSON et al., 1968). Im outras palavras, a interceptação não deveria ser considerada como perda no balanço hídrico de um sistema. Por outro lado, alguns re sultados experimentais não pareciam muito coerentes com este raciocínio. De fato, tem sido observado que a evaporação de florestas cujas copas se encontram molhadas é maior do que a que ocorre em condições secas, em idênticas condições ambientais (PEMMAN, 1967), (RUTTHR, 1968), (MCHAUGHT e BLACK, 1973). Devido a estas evidências experimen tais, a segunda linha de pensamento sugere que a interceptação realmen. te se constitui em perda. Im recente publicação, MURPHY e KNOHRR

(1975) realizaram simnificativa contribuição para o esclarecimento des te aspecto, através do estudo de um modelo simulado de interceptação e dos processos físicos que interagem no fornecimento de energia necessá ria à evaporação da água interceptada. Pela segunda linha de raciocí nio discutida, depreende-se que a energia disponível para a evaporação nâo se mantém fixa para um determinado ambiente, mas é maior quando as folhas se encontram molhadas do que quando secas. MURPHY e KNOERR concluiram que esta fonte extra de energia para a evaporação da água interceptada resulta de um acréscimo de radiação líquida que é causado pela diminuição da enissão de radiação de onda lonģa pelas superfícies molhadas, e também por uma diminuição no fluxo de calor sensível, modi ficações estas provocadas pelo fato das copas se encontrarem molhadas.

Um outro aspecto do estudo das relações de água em florestas diz respeito às interações entre o crescimento radial do povoamento e as quantidades de água disponível no solo. De modo geral, tanto o crescimento em diâmetro, como em altura, e o crescimento das raízes são todos mais ou menos sensiveis às deficiências hídricas. Pes quisas realizadas nas últimas décadas têm revelado que o crescimento estacional e mesmo diário das árveres está mais diretamente correlacio nado com as flutuações da água do solo do que com qualquer outro fator 
do meio (ZAHNER, 1968 ${ }^{\text {a }}$ ). A medida que o solo se torna mais seco, a absorção de nutrientes é reduzida, surểem déficits hídricos nas folhas, - processo de fotossintese e os processos circulatórios são diminuidos, e o crescimento dos meristemas, en consequência, fica prejudicado.

TRIMBLE (1969) afirma que para povoamentos homoşêneos e uniformes, O DAP (diâmetro a 1,30 m do solo) é o melhor indicador potencial de crescimento.

VALENZIANO e SCARAMUZZI (1967) acompanharam o crescimento de planțações de eucaliptos (E. camaldulensis e E. viminalis), através da medição periódica do DAP das árvores. Verificaram, entre ou tras conclusões, que as duas espécies apresentaram padrão similar de crescimento, e que durante o período estudado (18 mêses) ambas mostraram crescimento contínuo, ou seja, não apresentaram qualquer período de dormência.

MCCLURKIN (1958) estudou as relações entre umidade do solo e o crescimento radial em plantações de pinus echinata, de 19 anos de idade, determinando a existência de correlação significativa entre crescimento radial e água disponível no perfil de 1,20 m de solo. MOEHRING e RALSTON (1967) realizaram estudo semelhante em plantações de Pinus taeda, também concluindo que existe correlação siginificativa entre o crescimento em área basal e a umidade do solo. ZAHNER $\left(1968^{\mathrm{b}}\right.$ ) cita trabalho realizado por BOGGES (1953 e 1956), que mediu semanalmente a água do solo e a área basăl em Pinus echinata e em quercus alba durante 4 anos, chegando à conclusão de que a área basal acumulada, em ambas as espécies, dininuia quando cerca da metade da água disponível no primeiro netro de solo era consumida. No povoamento de Q.alba, o autor verificou ainda que num ano mais úmido o crescimento em área basal foi quase o dobro daquele ocorrido em ano seco.

Finalmente, um último aspecto do balanço hícirico em floresta é o relacionado com a interação da vegetação com a áğua da chuva que por ela passa, ou, em outras palavras, os efeitos das diferentes espécies florestais sobre a qualidade da água da chuva. McKEE e WOL $(1963)$ citam referências pelas quais certas espécies florestais (Alnus spp.; Acer spp.) não são recomendadas para plantio ao redor de reservatórios pois suas folhas podem descolorir a água e, na decomposição, causar odores desacradáveis. Citam também trabalhos realizados na Holanda, segundo os quais a água proveniente de áreas plantadas con 
pinus ou com carvajho apresentavam maior cor, maior demanda de oxigênio, maior concentração de bicarbonatos, maior dureza e maior concentração de cloretos do que a água proveniente de áreas revestidas com vegetação herbácea natural.

Segundo PIERCE (1965), as coniferas têm sido prefe ridas para o reflorestamento de áreas ao redor de reservatórios, mas, conclui o autor, estudos têm mostrado que cada espécie em particular causa diferentes alterações na composição da água da chuva.

Mas não é apenas pela possível deterioração de reservatórios de água que este aspecto é importante (KUNKLE, i974). Ao interagir com a vegetação, a água da chuva arrasta quantidades apreciáveis de nutrientes, fenômeno esse referido como lavagem (ChMARGo, 1968). Este processo desempenha papel significativo na ciclagem de nutrientes em ecossistemas florestais (JORDAN e KLINE, 1972), (ATTIWILI, 1966 ).

Após muitos anos de medições, TOLLENAAR e RYCKBORS: (1975) apresentam os resultados de um estudo, no qual se analisou a á-. gua de drenagem de lisimetros sob duas condições: um contendo apenas solo nu, e o segundo plantado com coniferas (Pinus sp.). Foi verificado, além de outros, que as coniferas interceptam cerca de $24 \%$ a mais de $\mathrm{Cl}^{-}, \mathrm{SO}_{4}{ }^{2-}, \mathrm{Na}^{+}$e $\mathrm{K}^{+}$da água da chuva do que o solo nu, e que as co níferas causam, também, redução do p̣H.

Pela análise das adições (precipitação) e das perdas (defluvio) em bacias hidrográficas experimentais é possivel conseguir-se informação mais geral sobre a ciclagem de nutrientes em relação a diferentes ecossistemas, como mostram os trabalhos de TAYLOR et al. (1971), LIKENS et al. (1967), JOHMSONe SWAMK (1973), HART et al. (1973), FISHER et al. (1968), IWATSUPO e TSUTSUMI (1968). Através do processo de lavagem, as diferentes condições de cobertura vegetal causam diferentes alterações na composição química da água da chuva, contribuindo, desta forma, de maneira distinta com a ciclagem de nutrientes. Assim, conforme esclarece WELLS et al.(1972), a compilação deste ciclo em florestas deve incluir também a medição da qualidade da água da precipitação interna e da água que escoa pelo tronco.

KIMMINS (1973) analisa o aspecto de amostragem de PI e de Et, a fim de que se possam obter dados com a necessária precisão. 
LIKDHS e BATON (1970) citam trabalhos nos quais foi mostrado que o escoamento pelo tronco contribui com cerca de 3 a $6 \%$ do total (precipitação + "litter") de $\mathrm{K}, \mathrm{Ca}$, Mg, e lla que chega ao solo florestal. Pela análise do pH do solo ao redor de caules de pinus pinaster e em vários pontos cada vez mais distantes destes, verificou-se que o pH nestes vários pontos variou bastante, provavelmente pelo efeito da água que escoa pelo tronco das árvores, que é extremamente ácida ( $\mathrm{pH} 3,9-4,4)$ (AnÔNIMO, 1969).

- AUSSEMAC et al. (1972) concluiram que apenas o $\mathrm{K}$ se apresentava em quantidades mensuráveis em amostras de água de PI e de Et em povoamentos de coníferas, na França. Também na kova Zelandia, WILJ (1955) já observara, em plantações de coníferas, que o K e o Na são devolvidos ao solo em maiores proporções através da água da chuva.

WELIS et al. (1972) e KAUL e BIJLINGS (1965), estü dando o ciclo de nutrientes em florestas de folhosas e de coníferas, observaram que a lavagem foi, em geral, maior nas primeiras do que nas segundas. Ou seja, a taxa de ciclagem foi maior para as folhosas do que para as coniferas.

SPRIANEARA (1970) verificou que as concentrações de $\mathrm{K}$ e Ca foram naiores em amostras da água da precipitação interna em florestas de folhosas mistas do que em amostras de água da chuva. Veri ficou também que o $K \dot{e}$, em geral, mais lavável do que o $\mathrm{Ca}$.

TARRANT (1968) estudou a qualidade de PI e de it em três sistemas diferentes, floresta de folhosas, floresta de conife ras e floresta mista de folhosa e conifera, observando diferenças nas taxas de ciclagens. Verificou também que o valor de Sólidos rotais Dis solvidos foi maior para it do que para PI, e que o pH de PI foi similar ao $\mathrm{pH}$ da chuva, o que também foi observado por MAHENDRAPPA (1974).

NISHIMURA (1973), estudando o ciclo de nutrientes em uma floresta de conifera, concluiu que do total anual de nutrientes contidos no "litter", mais água de PI, mais água de $z t$, cerca de 90\% de Na, $76 \%$ de $\mathrm{K}$ e $63 \%$ de $\mathrm{Mg}$ chegam ao solo via PI e Et . Tais resultados estão de acordo com as conclusões de EATON et al. (1973), pelas quais "os nutrientes reconhecidamente associados com moléculas or gânicas ( $P$ e N) têm, en geral, maior mobilidade via "litter". Já os nutrientes mais comumente encontrados na forma iônica movem-se mais rapida- 
mente via precipitação interna e escoamento pelo tronco".

McColi (1970) estudou as alterações de qualidade da água da chuva em floresta tropical na Costa Rica. O pil da água da chuva e da precipitação interna foi, praticamente, neutro, mas apresen tou-se bem mais ácido na água de escoamento pelo tronco. A condutivida de dobrou de valor da água da chuva para a da precipitação interna, sendo bem maior ainda para a água do escoamento pelo tronco, o que levou o autor a concluir que o it, embora de pequenas proporções, parece desempenhar papel, importante no regime químico e biológico do solo ime diatamente ao redor do tronco. Ista conclusão já havia sido sugerida antes por POZDNYAKOV (1956). Também MINA (1967) concluiu que a água de Et mostrou ter efeito sobre o solo através do aumento da acidez ativa (tanto trocável como hidrolítica) e também pelo aumento do conteúdo de Al e re móveis. Concluiu ainda. que este efeito é localizado e se restringe a cerca de $30-50 \mathrm{~cm}$ de raio a partir do caule e numa profundidade de $1 \mathrm{~m}$ aproximadamente, e que das espécies estudadas o pinus foi a que apresentou maior efeito sobre o solo. BRUCKERT e TOUTAIH (1971) observaram que a água de PI em plantações de Frasus sylvatica e Pinus sylvestris continha compostos orgânicos simples e polimerizados, concluindo que o processo de humificação na realidade inicia-se ainda na água da chuva, após interação desta com a vegetação. GESPTR e HOLOWAYCHUK (1971), analisando amostras da água do escoamento pelo tron co e correlacionando estes resultados con a análise de propriedades químicas do solo, concluiram que o : sobre o solo ao redor do tronco; na conclusão do trabalho, estes autores afirmam que "reconhecem este efeito como sendo definitivo fator de formação do solo, ao qual deram o nome de "fator biohidrológico", defi nido como a interação da precipitação com as plantas, particularmente árvores". 


\section{1. Área Experinental}

A área experimental acha-se localizada no campus di. E.S.A. "Luiz de Queiroz", no município de Piracicaba, entre as coordenadas geográficas de $22^{\circ} 42^{\prime} 30^{\prime \prime}$ de latitude sul e $47038100 "$ de longitude a oeste de Greenwich, numa altitude de $540 \mathrm{~m}$. Os povoamentos flores tais onde foram coletados os dados sjtuam-se à marrem esquerda do córreso Nonte Olimpo, no extremo leste do camus da ESALQ, numa área com declividade aproximada de 4,5\% (Figura 1 ).

o povoamento de eucalipto ter área aproximada de 1 hectare, e foi desenvolvido a partir de sementes da espécie 形. salic-m na Smith, provenientes da Austrália. o plantio foi realizado en dezembro de 1969, em espaçamento de $3 \times 2 \mathrm{~m}$. Por ocasião do início do presente estudo, o povoamento apresentava área basal de $15,4 \mathrm{~m}^{2} / \mathrm{ha}$ e altu ra média de 13,4 metros.

o povoamento de pinus foi plantado na mesma época e em área e espaçamento iguais ao anterior. Foi desenvolvido a partir de sementes da espécie P. caribaea Morelet var. caribaea provenientes de Cuba, e por ocasião do injecio do experimento apresentava áxea basal de $13,5 \mathrm{~m}^{2} /$ ha e altura média de 6 metros. 


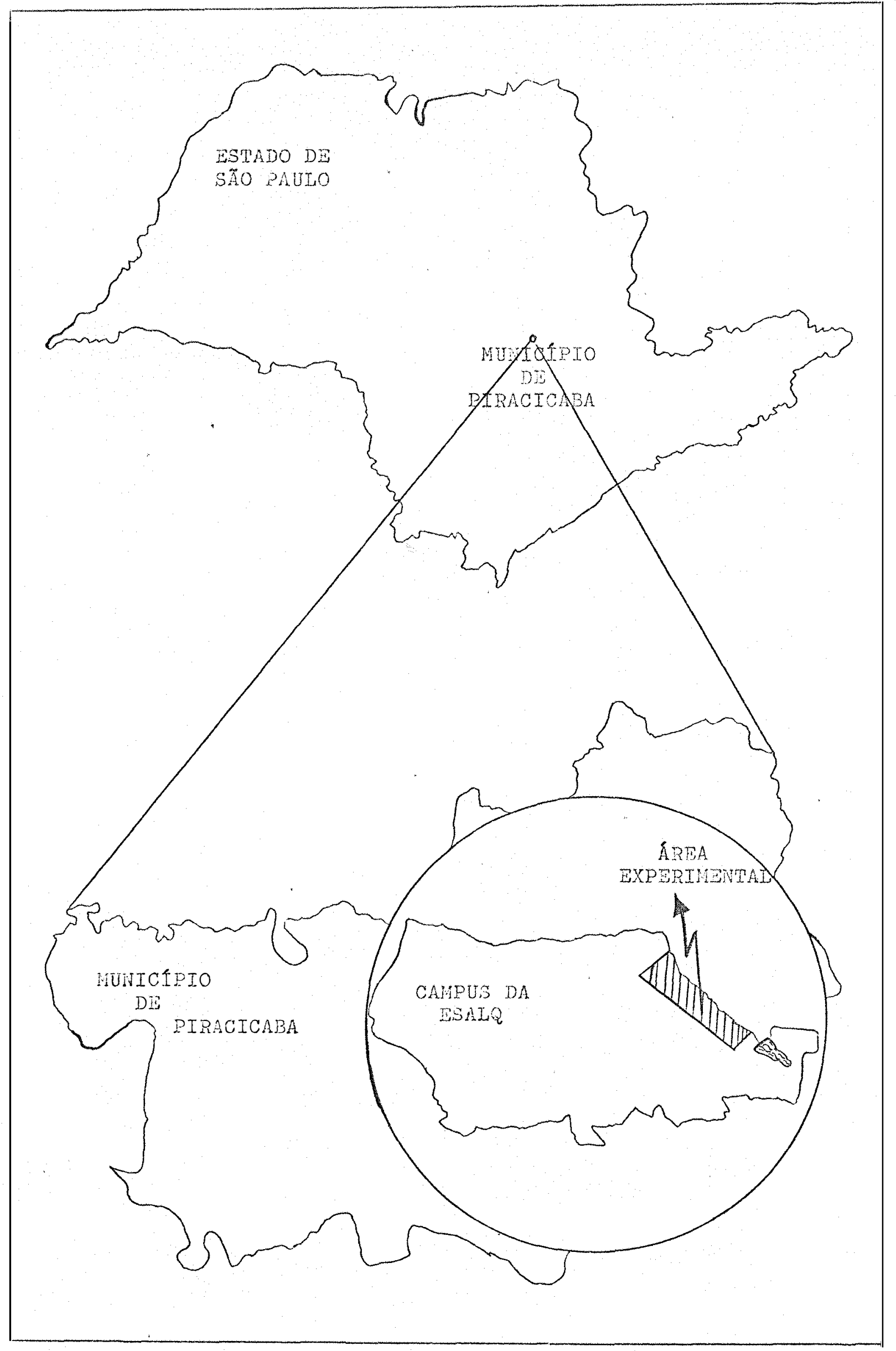

Fisura 1: Localização da Área Experimental em Relação ao Lsta de São Paulo, ao Município de Piracicaba e ao Campus da ZSALQ-USP. 


\subsection{Plano Experimental}

Para o alcance dos objetivos propostos, o experimento foi orientado para a determinação do balanço hídrico dos três sistemas estudados a partir da medição dos vários componentes do ciclo da água em cada caso, de acordo com a seguinte equação simplificada do balanço hídrico:

$$
P=E T+I+R+G \pm \Delta S
$$

onde:

$$
\begin{aligned}
P & =\text { precipitação } \\
E T & =\text { evapotranspiração } \\
I & =\text { interceptação } \\
R & =\text { escoamento superficial (runoff) } \\
G & =\text { percolação profunda } \\
\Delta S & =\text { variação do armazenamento da água do solo. }
\end{aligned}
$$

A Figura 2 ilustra as relaçöes entre estes vários componentes do ciclo da água em úm povoamento florestal.

Durante o período experimental foram medidos os termos PT, PI, Et, $S$ e Fo. Foram medidos também os seguintes aspectos qualitativos em anostrás de água de PT, PI e Et: pH, turbidez, alcalinidade, condutividade específica, sólidos totais dissolvidos e cor. Os valores de $\mathrm{PE}$ e de I são calculados, conforme já abordado na revisão de literatura, de acordo com:

$$
\begin{aligned}
& \mathrm{PE}=\mathrm{PI}+\mathrm{Et} \\
& I=\mathrm{PT}-\mathrm{PE}
\end{aligned}
$$

A fim de que os resultados obtidos pudessem permitir análises comparativas dos vários aspectos estudados entre as três diferentes coberturas vegetais, principalmente no que diz respeito à evapotranspiração, procurou-se estabelecer as parcelas de tal forma a eliminar, ou tornar desprezíveis, os efeitos de outros fatores do meio, especialmente as diferenças de solo, geologia, clima, declividade. A existência de um povoanento de eucalipto adjacente a um de pinus, e ambos adjacentes a uma área aberta, pareceu atender a estas restrições preziminares. 


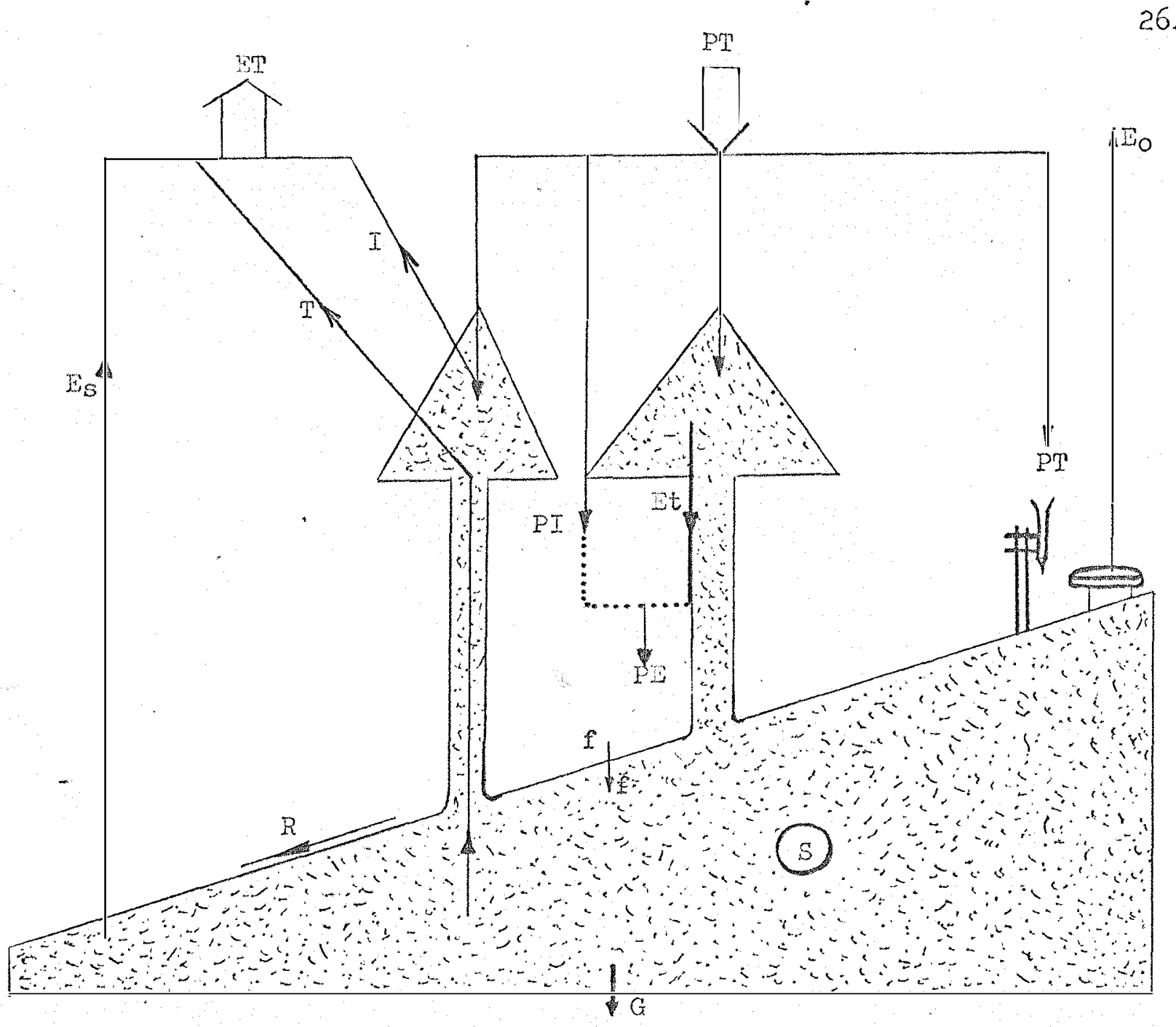

Figura2: Representação esquenática dos componentes do balanco hílico em um povómento florestal:

$P I=$ precipitação total (procinitação medida em área aberta)

$P I=$ precipitação total interna

$\mathrm{Et}=$ escoamento pelo tronco

$\mathrm{PI}=$ precipitação efetiva (PI + It)

$I=$ perda por interceptação

$T=$ transpiração

ES = Evaporação da ásua do solo

$\mathrm{ET}=$ evapotranspiração

$f=$ infiltração

$\mathrm{R}=$ escoamento superficial (runoff, enxurrada)

$\mathrm{G}=$ percolação profunda

Eo = evaporação de tanque classe $\mathrm{A}$. 
Conforme pode ser observado no esquema da Figura 2, o termo G, que inclui a água que drena além do limite inferior do perfil de solo considerado, é de difícil medição. De acordo com o discutido na revisão da literatura, existem métodos para se obter uma estimativa de G. No presente trabalho, todavia, nenhuma tentativa foi feita para se estimar o valor da percolação profunda.

Com relação ao termo $R$ pode-se afirmar que a sua medição é, no geral, mais fácil do que a de G. Uma das maneiras de mem dição de $R$ seria através do uso de parcelas dotadas de sistemas coleto res do escomento superficial, semelhantes, por exemplo, aos descritos em CROFT e HONMINGRR (3953). Tampouco este termo pôde, todavia, ser me dido no presente estudo, principalmente pelo volume considerável de in versões exigido para a construção de tais dispositivos.

Os aspectos discutidos nos três últimos paxágrafos definem, de certa forma, as limitações do plano experimental:

a) os resultados obtidos são válidos para a área experimental e para regiões em condiçōes de solo, geologia, clima e vegetação similares;

b) a estimativa do termo evapotranspiração (Ir) através da equaçâo simplificada do balanço hídrico, em virtude da não medição dos termos $R$ e $G$, fica restrita apenas para periodos secos do ano, conforme já discutido na revisão da literatura.

\subsection{Metodologia}

A precipitação total (PT) foi medida na parcela aberta (contendo vegetação herbácea), por meio de um pluviógrấo tipo Hellman e de pluviômetro comum com área de captaçäo de $311 \mathrm{~cm}^{2}$. O gráfico do pluviógrafo era trocado semanalmente, e a leitura do pluviômetro era feita imediatamente após cada chuva, para fins de cálculo da interceptação, conforme será explicado posteriormente. Os gráficos do pluviógrafo eram, depois, tabulados en chuvas isoladas e em totais diá rio e mensal de precipitação. 
Os dados de evaporação (Eo) foram obtidos em tanque Classe A instalado também na parcela aberta, mas tais mediçoes só puderam ser iniciadas em novembro de 1973. A evaporação foi medida pela quantidade de água que era adicionada ou retirada ao tanque a cada período de una semana, até atingir um nível de referência.

A precipitação interna (PI) foi medida por meio de pluviômetros pequenos (interceptômetros), com área de captação de 127 $\mathrm{cm}^{2}$. Foram utilizados 12 pluviômetros no povoamento de eucaliptos e 12 no de pünus. Conforme mostra a rigura 3, os pluviômetros foram instala dos sobre estacas e fixados a um suporte munido de parafusos, os quais permitiam o nivelamento do instrumento. Durante o periodo experimental, estes pluviômetros foram relocados 4 vêzes dentro dos povoamentos. As leituras forán feitas após cada chuva, sendo que, na medida do possível, procurou-se efetuar as medições depois de mais ou menoss 2 horas após o término das chuvas (GITGER, 1966). Os valores volumétricos medidos eran, posteriormente, tabulados en milímetro de altura de água, a partir da área de captação dos pluviônetros.

Com relação ao escoamento pelo tronco, este foi me dido em dispositivos coletores conforme mostra a Figura 3. Cada dispositivo constava de um segmento de borracha (borracha de revestimento de porta de automóvel) que era fixado ao redor do tronco da árvore por meio de percevejos de metal.e de cola araldite. As duas extremidades da borracha conduziam a água a um funil que, por sua vez, estava ligado a um recipiente de plástico com capacidade de 20 litros. Foram utilizados 10 dispositivos em cada povoanento, que eram afixados em árvores selecionadas de tal forma a incluir a variação de DAP do povoamento. Verificou-se que os anéis de borracha duravam, de modo geral, cerca de 2-3 meses, ao fim dos quais havia necessidade de se colocar nova borracha. A cada vez que esta operação era necessária, o novo dispositivo era afixado em árvores diferentes. A transformação dos valores de volume de ácua para milímetro foi feita de acordo com o seguinte proce dimento, baseado em informações da literatura, assim como em experiência adquirida em trabalhos semelhantes já realizados em outras regiões (KARSCHON, 1973): através de cuidadosa verificação no local, verificou se que para o povoamento de eucalipto havia, em média, 1.320 árvores por hectare, e não 2.667 , que é o total que deveria haver consideranco - espaçamento de $3 \times 2 \mathrm{~m}$. Desta forma, a projeção da copa de cada árvo 


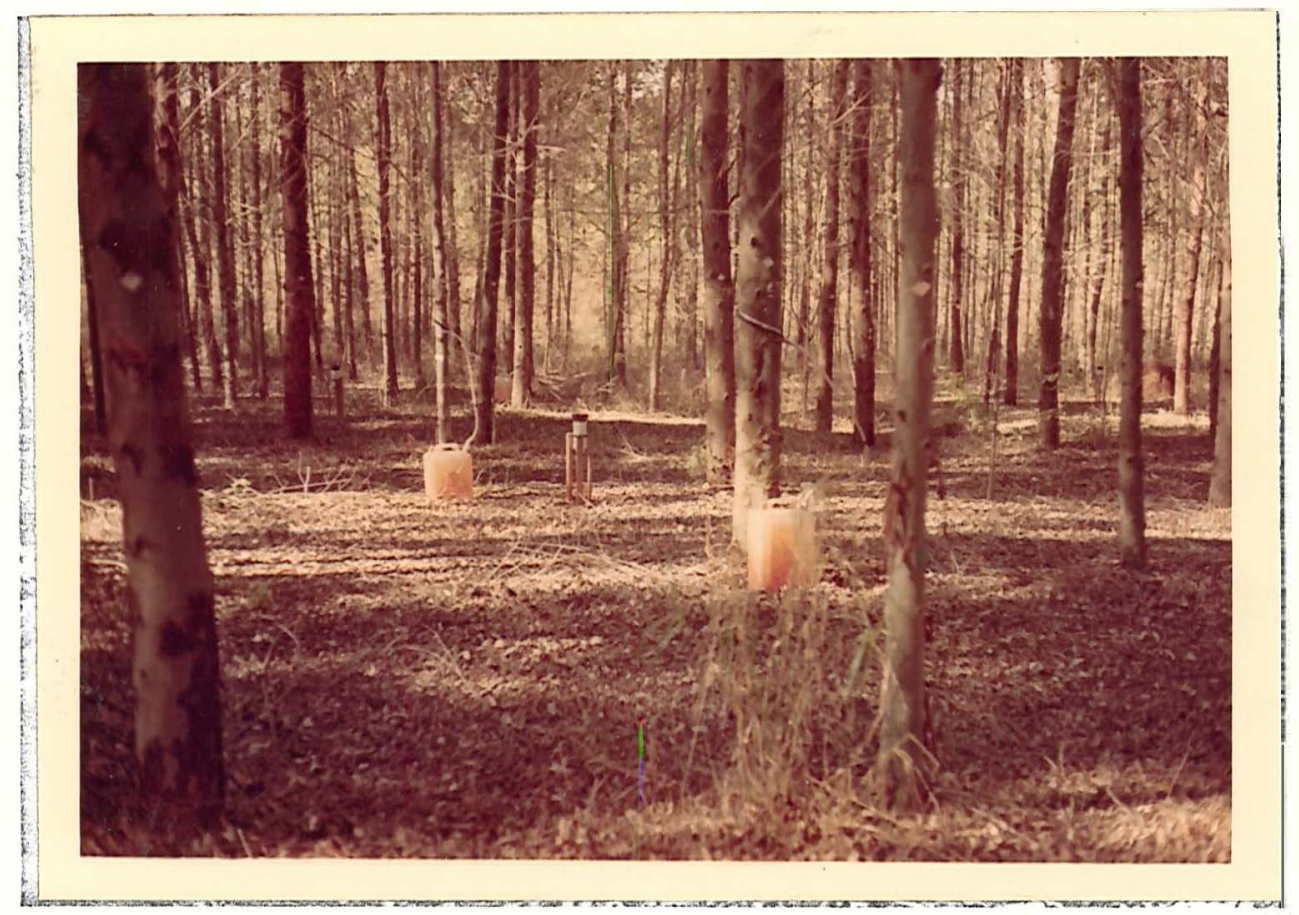

Figuma 3: Vista interna do povoamento de eucaIipto e dos dispositivos de medição da precipitação interna e do escoamento pelo tronco.

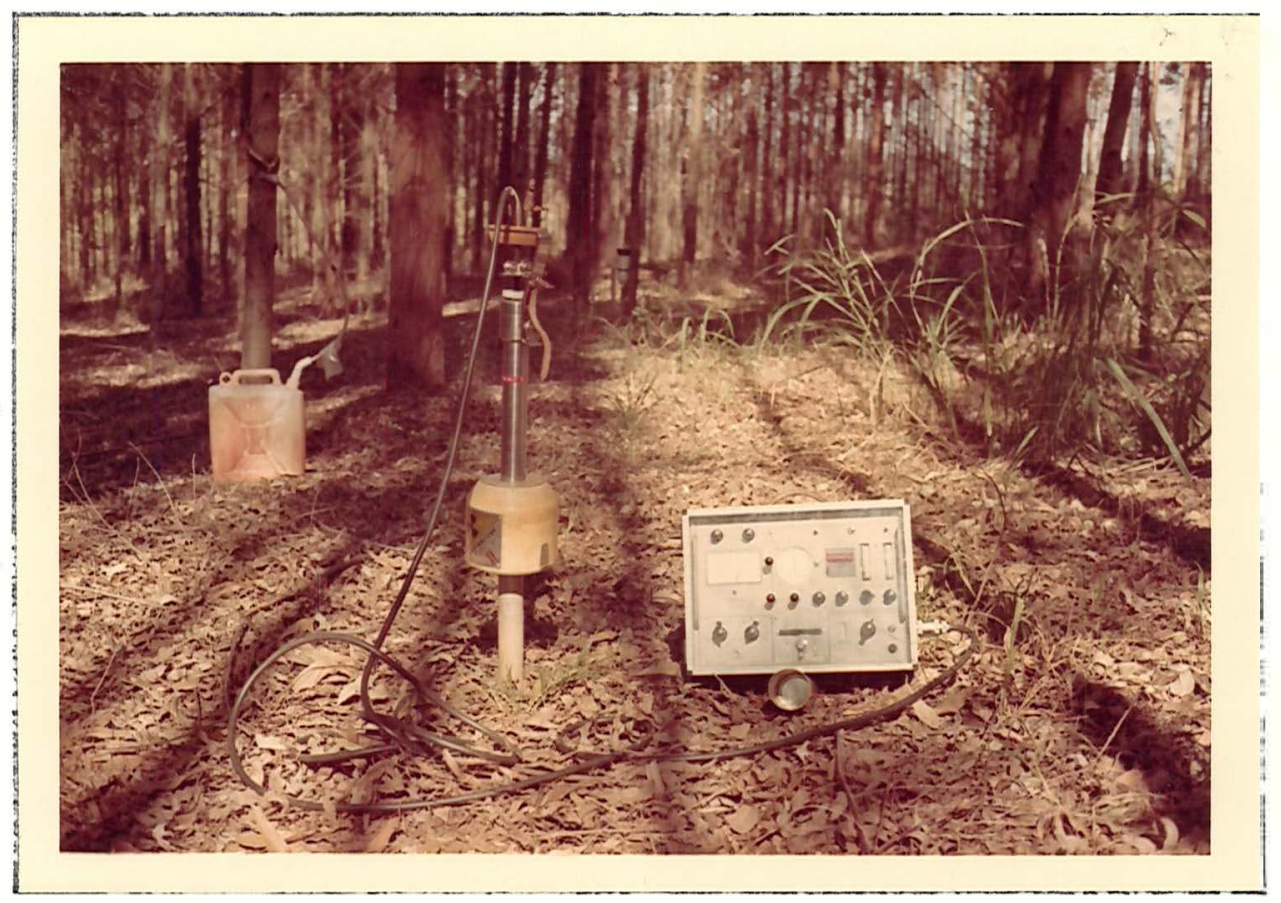

Fipura 4: Wetalhe da medição da ácua do solo, vendo-se a sonda de neutrons sobre o tubo de aluminio e o aparelho medidor de neutrons moderados. 
re corresponde, em teoria, a $7,6 \mathrm{~m}^{2}$, que foi o fator de conversão utilizado para o caso do eucalipto. Por procedimento semelhante, o fator de conversão para o povoamento de pinus foi de 6,9.

As relações entre precipitação total, precipitação interia, escoamento pelo tronco, precipitação efetiva e interceptação foram, em cada caso, analisadas por regressão linear simples.

A medição da água do solo foi realizada através do método de moderaçäo de neutrons, utilizando-se sonda do tipo "BASC Depth Woisture/Density Probel fabricada pela NEA - Nordisk Elektrisk Apparatfabrik, da Dinamarca, cuja fonte de neutrons é constituída por ${ }^{24} \mathrm{Am}-\mathrm{Be}$, com radioatividade nominal de $30 \mathrm{nCi}$. En cada povoamento flom restal, assim como na parcela de vegetação herbácea, foram introduzidos verticalmente no solo 3 tubos de alumínio com comprimento aproxima do de $2,20 \mathrm{~m}$, que ficaram situados a uma distância aproximada de $15 \mathrm{me}$ tros um do outro. Estes tubos serviam de acesso para a sonda de neutrons, conforme ilustrado na Figura 4. As leituras, obtidas por contagem durante 1 minuto, form feitas, em cada tubo, a partir dos $30 \mathrm{~cm}$ de profundidade, repetindo-se a intervalos de $30 \mathrm{~cm}$ até a profundidade de $1,80 \mathrm{~m}$. A determinação da umiciade do solo na camada superficial de 0-30 cm foi feita por sravimetria (REYNOLS, 1970). Durante o período experimental, as medições da água do solo foram realizadas en interva10 mínimo de 1 mês. Em algumas ocasiōes foram feitas leituras quinzenais. A calibragen da sonda de neutrons foi desenvolvida no campo, através da comparação da porcentaģem de umidade determinada çravimetricamente com os valores da contagem por minuto obtidos no mesmo instante em que as amostras iam seindo coletadas. A curva de calibragem assim obtida coincidiu com a curva de calibragem de fábrica do aparelho, e a transformação dos valores de contagem por minuto en porcentagem de umi dade com base em volume foi, após esta verificação, desenvolvida através da própria curva de calibrasom da fábrica. Finalmente, o cálculo da quantidade de ácua armazenada no perfil do solo (S) foi feito pela integração das áreas compreenảias entre leituras consecutivas de umidade pela sonda de neutrons.

Para a verificação do desenvolvimento, ou do cresm cimento radial dos povoamentos durante o periodo, procedeu-se a medicão estacional do DAP (diânetro a $1,30 \mathrm{~m}$ de altura) das árvores. A pri meira meaição foi realizada por ocasião do início do experimento, e as 
seguintes se repetiram a cada 3 meses, num total de 8 medições. A média do DAP em cada data foi obtida pela medição do DAP de 232 árvores devidamente identificadas em cada poroamento, utilizando-se trena dendrométrica.

Por fim, os aspectos qualitativos estudados foram medidos em anostras coletadas após cada chuva no pluviônetro, nos interceptônetros e nos recipientes plásticos utilizados para a medição da interceptação, recipientes estes que foram frequentenente lavados durante todo o pexíodo experimental. As amostras foram coletadas en garrafinhas de polietileno de $250 \mathrm{ml}$. Após cada chuva eram coletadas 2 garrafinhas da água coletada no pluviômetro, 4 garrafinhas da água de interceptômetros escolhidos ao acaso, e 4 garrafinhas dos recipientes plásticos de medição do escoamento pelo tronco, também escolnidos, em caka vez, ao acaso, tanto para o povoamento de eucalipto como no de pi nus. As análises eram realizadas imediatamente após a chegada das amos tras no laboratório. O pH foi medido en potenciônetro modelo 2075 fabricado ela HACH Chemical Company. A medição da turbidez foi feita em turbidínetro modelo $2100 \mathrm{~A}$, tambér fabricado pela HACH. Para a medição da condutância utilizou-se de um condutivímetro modelo.2511, também da MACH. Os valores dos Sólidos lotais Dissolvidos foram obtidos a partir dos resultados de conducância específica, conforme escala de conversão da HACH CHMMCAL COMPANY $\left(1973^{a}\right)$. A cor foi determinada colorimetricamente, em colorímetro modelo DI, da FACI, conforme método descrito em HACH CHMICAL COMPANY $\left(1973^{\mathrm{b}}\right)$. A alcalinidade foi determinada por titu lometria, conforme método descrito em AMERICAN PUBLIC HEAITH ASSOCIATION (1949). Os dados de laboratório foram, a seguir, comparados por análise a variância, a fim de determinar os possiveis efeitos das duas espécies florestais estudadas, assim como diferenças significativas entre as espécies. 


\subsection{Caracteristicas Fisjocas do Solo}

Através da abertura de uma trincheira entre os povoamentos florestais estudados, procedeu-se a análise morfolósica do so 1o, bem como coletaram-se anostras dos vários horizontes para a determi naçäo de suas características físicas. Os resultados são a presentados na Tabela 1.

$$
\text { Pelas caracteristicas morfológicas do pexfil, as- }
$$
sim como pelos resultados das análises físicas, verifica-se que se tra ta de un solo podzólico. Pela sua situação Eeocráfica, verifica-se ain da que este solo se encontra en posição de transição entre os solos da Série "Iuiz de queiroz" e os da Série "Sertãozinho", cujas descrições podem ser encontradas em RAMAAI et al. (1966). Do ponto de vista reom. lósico, é bem possível que a formação deste solo tenha sofrido influên cia tanto do conjunto de sedimentos da Formação Itapetininģa, quanto do derrame de diabásio da Série são Bento, conforme pode ser depreendi do do mapa seológico contido en RAHzAYI (1956). 
Tabela 1: Características Físicas do Solo

\begin{tabular}{|c|c|c|c|c|c|c|c|c|}
\hline \multirow[b]{2}{*}{ Hor. } & \multirow{2}{*}{$\begin{array}{c}\text { Espessura } \\
(\mathrm{cm})\end{array}$} & \multicolumn{4}{|c|}{ Análise Textural } & \multirow{2}{*}{$\begin{array}{c}\text { Densi- } \\
\text { dade } \\
\text { Apar. } \\
\left(8 / \mathrm{Cn}^{3}\right)\end{array}$} & \multicolumn{2}{|c|}{ Rotenção cie Unidade } \\
\hline & & $\begin{array}{c}\text { Areia } \\
(\%)\end{array} \mid$ & $\begin{array}{r}\operatorname{Iimo} \\
(\%)\end{array}$ & $\begin{array}{c}\text { Argila } \\
(\%)\end{array}$ & $\begin{array}{l}\text { Classe } \\
\text { Pextiral }\end{array}$ & & $\begin{array}{l}1 / 3 \mathrm{Atm} \\
(\% \text { vol. })\end{array}$ & $\begin{array}{c}15 \mathrm{Atm} \\
(\% \text { vol. })\end{array}$ \\
\hline $\mathrm{Ap}$ & $0-15$ & 73,9 & 12,8 & $3 \quad 23,4$ & ba & 1,5 & 23,3 & 11,0 \\
\hline $\mathrm{A}_{3}$ & $15-38$ & 68,5 & $12, ?$ & 18,8 & ba & 1,6 & 24,3 & 11,9 \\
\hline$B_{1}$ & $38-75$ & 61,0 & 11,4 & 27,6 & bra & 1,4 & 24,1 & 15,3 \\
\hline $\mathrm{B}_{2}$ & $75-102$ & 55,2 & $11, ?$ & 33,2 & bra & 1,5 & 28,1 & 14,5 \\
\hline $\mathrm{B}_{3}$ & $102-144$ & 57,9 & 11,5 & 530,6 & bra & 1,4 & 30,3 & 15,1 \\
\hline$c^{-}$ & $144>$ & 56,1 & 12.7 & 31,2 & bra & 1,3 & 29,3 & 15,4 \\
\hline
\end{tabular}




\subsection{Intercentação.}

Ao todo foram medidas, durante o período experimental, 64 chuvas isoladas para a determinação da interceptação nos povoa mentos de eucaliptos e de pinus, chuvas estas que variaram de um vaIor mínimo de $0,8 \mathrm{~mm}$ até um máximo de $65 \mathrm{~mm}$. A Tabela 2 contém a distribuição e a frequência das várias classes de tamanho das chuvas observadas durante o periodio, assim como os valores médios de precipitação interna è de escoamento pelo tronco em eucalipto e em pinus.

Tabela 2: Frequências das várias classes de tamanho de chuvas ocorridas durante o periodo experimental, $\epsilon$ respectivos valores médios de PI e Et repistrados nos povoamentos de Eucaliptos e de Pinus.

\begin{tabular}{c|c|c|c|c|c}
\hline \multirow{2}{*}{$\begin{array}{c}\text { Classes de tamanho } \\
\text { de chuva (mn) }\end{array}$} & \multirow{2}{*}{ Frequência } & \multicolumn{2}{|c|}{ Eucalipto } & \multicolumn{2}{c}{ Pinus } \\
\cline { 3 - 6 } & & PI (mm) & Et (mm) & PI (mm) & Et (mm) \\
\hline $0-2,5$ & 7 & 1,1 & 0,0 & 1,3 & 0,0 \\
$2,5-5,0$ & 3 & 3,3 & 0,2 & 3,8 & 0,1 \\
$5,0-10,0$ & 11 & 5,8 & 0,2 & 6,3 & 0,2 \\
$10,0-20,0$ & 16 & 13,6 & 0,7 & 14,2 & 0,6 \\
$20,0-30,0$ & 10 & 20,5 & 1,8 & 21,8 & 1,0 \\
$30,0-40,0$ & 8 & 29,2 & 1,9 & 29,8 & 0,8 \\
$40,0-50,0$ & 5 & 39,3 & 2,2 & 42,2 & 1,6 \\
$50,0-60,0$ & 3 & 49,6 & 2,8 & 52,4 & 1,2 \\
$60,0-70,0$ & 1 & 56,8 & 2,9 & 61,1 & 1,2 \\
\hline
\end{tabular}

Verifica-se, pela observação da Tabela 2, que os valores médios de PI aumentam proporcionalmente com o aumento da quantidade da precipitação total, sendo que os valores médios de PI em pinus são ligeiramente maiores que os de eucaliptos. Verifica-se, por ou tro lado, que os valores médios de it são maiores em eucalipto do que em pinus; resultados estes de acordo com o esperado, devido, principal mente, a maior rugosidade das cascas das árvores de pinus em compara- 
ção com as de eucaliptos. Observamse ainda que o et começou a ser medi do somente a partir de certos valores de precipitação total. Por exemplo, para chuvas de até $2,5 \mathrm{~mm}$, não houve formação de tit nem em eucalipto, nem em pinus. Essa quantidade mínina de chuva acima do qual começa a haver escoamento pelo tronco foi un pouco maior para o caso de pinus do que para o eucalipto. Foi observado, por exemplo, que mes mo para uma chuva de $4 \mathrm{~mm}$ não houve formação de tet em pinus (Tabela 5). Já a precipitação interna ocorreu desde valores baixos ảe precipi-. tação total, sendo incjusive, cerca de $80 \%$ para os valores mínimos de PT observados (Tabelas 4 e 5). Isto pode ser explicado pelas condiçóes de estrutura atual dos povoamentos, no que diz respeito à densidade e ao fechamento das copas. E de se esperar que a medida que o fechamento das copas se complete, tanbém a precipitação interna só começará a se verificar a partir de un certo valor mínimo de chuva.

Estas relações entre precipitação total, precipita ção interna, escoamento pelo tronco e precipitação efetiva são ilustra das através das F'iguras 5, 6 e 7, que contêm as curvas de regressão en tre precipitação total e precipitação interna, precipitação total e es coamento pelo tronco, e precipitação total e precipitação efetiva, res pectivamente, de forma comparativa entre eucaliptos e pinus.

Ita Iigura 5, por exemplo, observa-se, como já arie mado anteriormente, que para una mesma chuva, houve un volume ligeiramente maior de precipitação interna em pinus do que em eucalipto.

Mas o escomento pelo tronco foi bem maior em euca lipto do que em pinus, conforme ilustram as curvas de regressão da $F i-$ gura 6.

A Figura 7 mostra a relação entre a precipitação efetiva, isto é, a soma PI + Et, e a precipitação total. Conforme pode ser observado pela análise desta ficura, para as condições dos povoamentos estudados, o solo sob pinus recebeu, em média, quantidade de água aproximadamente $6 \%$ maior do que o solo sob o povoamento de eucaIiptos.

As equações de regressão que permitem a estimativa da precipitação interna (PI), do escomento pelo tronco (Et) e da precipitaça efetiva (PE) a partir dos dados da precipitação total, ou se ja, da precipitação medida em área aberta, são dadas na Tabeja 3. 


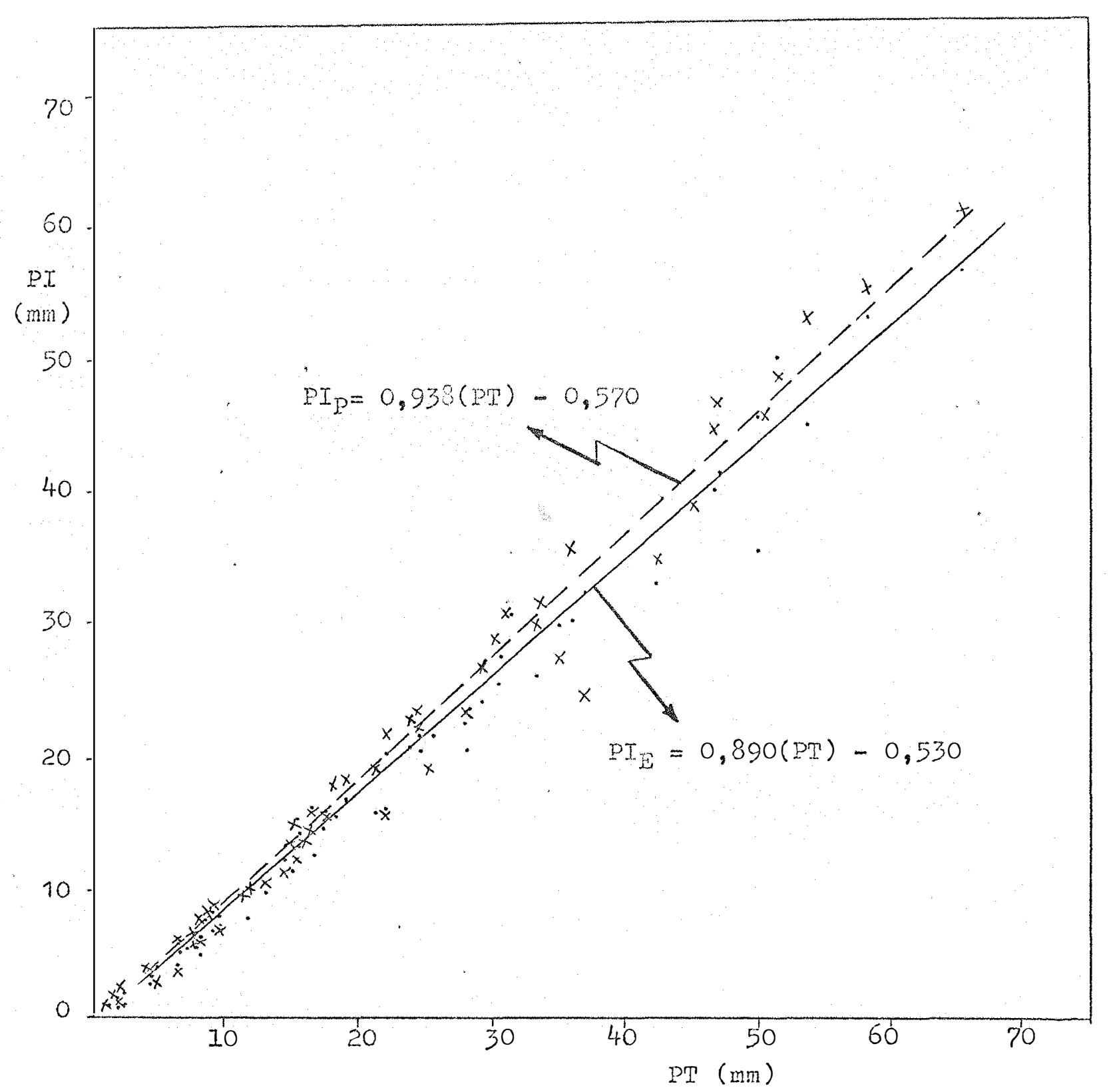

Fisura 5: Relação entre Precipitação Interna (PI) e Precipitação rotal (PT) en Eucalipto e pinus. 


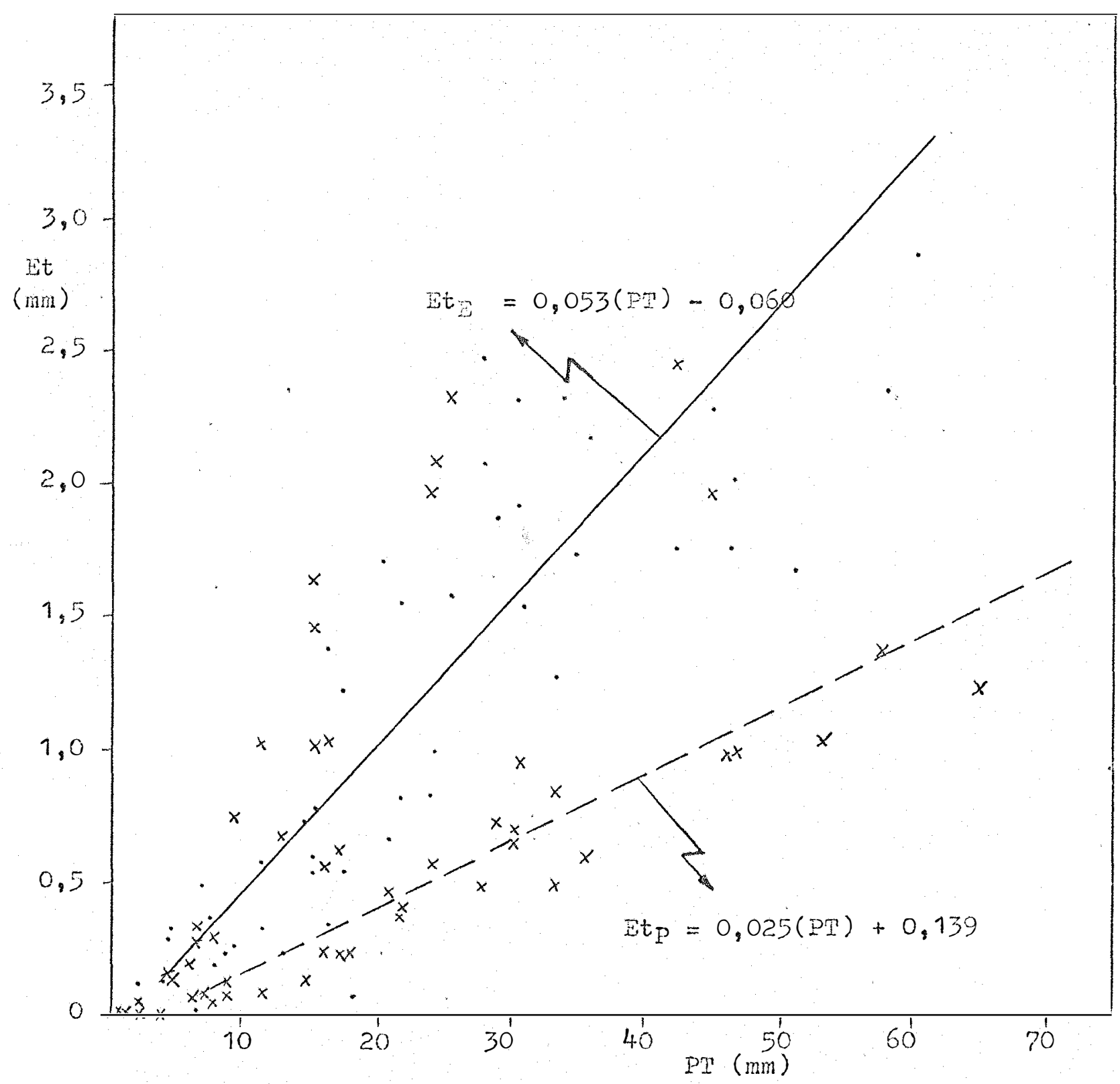

Figura 6: Relação entre Iscomento pelo tronco (Et) e Precipitação Total (PT) em Zucalipto e em Pinus. 


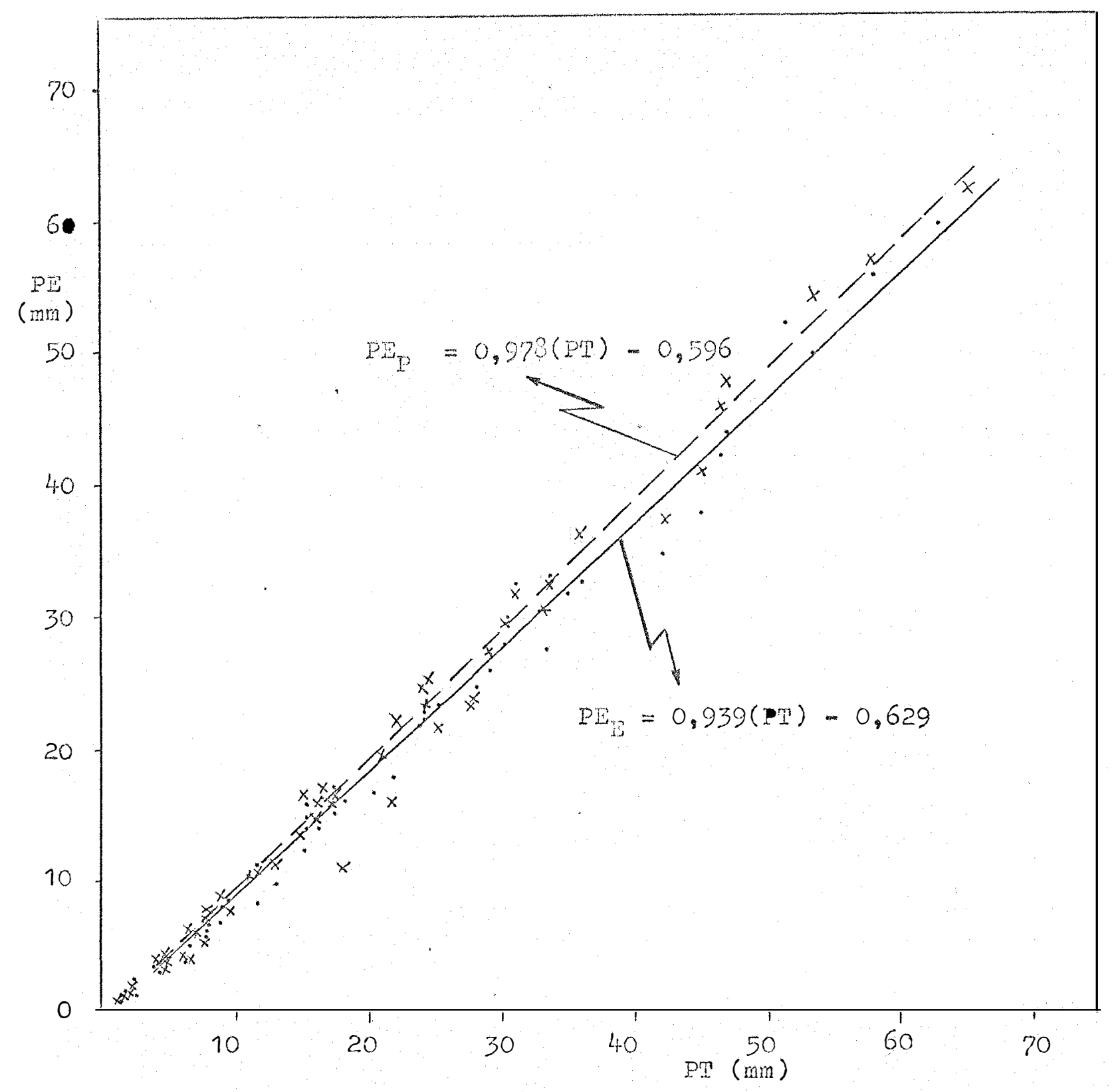

Figura 7: Relação entre Precipitação Efetiva (PI) e Precipitação rotal (PT) em Lucalipto e Pinus. 
Pabela 3: Equaçoos para a Estimativa da Precipitação Interna (PI), Escoamento pelo tronco (Bt) e Precipitacão Iretiva (PE), a partir da modição de Drecipitação Total.

\begin{tabular}{|c|c|c|c|c|}
\hline $\begin{array}{c}\text { Variável } \\
\text { Dependente }\end{array}$ & Tipo de Floresta & $\begin{array}{l}\text { Idade } \\
\text { (anos) }\end{array}$ & Reģressão & $r$ \\
\hline \multirow{2}{*}{$P I$} & Eucalyntus saligna & 6 & $P I=0,890(P T)-0,530$ & 0,99 \\
\hline & Pinus caribaea & 6 & $P I=0,938(P T)-0,570$ & 0,99 \\
\hline \multirow[t]{2}{*}{$E t$} & Eucalyptus saligna & 6 & $E t=0,053(\mathrm{PT})-0,060$ & 0,89 \\
\hline & Pinus caribaes & 6 & $E_{t}=0,025(\mathrm{DP})+0,139$ & 0,61 \\
\hline \multirow{2}{*}{$\mathrm{PE}$} & Eucalyptus saligna & 6 & $P E=0,939(P T)-0,629$ & 0,99 \\
\hline & Pirus caribaea & 6 & $\mathrm{PI}=0,978(\mathrm{PT})-0,596$ & 0,99 \\
\hline
\end{tabular}

Para a precipitação interna e a precipitação efetê va, as equaçôes da Tabela 3 são bastante significativas, mostrando que a variável "quantidade de chuva en milímetros" é responsável por cerca de $98 \%$ da variação de PI e de PE, en cada caso. Já as equações para a estimativa do escoamento pelo tronco parecem indicar que existem outros fatores que podem alterar os valores de Et, alén da quantidade de chuva. Yo caso de pinus, por exemplo, a equação determinada responde apenas por aproximadamente $37 \%$ da variação de Et. Este caráter errático do processo de escoamento pelo tronco é discutido en UELVIY e PATRIC $\left(1965^{\mathrm{a}}\right)$. Segundo a completa revisão feita por estes autores, o escoamento pelo tronco é muito variável não apenas de chuva para chuva, mas também de árvore para árvore. Iú trabalhos que mostram que a adição de uma segunda variável (ex. Dip das árvores) melhora um pouco a precisão da equação de regressão (LEONARD, 1961), (RUTTER, 1963). Dor outro lado, DEWALIE e PAULSEIL (1969) não encontraram correlação entre escoamento pelo tronco e DAP das árvores.

As equações da Tabela 3 podem ser usadas para a es timativa da precipitação interna, do escoamento pelo tronco, e da precipitação efetiva e, consequentemente, das perdas por interceptação en povoamentos de eucaliptos e de pinus em condições sinilores às da área experimental e são, evidentemente, válidas para o intervalo de varia- 
ção da precipitação total observado durante o período de estudo, ou se ja, de 0,8 a $65 \mathrm{~mm}$.

As Tabelas 4 e 5 contém os dados de precipitaçäo total, precipitação interna è escoamento pelo tronco medidos durante o experinento, assin como os valores calculados de precipitação efetiva e da resultante perda por interceptação ( $I$ ), tanto em milímetros como em valores porcentuais, para os povoanentos de eucaliptos e de pinus, respectivanente. Nas Tabelas 4 e 5 pode-se verificar que as perdas por interceptacão (I) em eucaliptos variaram, em porcentagem sobre a preci pitação totál, de $0 \%$ até $45 \%$, resultando num valor nédio de I de $12,4 \%$. Para o povomento de pinus, a variação verificada foi de $0 \%$ até $38 \%$, dando um valor médio de I de $7,2 \%$.

Na revisão da literáuru foi afirmado que as coniferas causam, em feral, maior interceptação do que as folhosas, e os resultados acima apresentados não vieram, aparentemente, de encontro a esta expectativa geral. A explicação pode ser dada com base nas condiçöes atuais do povoamento de pinus estudado, bastante jovem ainda, e en estágio de desenvolvimento tal que as copas mal começam a se tocar, o que pode ser observado pelo valor médio de precipitaçĩo interna maior em pinus do que em eucalipto $(90,4 \%$ contra $33,6 \%)$, de acordo com as ta belas 4 e 5 . E de se esperar que a medida que o povoamento de pinus se desenvolva, também as perdas por interceptação se tornem gradativamente maiores. Já o povoemento de eucaliptos estudado pode ser considerado como representativo de uma plantação em escala industrial próxima a época do primeiro corte.

Com base nos valores médios das Tabelas 4 e 5 , portanto, pode-se concluir que para a média anual de $1.40 \mathrm{~mm}$ de precí pitação total medidos durante o período experimental, as perdas por in terceptação foram de $174 \mathrm{~mm}$ anuais para o povoamento de eucalipto e $101 \mathrm{~mm}$ anuais para o de pinus. Isto simnifica que o solo sob o povoamento de pinus recebeu, em média, aproximadamente $73 \mathrm{~mm}$ a mais de ácua das chuvas do que o solo sob eucaliptos.

Estes resultados permitem, de certa forma, visuali zar a importancia do conhecimento destas fases do ciclo hidrolósico no que diz respeito a elaboração de normas de nanejo aảequadas para estas essências florestais e também de polfticas sadias de uso do solo e da água. sem entrar no mérito da diferença de desenvolvimento, ou seja 


\begin{tabular}{|c|c|c|c|c|c|c|c|c|}
\hline $\begin{array}{c}\mathrm{pr} \\
(\mathrm{mm})\end{array}$ & $\begin{array}{c}P I \\
(\mathrm{~mm})\end{array}$ & 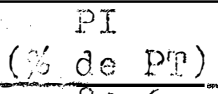 & $\begin{array}{c}\mathrm{Et} \\
(\mathrm{mm})\end{array}$ & $(\% \mathrm{de} \mathrm{pm})$ & $\begin{array}{c}1 \mathrm{P} \\
(\mathrm{ma})\end{array}$ & $\left(\begin{array}{cc}2 \mathrm{~d} \\
\mathrm{de}\end{array}\right.$ & $\begin{array}{c}1 \\
(\mathrm{~mm}) \\
\end{array}$ & $\begin{array}{ll}I & \\
( & \text { de }\end{array}$ \\
\hline 6,7 & 5,4 & 30,6 & 0,49 & 7,4 & 5,9 & 80,0 & 0,03 & $2 i_{2}, 0$ \\
\hline 1,5 & 1,2 & 80,0 & 0,03 & 2,0 & 1,2 & 82,0 & 0,27 & 18,0 \\
\hline 4,3 & 3,2 & 74,4 & 0,27 & 6,3 & 3,5 & 80,1 & 0,83 & 19,3 \\
\hline 4,5 & 3,8 & 84,4 & $0,2,7$ & 6,0 & 4,1 & 90,4 & 0,43 & 9,6 \\
\hline 1,0 & 1,0 & 100,0 & 0,01 & 1,1 & 1,0 & 101,1 & 0,00 & 0,0 \\
\hline 44,9 & $35, ?$ & 79,5 & 2,27 & 5,1 & 33,0 & 84,6 & 6,93 & 15,4 \\
\hline 0,8 & 0,6 & 75,0 & 0,01 & 0,9 & 0.6 & 75,9 & 0,19 & 24,1 \\
\hline 25,1 & 21,8 & 86,9 & 1,56 & 6,2 & 23,4 & 93,1 & 1,74 & 6,9 \\
\hline 24,1 & 21,6 & 89,6 & 0,96 & 4,0 & 22,6 & 93,6 & 1,54 & 6,4 \\
\hline 0,8 & 0,6 & 75,0 & 0,00 & 0,0 & 0,6 & 75,0 & 0,20 & 25,0 \\
\hline 42,1 & 33,2 & 73,9 & 1,76 & 4,2 & 35,0 & 83,0 & 7,24 & 17,0 \\
\hline 0,9 & 0,8 & 38,9 & 0,00 & 0,0 & 0,8 & 88,9 & 0,10 & 11,1 \\
\hline 16,4 & 16,1 & 98,2 & 0,29 & 1,8 & $3.6,4$ & 100,0 & 0,01 & 0,1 \\
\hline 51,2 & 50,4 & 98,4 & 1,69 & 3,3 & 52,1 & $3.01,7$ & 0,00 & 0,0 \\
\hline 2,2 & 2,0 & 90,9 & 0,13 & 5,9 & 2,1 & 96,8 & 0,07 & 3,2 \\
\hline 15,1 & 13,2 & 87.4 & 0,79 & 5,2 & 24,0 & 92,6 & $1,1]$ & 7,4 \\
\hline 23,7 & 20,9 & 88,2 & 0,81 & 3,4 & 21,7 & 91,6 & 1,99 & 8,4 \\
\hline 9,3 & 7,9 & 84,9 & 0,27 & 2,9 & 8,2 & 87,9 & 3,13 & 12,1 \\
\hline 6,4 & 5,1 & 79.7 & 0,02 & 0,3 & 5,1 & 80,0 & 1,28 & 20,0 \\
\hline $11 ; 4$ & 10,3 & 90,4 & 0,58 & 5,1 & 10,9 & $95: 4$ & 0,52 & 4,6 \\
\hline 15,4 & 14,2 & 92,2 & $0,52$. & 3,3 & $3.4,7$ & 95,5 & 0,69 & 4,5 \\
\hline 6,0 & 4,3 & 71,7 & 0,09 & 1,4 & 4,4 & 73,1 & 1,61 & 26,9 \\
\hline 12,9 & 9,7 & 75,2 & 0,24 & 1,8 & 9,9 & 77,0 & 2,96 & 23,0 \\
\hline 7,6 & 6,3 & 83,0 & 0,18 & 2,3 & 6,5 & 85,2 & 1,12 & 14,8 \\
\hline 34,7 & 30,0 & 86,5 & 1,76 & 5,1 & 31,8 & 91,5 & 2,94 & 8,5 \\
\hline 15,1 & 15,1 & 100,0 & 0,58 & $3, .8$ & 15,8 & 103,8 & 0,00 & 0,0 \\
\hline 21,0 & 25,9 & 75,7 & 0,67 & 3,2 & 16,6 & 78,9 & 4,43 & 21,1 \\
\hline 8,7 & 7,8 & 89,7 & 0,20 & 2,3 & 8,0 & 92,0 & 0,70 & 8,0 \\
\hline 30,8 & 30,8 & 100,0 & 1,53 & 5,0 & 33,3 & 105,0 & 0,00 & 0,0 \\
\hline 21,9 & 20,5 & 93,6 & 0,81 & 3.7 & 21,3 & 97,3 & 0,59 & 2,7 \\
\hline 46,4 & 40,4 & 87,1 & 1,75 & 3,8 & 42,1 & 90,8 & $4, ? 25$ & 9,2 \\
\hline 6,1 & 4,3 & 70,5 & 0,07 & 1,1 & 4,4 & $7.1,6$ & $x, 74$ & 28,4 \\
\hline 8,6 & 6,7 & 77,9 & 0,05 & 0,6 & 6,8 & 73,5 & 1,85 & 21,5 \\
\hline 57,6 & 53,2 & 92,4 & 2,38 & 4,1 & 55,6 & 96,5 & 2,02 & 3,5 \\
\hline 18,0 & 15,5 & 86,1 & 0,55 & 3,1 & 16,1 & 89,2 & 1,95 & 10,8 \\
\hline $\begin{array}{l}65,0 \\
17.3\end{array}$ & $\begin{array}{l}56,8 \\
14,8\end{array}$ & $\begin{array}{l}87,4 \\
85,5\end{array}$ & $\begin{array}{l}2,86 \\
0.52\end{array}$ & $\begin{array}{l}4,4 \\
3,0\end{array}$ & $\begin{array}{l}59,7 \\
15.3\end{array}$ & $\begin{array}{l}91,8 \\
88,6\end{array}$ & $\begin{array}{l}5,35 \\
198\end{array}$ & $\begin{array}{r}8,2 \\
11,4\end{array}$ \\
\hline 27,7 & 22,8 & 82,3 & 2, 08 & 7,5 & $\begin{array}{l}13,3 \\
24,9\end{array}$ & 89,8 & 2,82 & $\begin{array}{l}11,4 \\
10,2\end{array}$ \\
\hline 24,1 & 20,6 & 85,5 & 1,71 & 7,1 & 22,3 & 92,6 & 2,80 & 7,4 \\
\hline 33,1 & 26,2 & 79,2 & 1,29 & 3,9 & 27,5 & 83,1 & 5,61 & 16,9 \\
\hline 46,6 & 41,5 & 89,1 & 2,01 & 4,3 & 43,5 & 93,4 & 3,10 & 6,6 \\
\hline 7,5 & $5, ?$ & 76,0 & 0,38 & 5,0 & 6,1 & 81,0 & 1,42 & 19,0 \\
\hline 30,2 & 25,8 & 85,4 & 9,93 & 6,4 & 27,7 & 91,8 & 2,47 & $\begin{array}{l}8,2 \\
0.4\end{array}$ \\
\hline 28,9 & 24,3 & 34,1 & $\begin{array}{l}1,89 \\
27\end{array}$ & 6,5 & $\begin{array}{l}26,2 \\
32\end{array}$ & 90,6 & 2,71 & $9 ; 4$ \\
\hline 33,4 & $\begin{array}{r}30,4 \\
7,3\end{array}$ & $\begin{array}{l}91,0 \\
54, ?\end{array}$ & 2,33 & $\begin{array}{l}7,0 \\
0,0\end{array}$ & $\begin{array}{r}32,7 \\
1,3\end{array}$ & $\begin{array}{l}98,0 \\
54,2\end{array}$ & $\begin{array}{l}0,67 \\
1.10\end{array}$ & $\begin{array}{r}2,0 \\
45,8\end{array}$ \\
\hline $\begin{array}{r}2,4 \\
21,6\end{array}$ & $\begin{array}{r}1,3 \\
16,0\end{array}$ & $\begin{array}{l}34,2 \\
74,1\end{array}$ & $\begin{array}{l}0,00 \\
1,57\end{array}$ & 7,3 & 17,6 & 81,3 & 4,03 & 18,7 \\
\hline 17,4 & 16,0 & 92,0 & 1,23 & 7,1 & 17,2 & 99,0 & 0,17 & 1,0 \\
\hline 35,6 & 30,3 & 85,1 & 2,34 & 6,6 & 32,6 & $91, ?$ & 2,96 & 8,3 \\
\hline 30,2 & 27,5 & 91,1 & 2,34 & 7,7 & 29,9 & 98,8 & 0,36 & 1,2 \\
\hline 53,4 & 45,2 & 84,6 & 4,39 & 8,2 & 49,6 & 32,9 & 3,81 & 7,1 \\
\hline 27,6 & 20,8 & 75,4 & 2,50 & 9,0 & 23,3 & 84,4 & 4,30 & 15,6 \\
\hline 4,0 & , & 75,0 & 0,12 & 3,0 & 3,2 & 78,0 & 0,83 & 22,0 \\
\hline 14,8 & 12,6 & 73,4 & 0,74 & 5,0 & 12,3 & 83,4 & 2,46 & 15,6 \\
\hline 7,7 & 5,2 & 67,5 & 0,30 & 3,9 & 5,5 & 71,4 & $2 ; 20$ & 28,6 \\
\hline 21,5 & 7,8 & 67,8 & 0,34 & $2, ?$ & 8,1 & 70,8 & 3,36 & 29,2 \\
\hline 16.1 & $1.2,7$ & 78,9 & 1,33 & & 14,3 & 37,4 & 2,02 & 12,6 \\
\hline
\end{tabular}


Iabela 5: Valores de Precipitaçäo Tnterna (PI), Jrcoanento pelo

42.

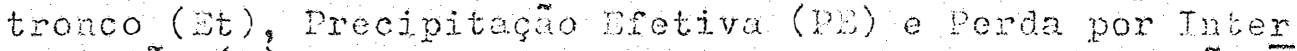
covtação (I) en m e em porcentagen sobre Drecipjtação. Total (PT) para o povornento de Pinus.

\begin{tabular}{|c|c|c|c|c|c|c|c|c|}
\hline $\begin{array}{r}\mathrm{PT} \\
(\mathrm{mm}) \\
\end{array}$ & $(\mathrm{min})$ & $(\%$ de & $\begin{array}{c}\mathrm{xt} \\
(\mathrm{nm})\end{array}$ & $\left(\begin{array}{c}\mathrm{t} \\
(\mathrm{gep})\end{array}\right.$ & $\begin{array}{l}\text { DE } \\
(\mathrm{mm})\end{array}$ & $\left(\begin{array}{ll}P E \\
d e & P r\end{array}\right)$ & (1n) & $\begin{array}{c}I \\
(\sec p)\end{array}$ \\
\hline $\begin{array}{r}6,7 \\
1,5 \\
4,3 \\
4,5 \\
16,1 \\
1,0 \\
44,9 \\
0,8 \\
25,1 \\
24,1 \\
0,8 \\
42,1 \\
0,9 \\
16,4 \\
2,2 \\
15,1 \\
23,7 \\
9,3 \\
6,4 \\
11,4 \\
15,4 \\
6,0 \\
12,9 \\
7,6 \\
15,1 \\
21,0 \\
8,7 \\
30,8 \\
21,9 \\
46,4 \\
6,1 \\
8,6 \\
57,6 \\
18,0 \\
65,0 \\
17,3 \\
27,7 \\
24,1 \\
33,1 \\
46,6 \\
7,5 \\
30,2 \\
28,9 \\
33,4 \\
2,4 \\
21,6 \\
17,4 \\
35,6 \\
30,2 \\
53,4 \\
27,6 \\
4,9 \\
14,8 \\
7,7 \\
11,5 \\
16,1 \\
\end{array}$ & $\begin{array}{r}5,5 \\
1,3 \\
1,2 \\
3,1 \\
15,3 \\
1,0 \\
39,0 \\
0,8 \\
19,0 \\
23,2 \\
0,8 \\
34,8 \\
0,9 \\
15,9 \\
2,0 \\
12,1 \\
23,0 \\
7,0 \\
5,9 \\
9,6 \\
13,2 \\
3,9 \\
10,5 \\
6,5 \\
15,0 \\
19,0 \\
8,7 \\
30,8 \\
21,9 \\
44,8 \\
3,7 \\
8,3 \\
55,2 \\
18,0 \\
61,1 \\
15,7 \\
23,3 \\
22,6 \\
29,9 \\
46,6 \\
6,0 \\
29,1 \\
26,6 \\
31,7 \\
2,3 \\
15,5 \\
15,5 \\
35,5 \\
23,9 \\
53,2 \\
23,4 \\
4,0 \\
13,1 \\
7,6 \\
10,0 \\
14,3 \\
\end{array}$ & 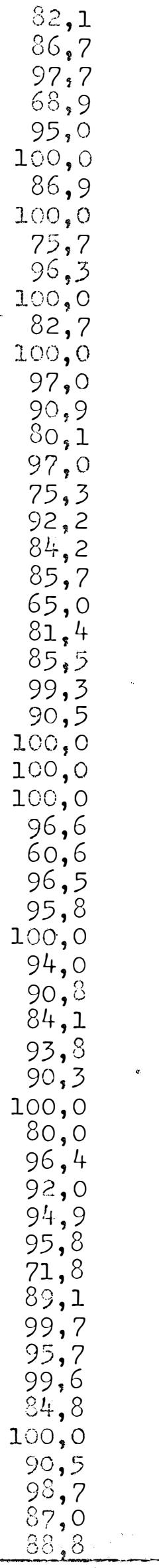 & $\begin{array}{l}0,31 \\
0,01 \\
0,15 \\
0,13 \\
0,56 \\
0,01 \\
1,06 \\
0,01 \\
2,35 \\
2,09 \\
0,00 \\
2,45 \\
0,00 \\
1,01 \\
0,02 \\
1,63 \\
1,97 \\
0,74 \\
0,27 \\
1,07 \\
1,01 \\
0,18 \\
0,67 \\
0,28 \\
1,46 \\
0,45 \\
0,11 \\
0,94 \\
0,40 \\
0,98 \\
0,06 \\
0,07 \\
1,37 \\
0,21 \\
1,24 \\
0,22 \\
0,50 \\
0,57 \\
0,50 \\
0,99 \\
0,06 \\
0,69 \\
0,72 \\
0,83 \\
0,00 \\
0,39 \\
0,61 \\
0,59 \\
0,65 \\
1,02 \\
0,27 \\
0,00 \\
0,11 \\
0,04 \\
0,07 \\
0,23 \\
0,0\end{array}$ & $\begin{array}{l}1,7 \\
0,3 \\
3,5 \\
2,8 \\
3,5 \\
0,7 \\
4,4 \\
0,3 \\
9,4 \\
8,7 \\
0,0 \\
5,8 \\
0,0 \\
6,2 \\
1,0 \\
10,8 \\
8,3 \\
8,0 \\
4,2 \\
9,4 \\
6,6 \\
3,0 \\
5,2 \\
3,7 \\
9,7 \\
2,2 \\
1,2 \\
3,1 \\
1,8 \\
2,1 \\
1,0 \\
0,8 \\
2,4 \\
1,2 \\
1,9 \\
1,3 \\
1,8 \\
2,4 \\
1,5 \\
2,1 \\
0,8 \\
2,3 \\
2,5 \\
2,5 \\
0,0 \\
1,3 \\
3,5 \\
1,7 \\
2,1 \\
1,9 \\
1,0 \\
0,0 \\
0,7 \\
0,5 \\
0,6 \\
1,5 \\
0\end{array}$ & $\begin{array}{r}5,8 \\
1,3 \\
4,3 \\
3,2 \\
15,9 \\
1,0 \\
41,0 \\
0,8 \\
21,3 \\
25,3 \\
0,8 \\
37,2 \\
0,9 \\
16,9 \\
2,0 \\
13,7 \\
25,0 \\
7,7 \\
6,2 \\
10,7 \\
14,2 \\
4,1 \\
11,2 \\
6,8 \\
16,5 \\
19,5 \\
8,8 \\
31,7 \\
22,3 \\
45,8 \\
3,8 \\
8,4 \\
56,6 \\
10,2 \\
62,3 \\
15,9 \\
23,8 \\
23,2 \\
30,4 \\
47,6 \\
6,1 \\
29,3 \\
27,3 \\
32,5 \\
2,3 \\
15,9 \\
16,1,1 \\
36,1 \\
29,5 \\
54,2 \\
23,7 \\
4,0 \\
23,5 \\
7,6 \\
10,1 \\
14,5 \\
\end{array}$ & $\begin{array}{r}86,7 \\
86,9 \\
101,1 \\
71,7 \\
98,5 \\
100,7 \\
91,2 \\
100,3 \\
85,0 \\
104,9 \\
100,0 \\
88,5 \\
100,0 \\
103,1 \\
92,0 \\
90,9 \\
105,4 \\
83,2 \\
96,4 \\
93,6 \\
92,3 \\
68,0 \\
86,5 \\
89,2 \\
109,0 \\
92,6 \\
101,2 \\
103,1 \\
101,8 \\
98,7 \\
61,6 \\
97,3 \\
98,2 \\
101,2 \\
95,9 \\
92,0 \\
85,9 \\
96,1 \\
91,8 \\
102,1 \\
80,8 \\
98,6 \\
94,5 \\
91,8 \\
85,8 \\
100,0 \\
91,3 \\
99,2 \\
87,5 \\
95,8 \\
90,3 \\
73,6 \\
92,6 \\
101,4 \\
\end{array}$ & $\begin{array}{l}0,89 \\
0,20 \\
0,00 \\
1,27 \\
0,24 \\
0,00 \\
3,94 \\
0,00 \\
3,75 \\
0,00 \\
0,00 \\
4,85 \\
0,00 \\
0,00 \\
0,18 \\
1,37 \\
0,00 \\
1,56 \\
0,23 \\
0,73 \\
1,19 \\
1,92 \\
1,74 \\
0,02 \\
0,00 \\
1,55 \\
0,00 \\
0,00 \\
0,00 \\
0,62 \\
2,34 \\
0,23 \\
1,04 \\
0,00 \\
2,66 \\
1,38 \\
3,90 \\
0,93 \\
2,70 \\
0,00 \\
1,44 \\
0,42 \\
1,58 \\
0,87 \\
0,10 \\
5,71 \\
1,29 \\
0,00 \\
0,65 \\
0,00 \\
3,93 \\
0,00 \\
1,29 \\
0,06 \\
1,43 \\
1,57 \\
1\end{array}$ & $\begin{array}{r}13,3 \\
13,1 \\
0,0 \\
28,3 \\
1,5 \\
0,0 \\
8,8 \\
0,0 \\
14,9 \\
0,0 \\
0,0 \\
11,5 \\
0,0 \\
0,0 \\
8,0 \\
9,1 \\
0,0 \\
16,8 \\
3,0 \\
6,4 \\
7,7 \\
32,0 \\
13,5 \\
10,3 \\
0,0 \\
7,4 \\
0,0 \\
0,0 \\
0,0 \\
1,3 \\
38,4 \\
2,7 \\
1,8 \\
0,0 \\
4,1 \\
8,0 \\
14,1 \\
3,9 \\
8,2 \\
0,0 \\
19,2 \\
1,4 \\
5,5 \\
2,6 \\
4,2 \\
26,4 \\
7,4 \\
0,0 \\
2,2 \\
0,0 \\
14,2 \\
0,0 \\
8,7 \\
0,3 \\
2,5 \\
2,2\end{array}$ \\
\hline & & $90,4 \%$ & & $3,0 \%$ & & $93.4 \%$ & & $7,2 \%$ \\
\hline
\end{tabular}


comparando-se os dois povoamentos florestais estudados de nodo cono eles se encontram agora, os resultados, no conjunto, permitem al cumas considexaços interessantes. Por exemplo, pode-se deduzir que tanto o rendinento hídrico (produção de áçua na forma de defiúvio superficial) quanto o suprimento de ásua para o Iençol subterrâneo serian ligeiramente maiores em áreas com cobertura de pinus do que em áreas con euca liptos, como consequencia da naior quantiaacie de água que chega ao solo sob pinus. Supondo-se ainda que se tratasse de 2 bacias hidrosráficas de 40 hectares cada, ume contendo Ploresta de eucalipto e outra contendo pinus, em tudo sinilar dis condições do presente estudo, podese, por cálcujos simples, deduzir que ajenas como consequencia las per das por interceptação o defíuvio anul médio da primeira bacia seria reduzido de cerca de 69,6 mijhões de litros de ácua, e o da segunda se ria reduzido de aproximadamente 40,4 milhões de litros de ácua, reduções que, sem dúvida, merecem consideração.

Evidentemente, não se deve tomar tais estimativas como base para a conclusão de que o reflorestanento com eucaliptos ou com pinus podern ciusar efeitos adversos sobre os recursos hídricos. Una cobertura de floresta subtropjcol natural, de acordo con GaIGER (1966), pode apresentar perdaspor interceptacäo da orden de 38\%, ou seja, cerca de 3 vezes mais que a nédia obtida para eucalipto. Isstes resultados, ao contrário, devem se constituir em informação útil para o administrador de recursos naturais, isto é, para aciuele que tem a seu cargo as decisões sobre o uso do solo em geral; este deve reconhecer que en áreas onde o recurso água é mais importante as práticas silviculturais que resultem numa diminuição da interceptaça podem apresentar consequências desejáveis. 


\subsection{Regine da Água do Bolo.}

A Figura 8 mostra as variaçõos mensais do total de água amazenada no perfil todo do solo (S), com a indicaça dos respec tivos desvios praroes em alzuns dos períobos, ben como os valores nédios de retengão de umjare às pressés de $1 / 3$ de atmosfera e de 25 at mosteras, e a distribuição nensal da precipitação durante os 24 meses comproendios pelo periodo experimental.

De nodo geral, pode-se verificar que sempre houve água disponfivel no solo sob os três tipos de cobertura vegetal estudada, a não ser nos meses de setembro e outubro de 1974, quando o conteú do de água nos três casos foj inferior ao valor médio de retenção de áfua a 15 atmosferas. No periodo agosto-setembro de 1973, apenas o so10 "sob eucalipto apresentou valores de água armazenada inferiores co $10 \mathrm{r}$ médio correspondente a 75 atmosferas. A despeito de pequenas diferen cas de s observadas em alguns dos meses, pode-se afirmar tanbém que o regine da água do solo foi praticamente o mesmo para os três sistemás estudados. Comparando o povoamento de eucalipto com o de pinus, por exemplo, nota-se que os valores mensais de s deste último foram liejramente superiores aos do primeiro. Comparando a vegetaçäo herbácea com ambos os povoamentos floxestais, por outro lado, pode ser observado uma aparente tendência de $S$ ser ligeiramente maior na vegetação her bácea do que nos povoanentos florestais durante o período de verão, ao passo que o reverso se verificaria durante o período seco do ano. Esta conclusão, todavia, carece ser reforçada por un período maior de obser vação.

E interessante observar na Fighura 8 ainda, as rele ६̧ões entre as variações da água no solo e a distribuição da precipitação. O verão 1973-1974, por exenplo, apresentou o mês de fevereiro relativamente seco, com pouco mais de $70 \mathrm{~mm}$ de chuva; já o mês de marco apresentou queda pluviométrica comparativanente maior que a normal; abril. e março foram também mais secos que o normal e junho apresentou alta precipitação. Estas variações de distribuição da precipitação são, de certa forma, refletidas nas curvas da marcha anual da água do solo. lios meses de dezembro de 1973 e janeiro e fevereiro de 1974, por exemplo, pode ser notrado que - conteúdo de áfua no solo sob eucalipto dosceu a ureis bem mais bairos do que os outros dois sistenas. 


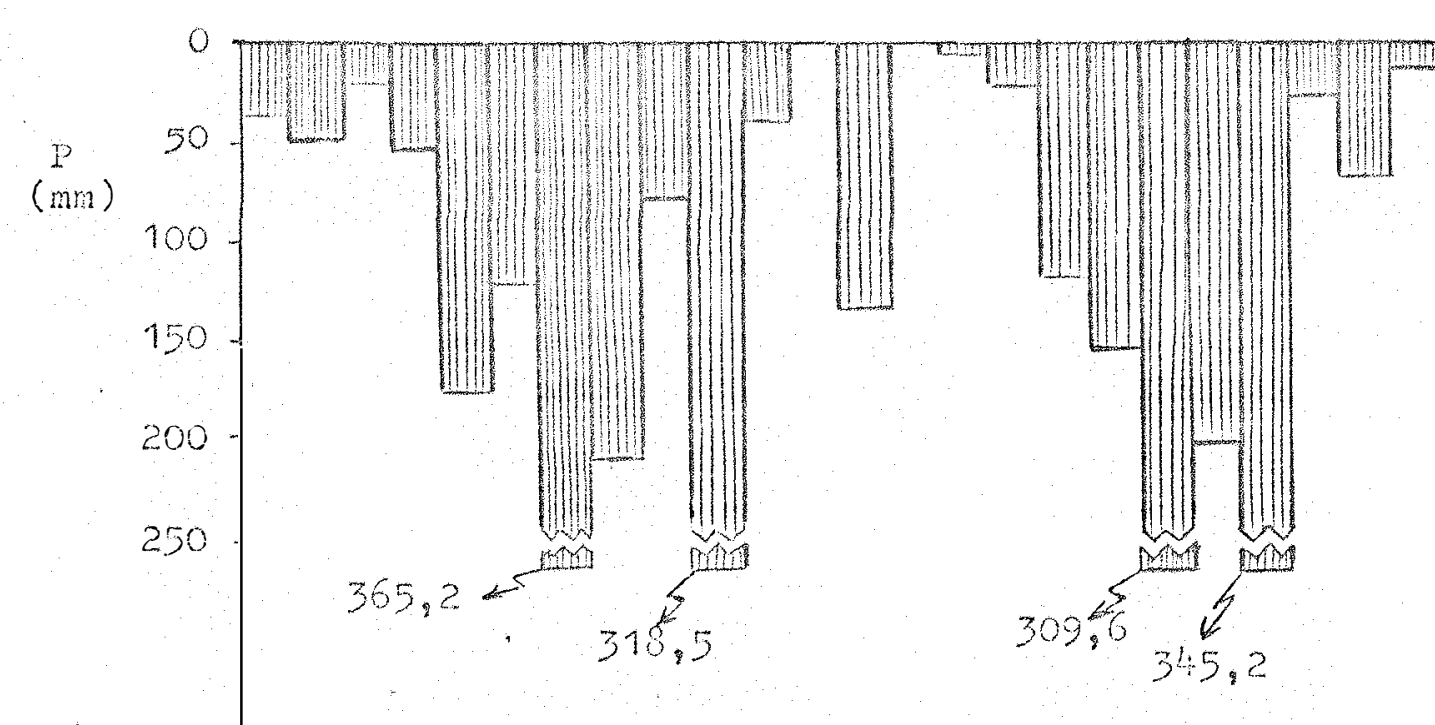

$470 \mathrm{~mm}$

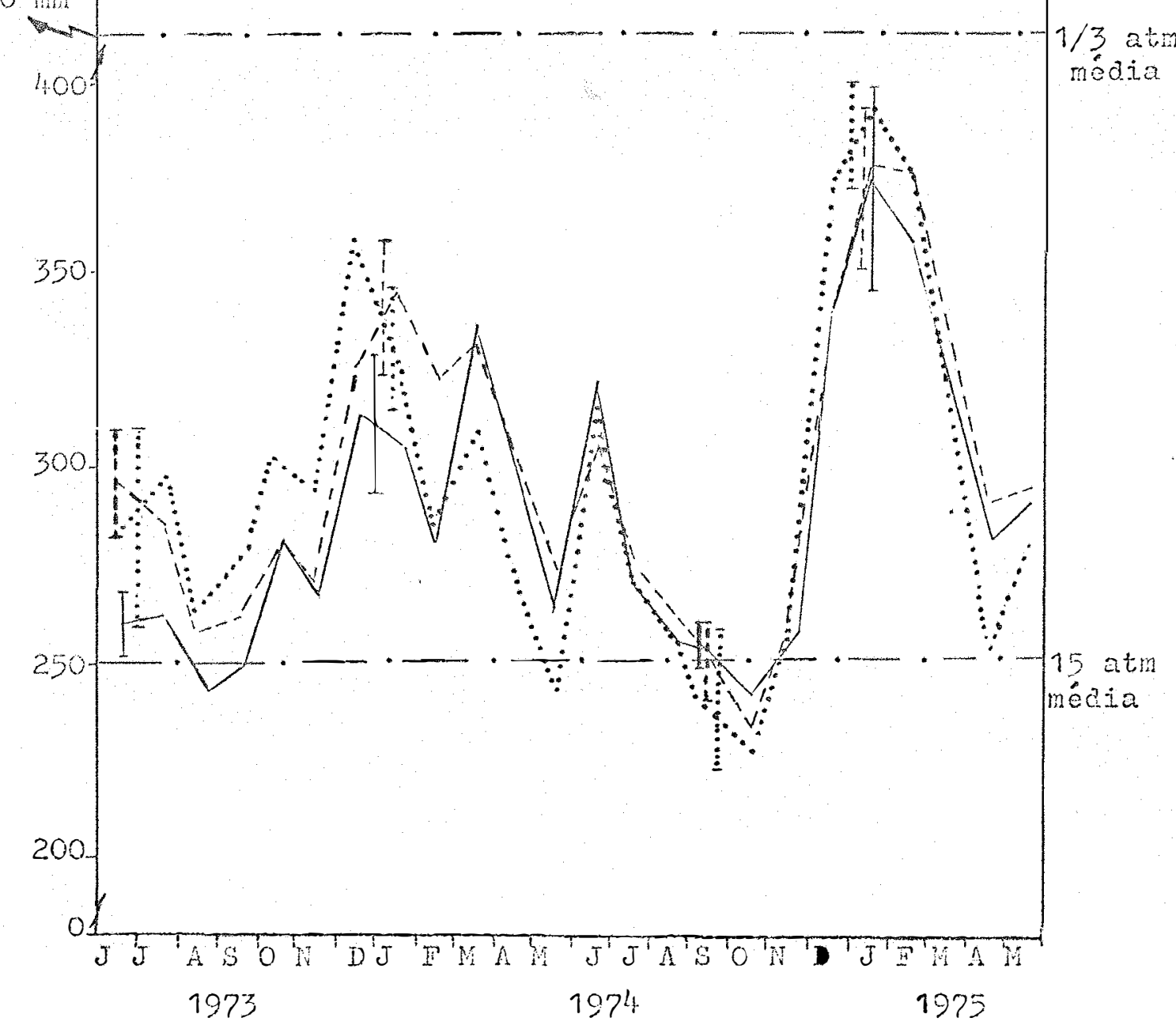

Lesenda: Pinus -....

Eucalipto -

Figura 8: Variaça do Armazonamento de água no perfil $(1,80 \mathrm{~m})$. 
Na Figura 9 é mostrado o regime anual dá ácua do solo nos três tipos de vegetaçẽo estudacios, recime este baseado na média dos 2 anos de medições. A disposição dos meses nesta ficura é de acordo con o ano hídrológico para as concicones climáticas da área de estudo, notando-se o períojo de recarga da água do solo (setembro a fe vereiro) e o periodo de depleção da água do solo (fevereiro a agosto). Em termos dos valores médios utilizados na Figura 9, pode-se observar, como já afirmado, um valor ligeiramente major de $S$ para pinus do que para eucalipto, sendo que a diferenca maior predomina nos meses de vem rão, dando alguma indicação de um maior consumo de ácua por cucalipto neste período do axo. A interossante observar que esta aparente indica ção está mais ou menos coerente com os resultaros obtidos por MIIIO (1960), que encontrou valores máximos de transpiração pela espécie D. alba justamente nos meses de verão, em comparação com as demais éstações do ano. Comparando o regime anual da água do solo entre vegetação herbácea e as duas espécies floxestajs, nota-se aqui também a tendência de haver, de modo êral, mais água na vegetação herbácea durante o período de recarga da água do solo, situação esta que se reverte no periodo de menor conteúdo de umidade no solo.

A Ficura 10 ilustra a marcha anual das variaçós da água no solo nas diferentes camadas estudadas. Primeiromente cabe ressaltar nesta figura as diferenças de variaços mensajs e estaciontis do armazenamento de ácua entre as canadas, notando-se as camadas super ficiais ( 0 a $90 \mathrm{~cm}$ ) são as que apresentam maiores flutuaçōes de umidade, em decorrência da recarga de água pelas precipitações e da retirada de água por evaporação. Istas seriam, no dizer de SHPAK (1971), as camadas ativas de trocas de umidade, ou as camadas hidrologicamente mais ativas. Cabe observar, também, o fato de que a partir de $1,20 \mathrm{~m}$ para baizo o conteúdo de áqua do solo nos três tipos de vegetação estu dadas se encontrou, na maior parte do período experimental, muito próximo do conteúdo de águla correspondente a 15 atmosferas de pressão, a não ser nos meses de verão de 1974-1975. No que diz respeito às diferenças de comportamento entre as espécies em cada camala, pode-se veri ficar que o regime da água do solo nas duas primeiras camadas foi praticamente idêntico em todos os casos, ou seja, não sobressaem diferenças marcantes entre as vegetaçoes estudadas. Nas camadas de 60-90 e 90-120 nota-se que os valores mensais de $\mathbf{s}$ no povoamento de pinus foram liseiramente menores do que os de eucalipto e os de vegetação her- 


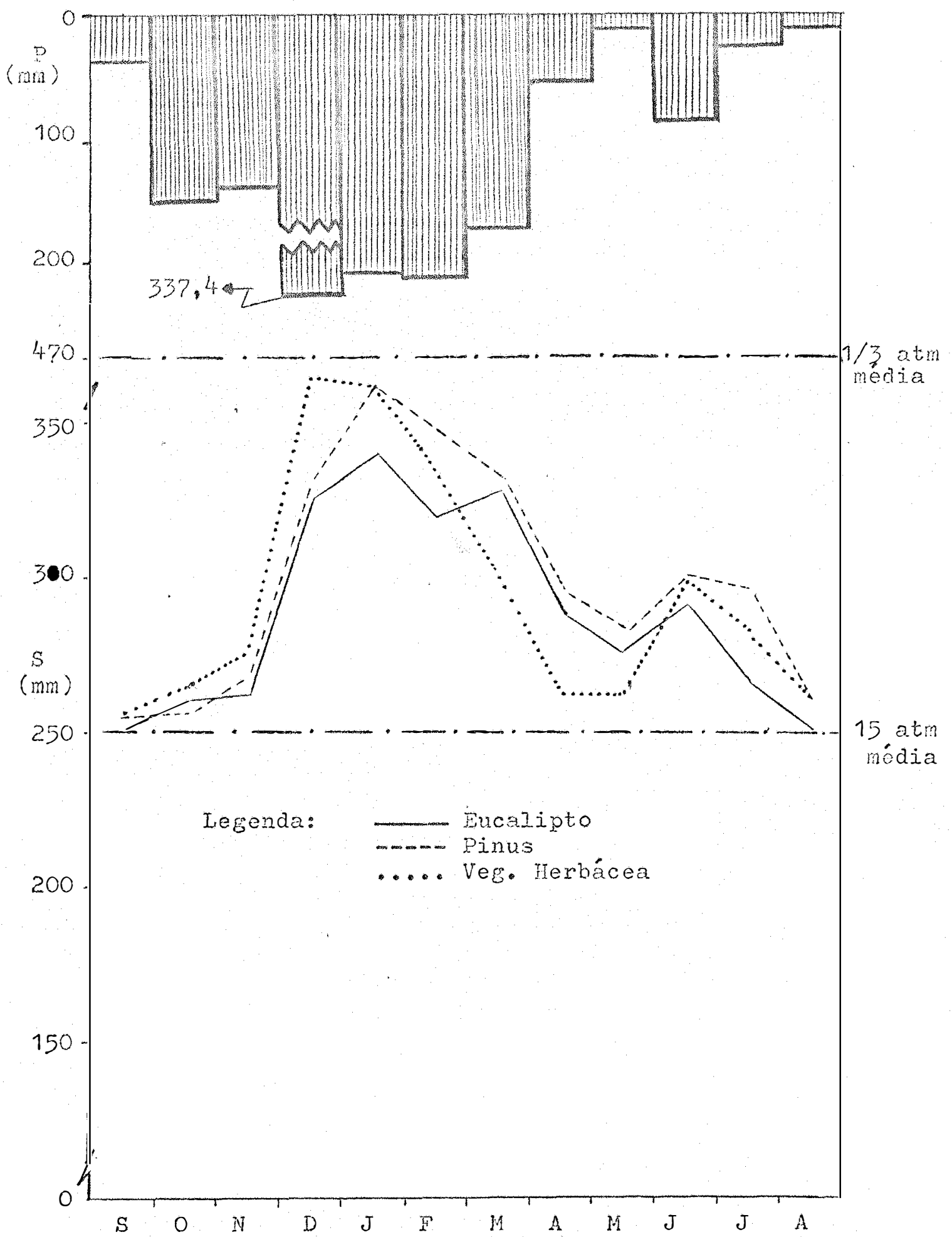

Figura 9: Regime Anual da Água do solo $(1,80 \mathrm{~m})$. Média de dados de 2 anos. 


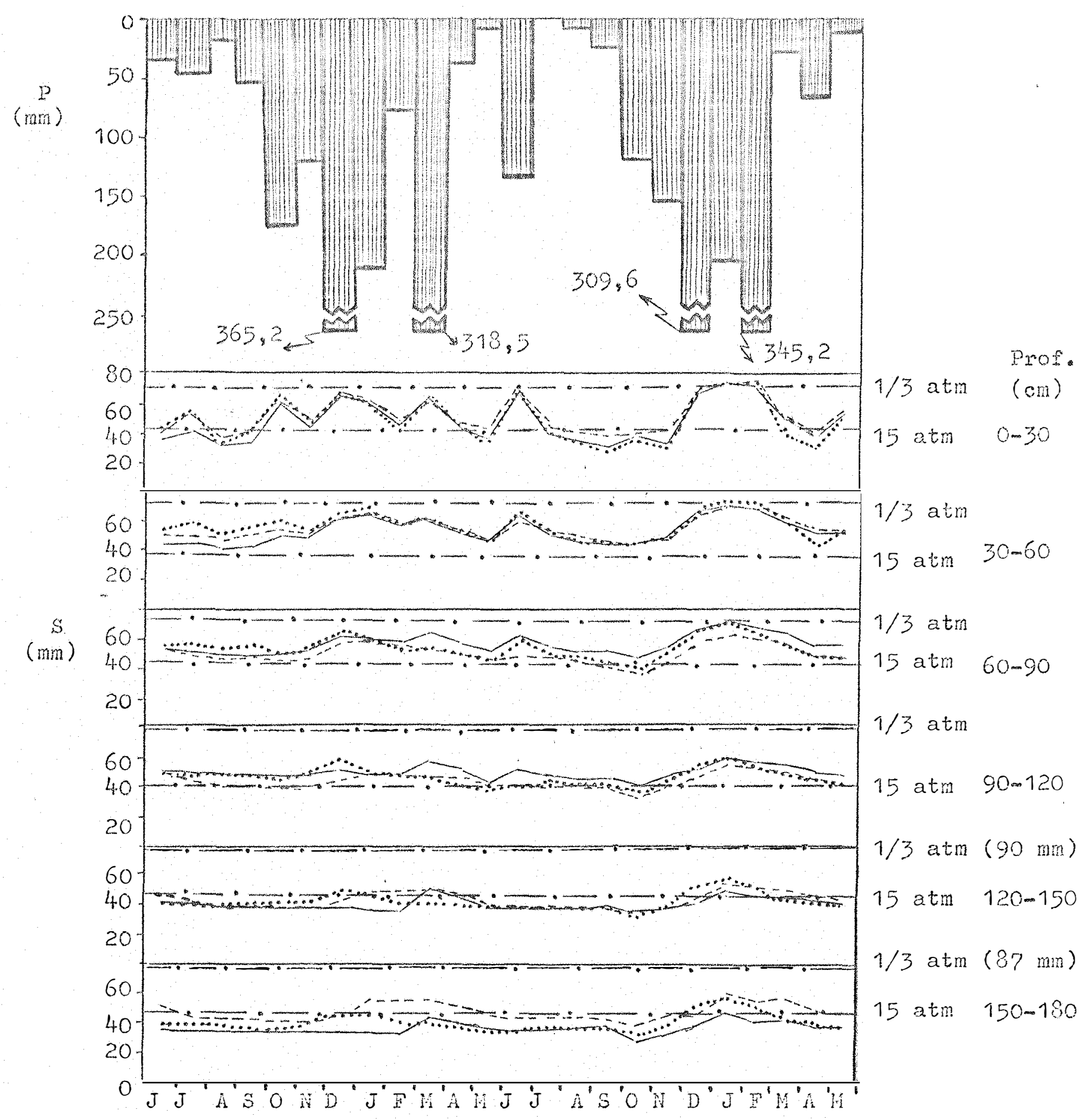

1973

1974

1975

Legenda:

Eucalipto

...... Pinus

.... Veg. Herbácea

Figura 10: Variação Inual da Água do Solo em Diferentes profundidades. 
bácea durante todo o periodo; este fato pode ser interpretado como indicador de uma maior concentração de raízes dos pinus nestas profundida des do perfil. Nas camadas mais inferiores, principalmento na útima, observa-se que os valores de $s$ em eucaliptos foram, na maior parte do período, ligeiramente inferiores aos demais.

A Figura 11 contém os gráficos construídos a partir dos valoxes máximos e mínimos de água no solo observados durante os 2 anos de nediçöes. Näo são os valores observados en uma dada meição apenas, mas sim valores selecionados em cada camada e em cada parcela dentre as 28 determinaçōes de unidade do solo realizadas durante - estudo. A Figura 11 mostra, desta forma, a amplitude máxima de varia ção da á̧ua do solo, em cada camada e em cada parcela observada durante o período. A zona de concentração de raízes do pinus na camada de $60-120 \mathrm{~cm}$ é outra vez evidenciada nesta figura, velos valores mais bai xos de conteúdo de unidade em comparação com as mesmas camadas do euca lipto e da vegetação herbácea. Nas camadas mais profundas o solo sob eucaliptos se apresentou comparativamente mais seco que os demais. Nos três casos, todavia, o corteúdo de umidade nas camacias inferiores a 60 cm de profundidade sempre esteve menor que o correspondente a $1 / 3$ de atmosfera.

Esta mesma distribuição dos valores máximos e ríni mos de água no solo para as três difexentes coberturas vegetais pode ser quantitativamente analisada. através da Tabela 6. Esta tabela mostra a amplitude máxima de variação da água do solo resultante dos $2.712 \mathrm{~mm}$ de chuva registrados durante o período, e pode ser interpreta da como indicadora da quantidade máxima de água do solo que foi disponível para a vegetação nas dîierentes parcelas durante o período. Veri fica-se, por exemplo, que os valores mínimos das camadas de 1,30 m para baixo foram menores en eucalipto do que nos demais casos. Enquanto - conteúdo de umidade equivalente aos valores mínimos observados para todo o perfil diferiu de aproximadamente $6 \mathrm{~mm}$ entre o eucalipto e a ve getação herbácea, de $12 \mathrm{~mm}$ entre pinus e vegetação herbácea, e de cerca de $6 \mathrm{~mm}$ entre eucalipto e pinus, a recarga da água do solo devido às chuvas foi cerca de $40 \mathrm{~mm}$ maior na vegetação herbácea do que em eucalipto, e de aproximadamente $23 \mathrm{~mm}$ maior na veşetação herbácea do que em pinus. Estas diferenças, embora não podendo ser totalmente atri buídas às diferenças de recarça da áqua do solo, mas também à diferen- 


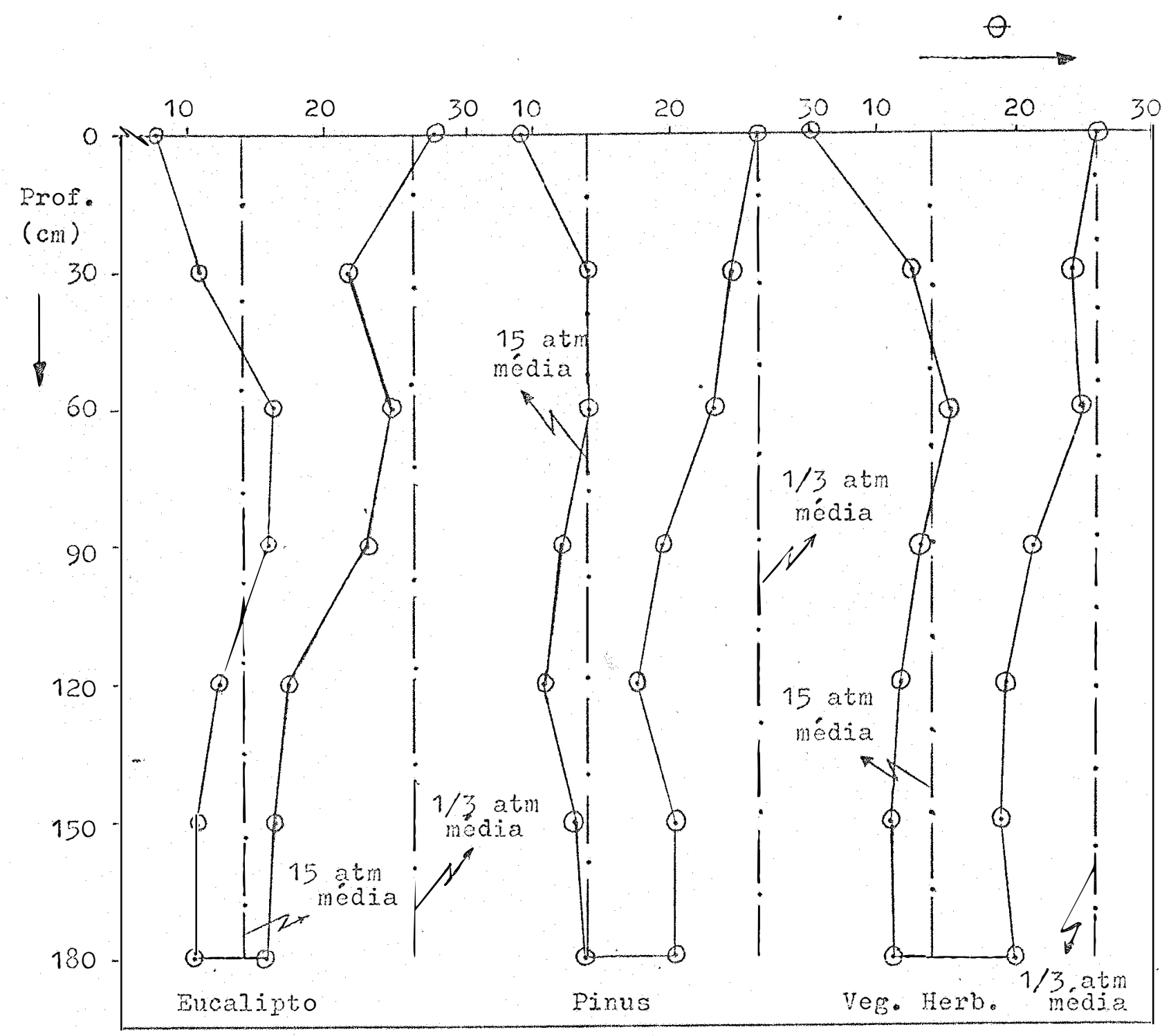

Figura 11: Valores Máximos e Mínimos de hgua no Solo, nas diferentes camadas, observados em dojs anos de medições. 
Tabela 6: Valores Náximos e Minimos de hrua do solo Obserm vados durante o periodo Bxperimental.

\begin{tabular}{|c|c|c|c|c|c|}
\hline \multirow{3}{*}{$\begin{array}{l}\text { Prof. } \\
(\mathrm{cm})\end{array}$} & \multirow{3}{*}{$\begin{array}{l}\text { espessum } \\
\text { ra }(\mathrm{cm})\end{array}$} & \multicolumn{4}{|c|}{$E U C A L I P T O$} \\
\hline & & \multirow{2}{*}{$(\%$ vol. $)$} & \multirow{2}{*}{$\begin{array}{l}\text { Mino } \\
(s \text { vol. })\end{array}$} & \multicolumn{2}{|c|}{ Diferenca } \\
\hline & & & & $(\%$ vol. $)$ & $(\mathrm{mm})$ \\
\hline $0-10$ & 10 & 27,8 & 7.9 & 19,9 & 19,9 \\
\hline $10-40$ & 30 & 21,7 & 10,6 & 11,1 & 33,3 \\
\hline $40-70$ & 30 & 24,8 & 16,1 & 8,7 & 26,1 \\
\hline $70-100$ & 30 & 23,0 & 15,7 & 7,3 & 21,9 \\
\hline $100-130$ & 30 & 17,3 & 12,2 & 5,1 & 15,3 \\
\hline $130-160$ & 30 & 16,2 & 10,6 & 5,6 & 16,8 \\
\hline \multirow[t]{2}{*}{$160-190$} & 30 & 15,5 & 10,3 & 5,2 & 15,6 \\
\hline & & \multicolumn{3}{|c|}{ Amplitude máxima de variação: } & 148,9 \\
\hline & & \multicolumn{4}{|c|}{$P I N U S$} \\
\hline $0-10$ & 10 & 26,4 & 9,3 & 17,1 & 17,1 \\
\hline $10-40$ & 30 & 24,4 & 14,0 & 10,4 & 31,2 \\
\hline $40-70$ & 30 & 23,0 & 14,0 & 9,0 & 27,0 \\
\hline $20-100$ & 30 & 19,3 & 12,0 & 7,3 & 21,9 \\
\hline $100-130$ & 30 & 17,5 & 10,9 & 6,6 & 19,8 \\
\hline $130-160$ & 30 & 20,2 & 12,5 & 7.7 & 23,1 \\
\hline \multirow[t]{2}{*}{$160-190$} & 30 & 20,4 & 13,8 & 6,6 & 19,8 \\
\hline & & \multicolumn{3}{|c|}{ Amplitude máxima de variação: } & 159,9 \\
\hline . & & \multicolumn{4}{|c|}{$V E G E D A C X O H E B A C D A$} \\
\hline $0-10$ & 10 & 25,7 & 5,0 & 20,7 & 20,7 \\
\hline $10-4$ & 30 & 24,2 & 12,4 & 11,8 & 35,4 \\
\hline $40-70$ & 30 & 24,7 & 15,2 & 9,5 & 28,5 \\
\hline $70-100$ & 30 & 21,4 & 13,2 & 8,2 & 24,6 \\
\hline $100-130$ & 30 & 19,2 & 11,6 & 7,6 & 22,8 \\
\hline $130-160$ & 30 & 19,0 & 11,0 & 8,0 & 24,0 \\
\hline \multirow[t]{2}{*}{$160-190$} & 30 & 20,0 & 11,1 & 8,9 & 26,7 \\
\hline & & Amplit & máxima a & ariação: & 182,7 \\
\hline
\end{tabular}


cas inerentes aos próprios perfis estudados, devem ser comparadas com as taxas de interceptação da ácua da chuva pelos povoanentos florestais. De fato, na vegietação herbácea, onde não houve interceptação, maior quentiadade de á̧ua das chuvas chegou ao solo. Para o eucalipto e para o pinus, as taxas médias de perda por interceptação determinadas são proporcionais a estas diferenças de recarga da ácua do solo.

Na Figura 12 são apresentados os conteúdos médios de umidade nas diferentes canadas do solo para as estações secas e chuvosas do ano. Sob outro ângulo, esta figura ilustra alguns dos aspectos já discutidos, como por exemplo os valores comparativamente mais secos de umidade na camada de $90-120 \mathrm{~cm}$ do solo sob pinus, e o solo da vegetação herbácea ligeiramente mais úmido na estação chuvosa.

A Figura 13 ilustra os resultados de duas determinaçöes individuais realizadas durante o periodo. A de 16/10/74 foi a determinação que apresentou os valores mais baixos de áģua no solo, e a de 13/01/75 foi a que apresentou os valores máximos, notando-se também, os respectivos desviós padrões em cada camada. Im comparação com os valores médios apresentados na fiøura anterior, a Fifura 23 ilustra entre outras coisas, o processo de redistribuição e percolação dá ácua através do perfil. Supondo, por exemplo, que em virtude da percolação as camadas mais profundas $(1,20-1,80 \mathrm{~m})$ atingissem conteúdo de unidade idêrtico nos três casos, pode-se inferir que o eucalipto causa depleç̃̃o mais rápida da água do solo nestas profundidades. Mas a Figura 14, por outro lado, permite observar que a depleção da água do solo nestas camadas mais profundas foi praticaraente semelhante, tanto em eucalipto como na vegetação herbécea.

Os processos de depleção e de recarģa da água do solo nos três casos podem ser melhor analisados através dos gráficos apresentados nas Figuras 15 e 16. Dstes gráficos foram construíos a partir de leituras cuidadosamente selecionadas, conforme é explicado nos títulos das respectivas figuras. De modo geral, observa-se semeIhança no processo geral de depleção da água do solo para as três situ ações de vegetação (Figura 15). As diferenças que se podem observar são aquelas já apontadas anteriromente. O povoamento de pinus, por exemplo, causa depleção maior na camada de $90-120 \mathrm{~cm}$; o eucalipto e a vegetação herbácea causam depleção tambén das camadas mais profundas (de $120 \mathrm{~cm}$ para baixo); sendo esta Iifeiranente mais acentuacla para o 
Média de 2 estações socas (1bril-set., 1973-1975)
Médja de 2 estações chuvosas

(Out.-1arco, 1973-19,5).

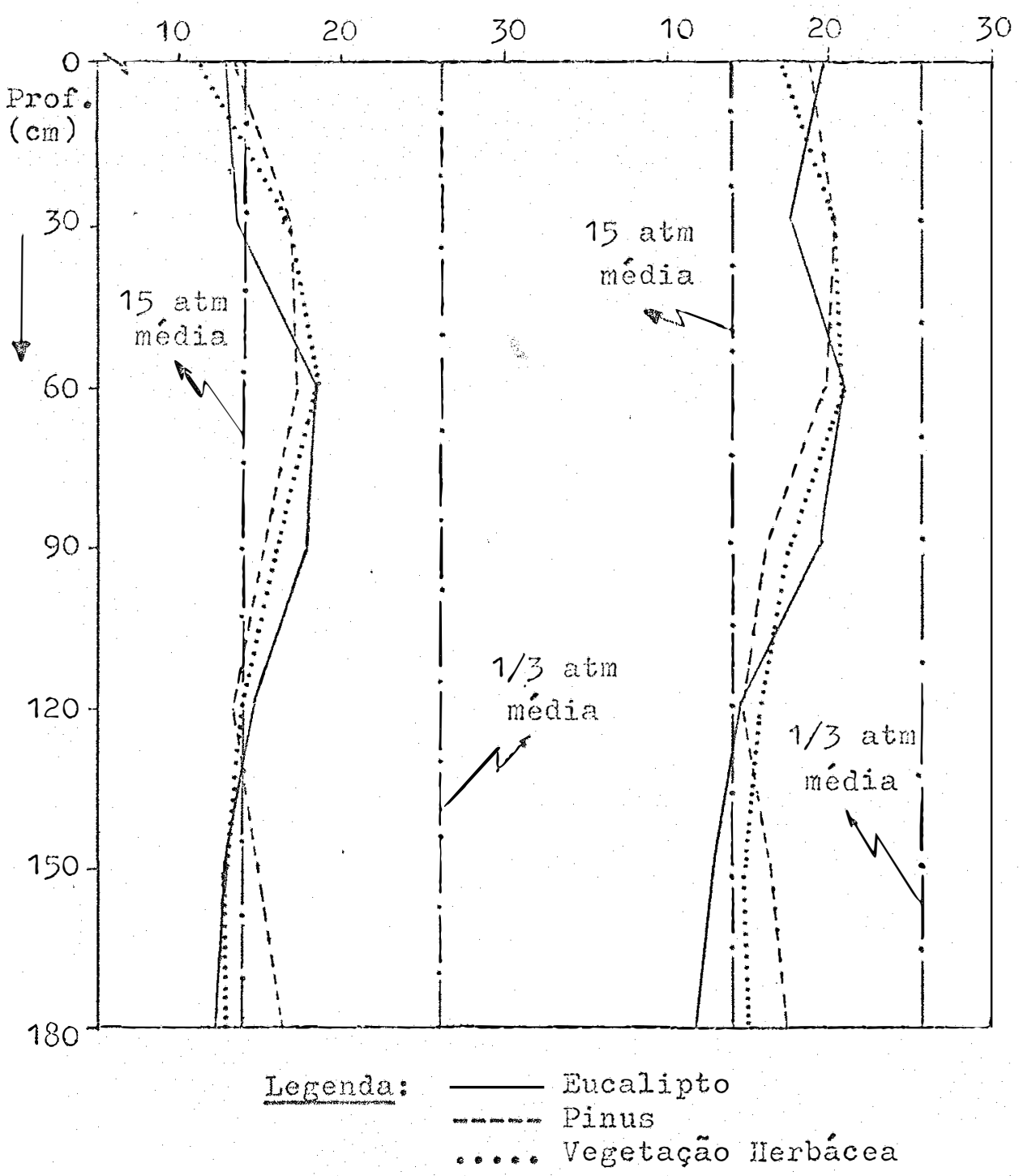

Figura 12: Distribuição da Água no Perfil do solo. 


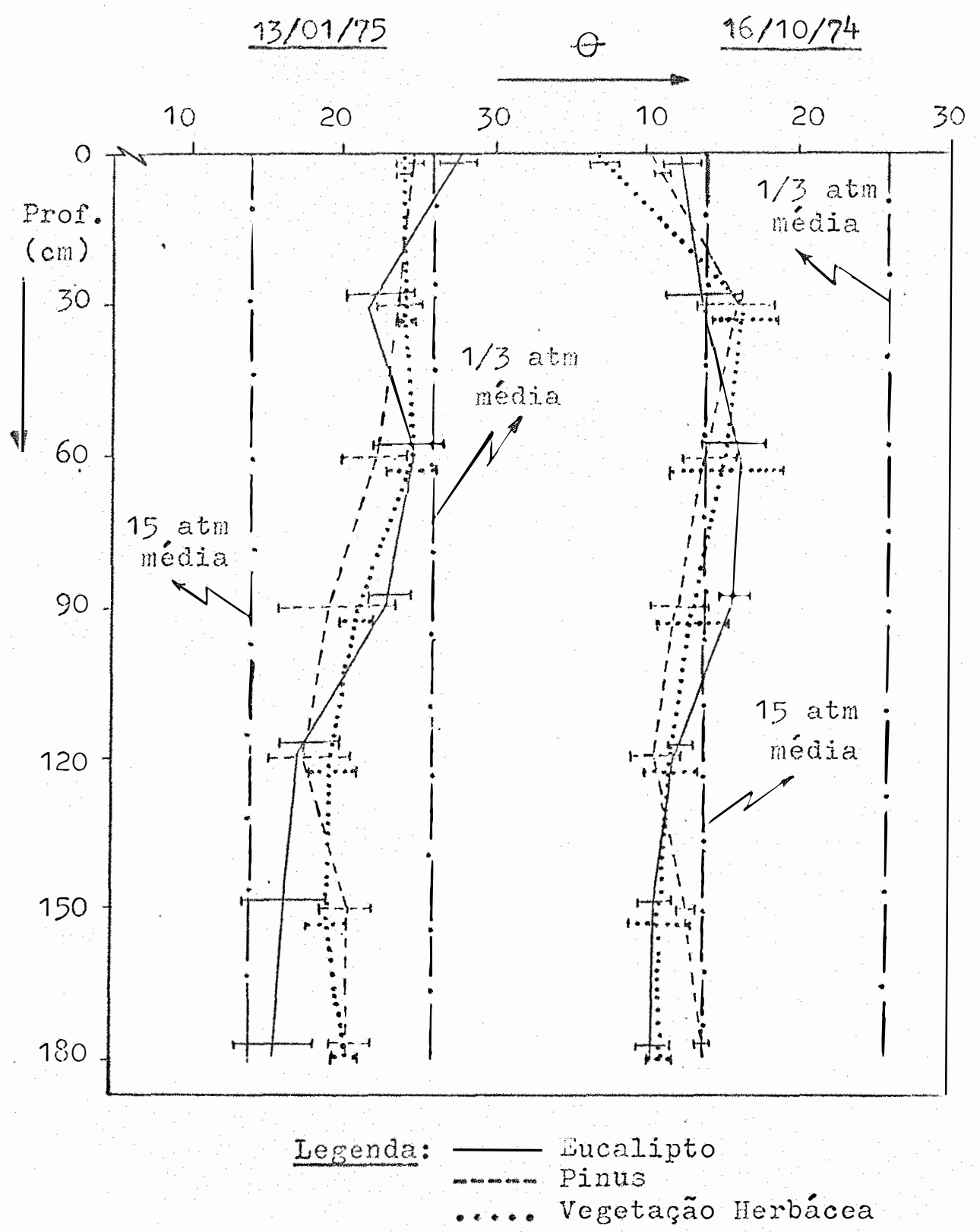

Figura 13: Distribuiçäo da Água no Perfil do 3olo.

Períodos: 13/01/75 - Zeitura maxima observada. $16 / 10 / 74$ - leitura mínima observada. 


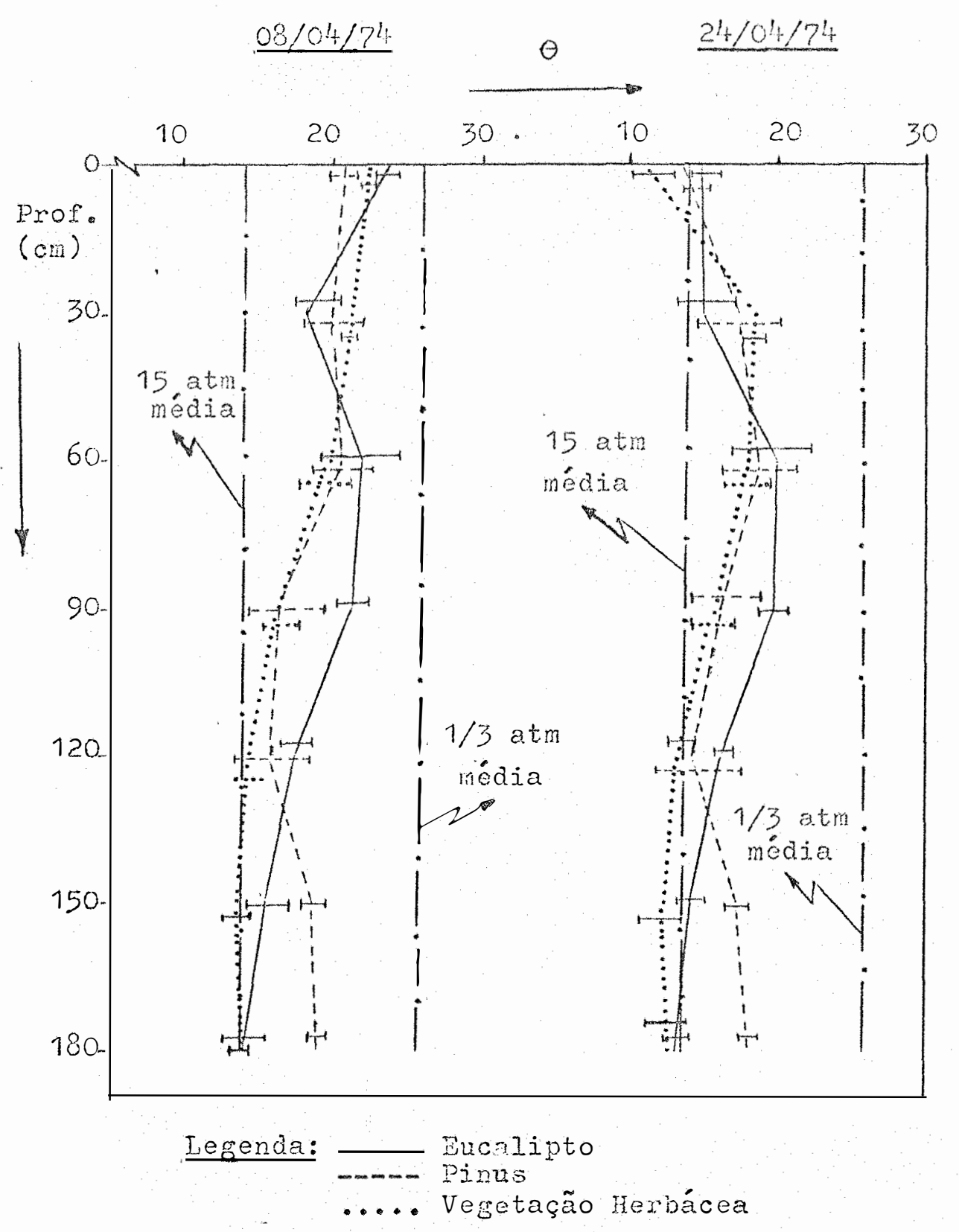

Fisura 14: Distribuiçäo da Água no Perfil do Solo.

Valores obtidos 3 dias após chu va de $28 \mathrm{~mm}(08 / 04 / 74)$.

Valores obticios 16 dias após a leitura anterior ( $24 / 04 / 74)$, sendo que näo foi registrada ne nhuna chuva no intervajo. 


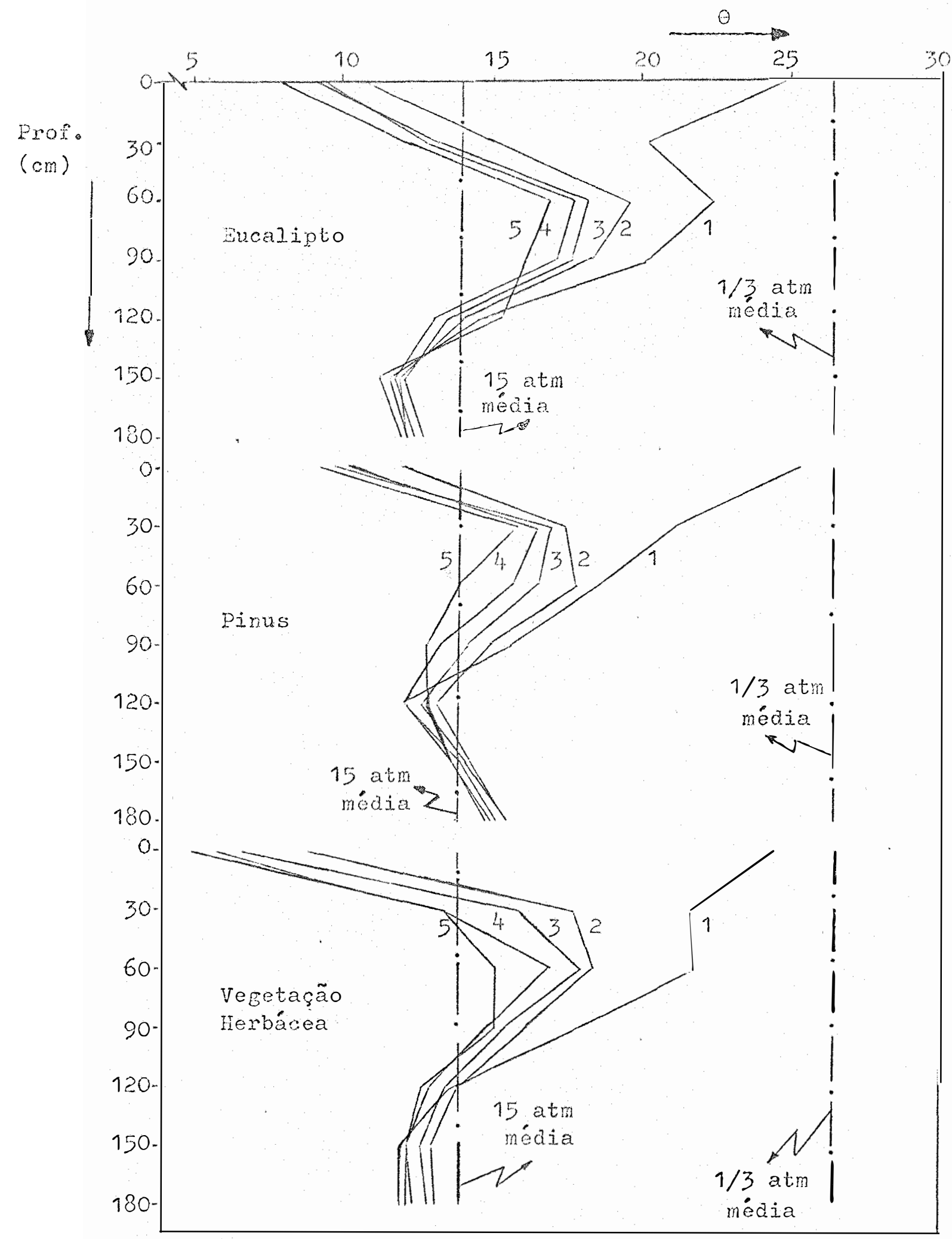

Figura 15: Depleção da Água do Solo. Periodo: 18/06/74 até 19/09/74.

Leitura : (1) $18 / 06 / 74$ : 4 dias após chuva de $70 \mathrm{~mm}$.

(2) $29 / 07 / 74$ : 50 nm de chuva na semuna secuin te a 13/06, nas depois nenhuma chuva até esta data.

(3) 14/08/74: nenhuma chuva desde a últina da ta.

(4) 03/09/74: Praticamente sem chuva desce a U.tima ciata.

(5) 19/09/74: Nonhma chuva desoe a útima da ta. 


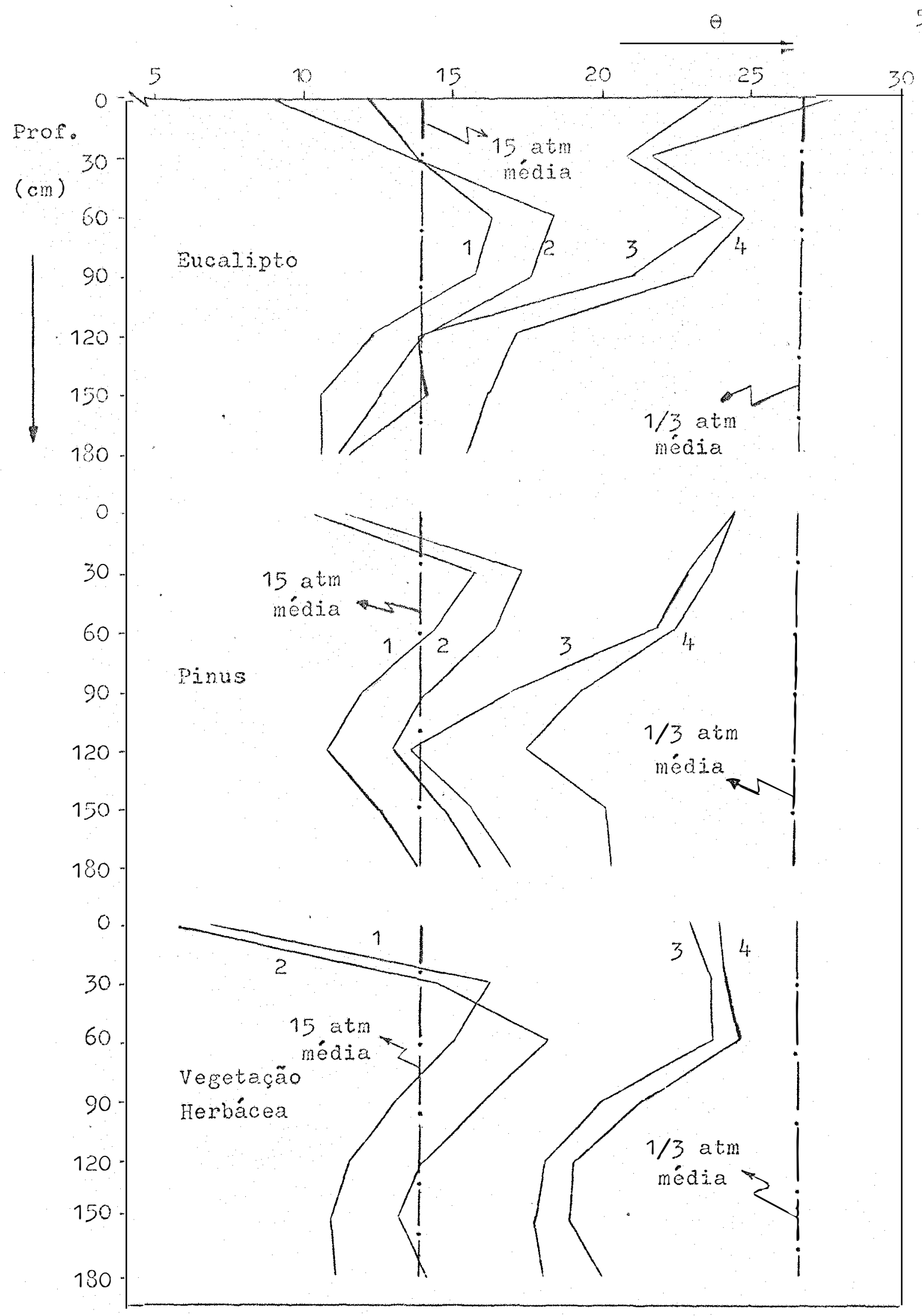

Figura 16: Recarga da Água do Solo.

(1) Leitura de 16/10/74 (início da estação chuvosa)

(2) leitura de $20 / 11 / 74$

(3) Ieitura de 12/12/74

(4) Iejtura de 13/01/75 
povoanento florestal do que para a vegetaçäo herbácea. Na pisura 15 no ta-se ainda que en algumas camadas, por exemplo a 120 cin de profuncida de, houve ganho de unidade quando o normal seria ter havido depleção. Uma explicação que poderia ser dada a este fenômeno seria a ocor rência, nestas situações, de escoamento subsuperficial de ácua, pois, conforme já esclarecicio, as parcelas estudacias apresentam declividade ao redor de $5 \%$.

Na Figura 16, que ilustra o processo de recarga da água do solo, pode ser observado que a recarga das camadas superficiais se processa mais ou menos semelhante nos três casos. Já para as ca madas inferiores, verificamse que a recarga é maior em vegetação heró cea e em pinus do que en eucalipto.

As Pifuras 17, 18 e 19 foram construídas com o objetivo de evidenciar as possivejs diferencas de comportamento entre os três sistemas estudados no que diz respeito ao regine de água do solo. Pela Fífura 17, por exemplo, observa-se que em periodos de alta umidade no solo, havia, en seral, maior conteúdo de ácua no solo sob vegeta ção herbácea do que sob eucajioto; em períodos de baixa unidade do solo, todavia, a diferença entre os dois casos tende a desaparecer.

A Figura 78 mostra que o solo sob pinus esteve, de modo ceral, liß̈eiramente mais úmido do que o solo sob vegetação herbácea. E a Ficura 19, finalmente, permite verificar que o solo sob eucaliptos esteve, en geral, ligeiramente mais seco do que o solo sob pinus.

De acordo com um dos objetivos deste trabalho, e levando en conta os aspectos discutidos na revisão da Jiteratura, procurou-se, utilizando os dados obtidos pelas medições da áçua do solo, estimar o consumo de água em cada um dos tipos de vegetação estudadas. Foi discutido na revisão da literatura que para condições semi-áridas - consumo de água do solo é simplesmente o balanço de s, ou seja, do total de ácua armazenada no peril. Foi discuticio, também, que para re Eiöes de alta pluviosidade os termos $R$ (runof̂r) e $G$ (percolação profur da) da equação do balanço hídrico devem ser necessariamente conhecido se se quizer obter estimativas razoáveis da evapotranspiração.

por estas razões, as estimativas do consumo de áGua foran, neste trabajho, calculadas apenas para as estações secas compreendidas pelo pexiodo exprimental, através da equação simplifica 
59.

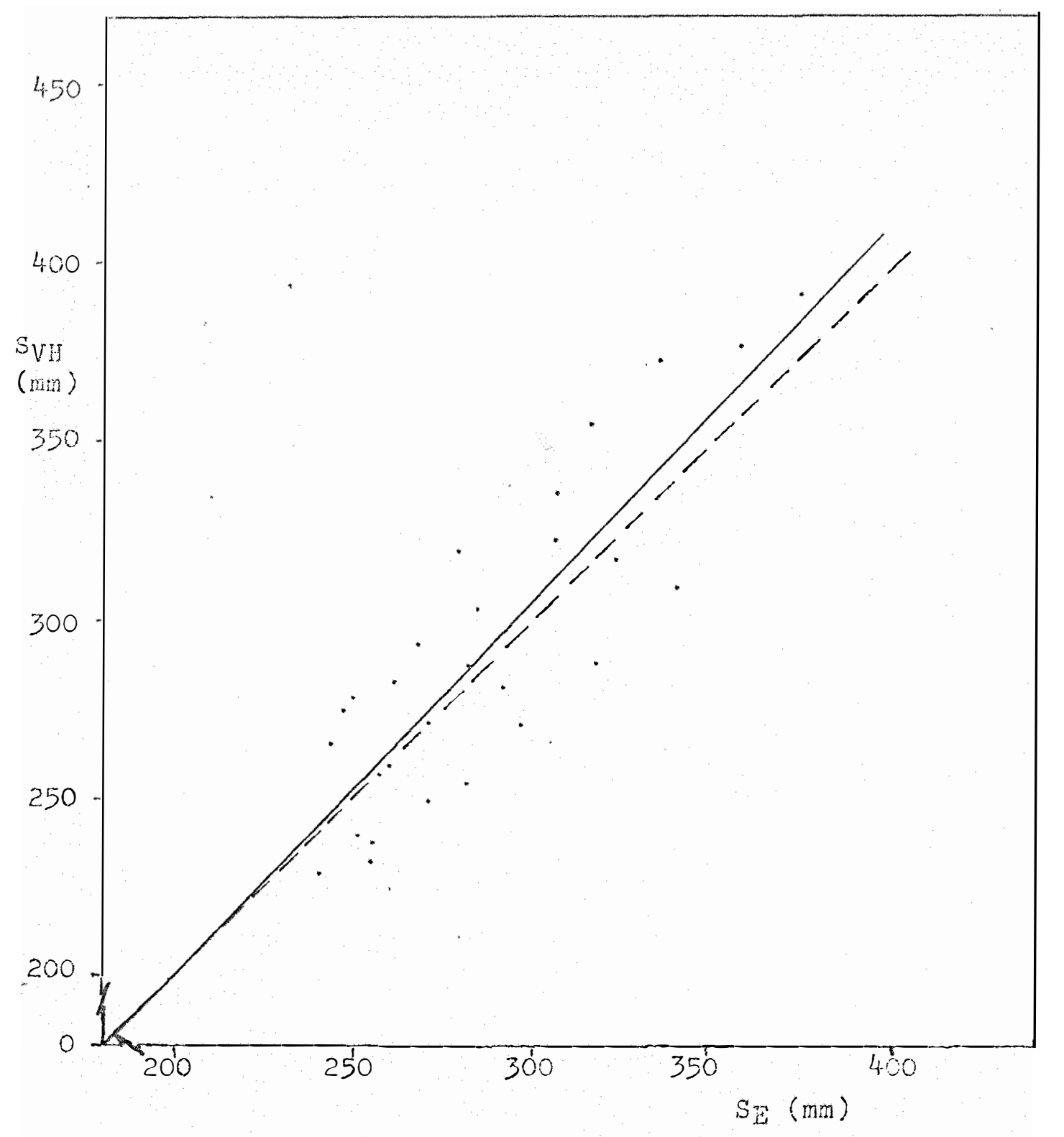

Legenda: - - - Linha de Valores Iguais

$\mathrm{SVH}_{\mathrm{VH}}=1,053 \mathrm{~S} \mathrm{\textrm {z }}-\mathrm{9}, 589$

Figura 17: Comparação do Total de Ácua Armazenada no Perfil de $1,80 \mathrm{~m}$ (S) entre Bucalipto e Vegetação Herbácea. 


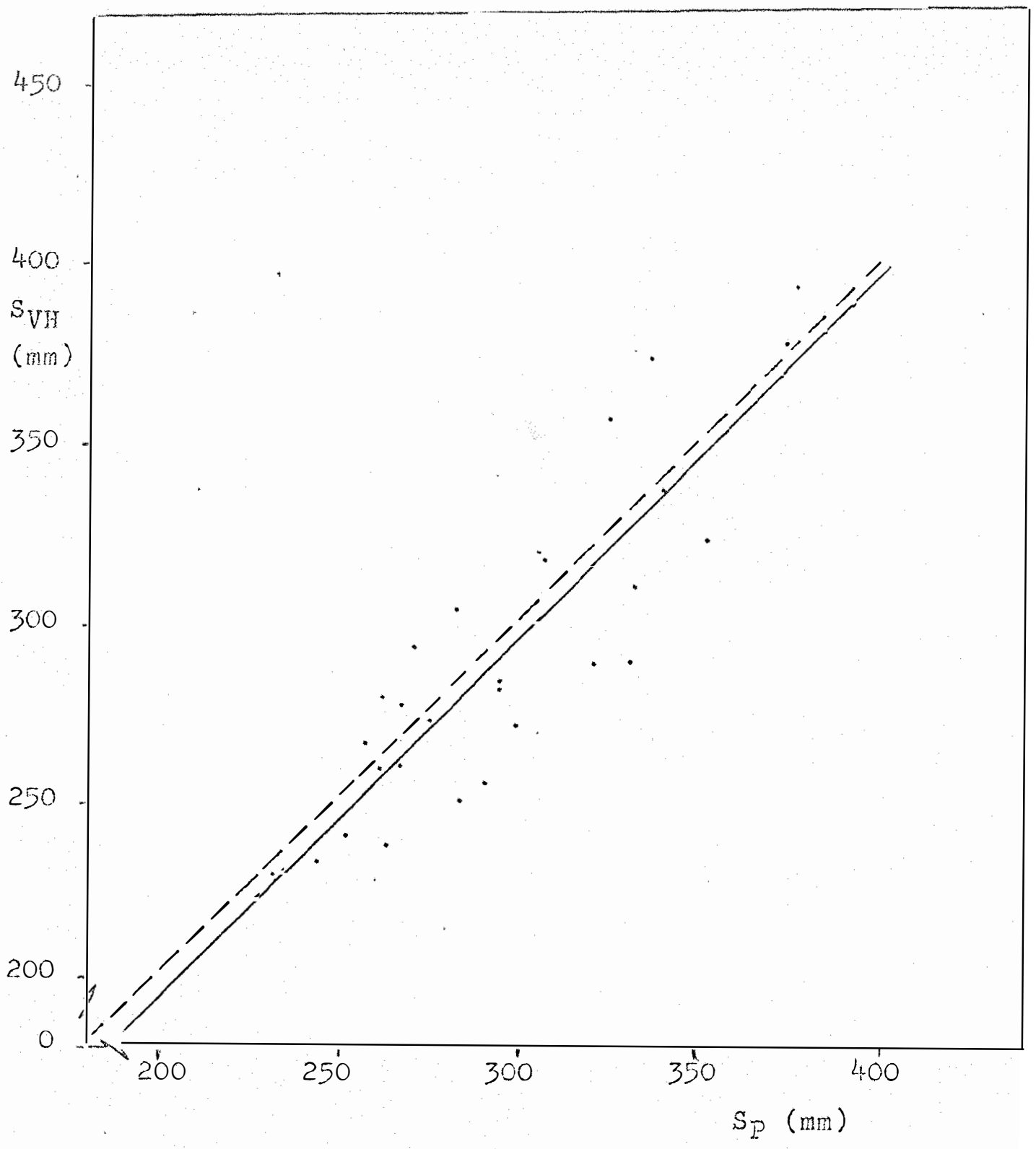

Legenda: --..- Linha de Valores Iguais. $-S_{\mathrm{VH}}=1,011 \mathrm{SP}-3,473$

Finura 18: Comparaça do Total de Árua Mrnazenada no Perfil de 1,80 m (S) entre Pinus e Vegetação Herbacea. 


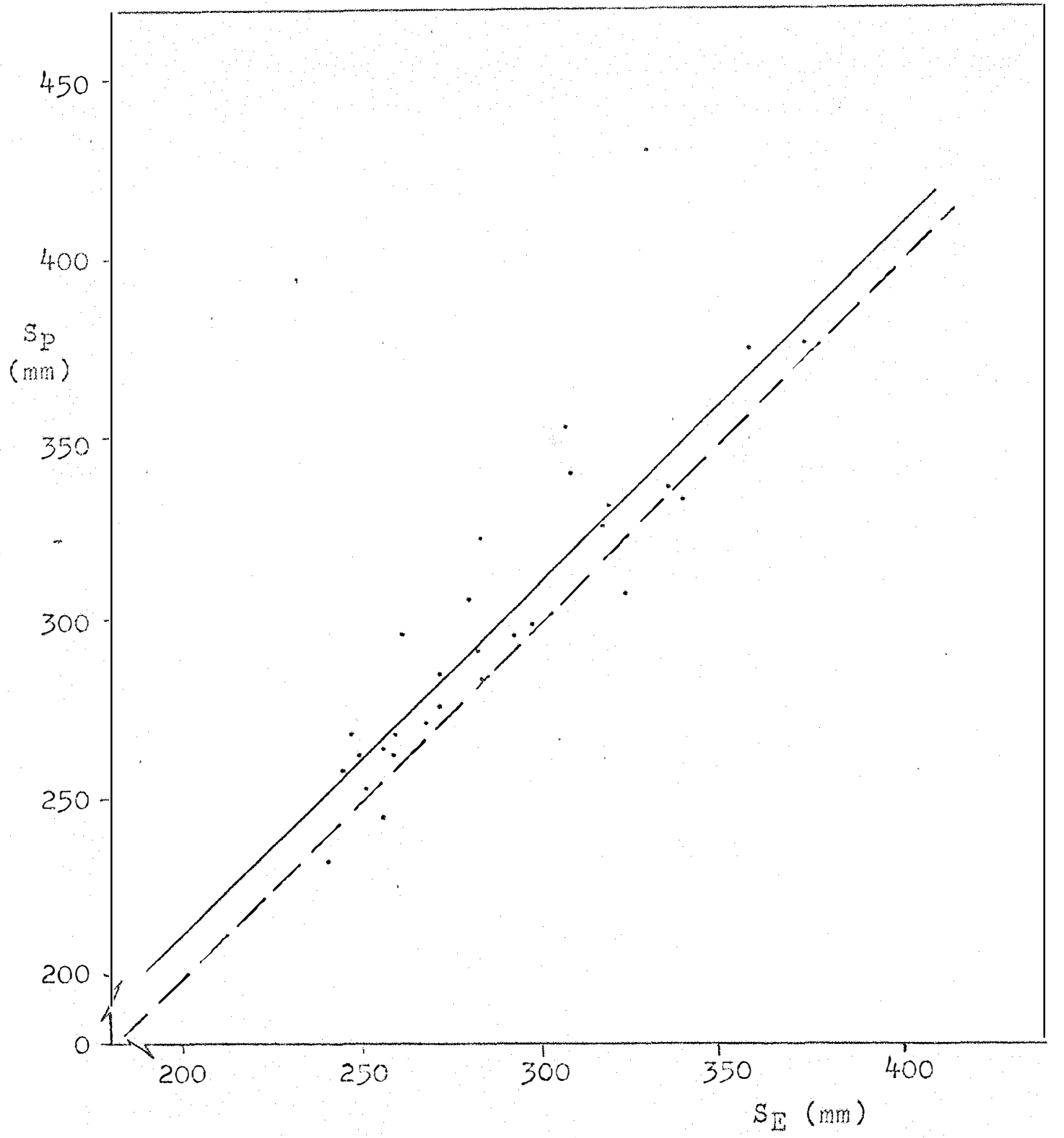

Legenda:-..-- Linha de Valores Icuais.

$-s_{p}=0,981 s_{z}+16,283$

Fífura 19: Comparação do Total de Agua Armazenada no Perfil de $1,80 \mathrm{~m}(S)$ entre Bucalipto e Pinus. 
da:

$$
E=P+D e p l e c j o \text { da água do solo }
$$

Para este perído seco do ano, a análise das pisuras 3, 10, 12 e 15 permite concluir que a percolaça profunda (água gravitacional que dre na alón do limite inferior do perfil do solo) pode ser desprezada. Con relaçăo a fator $\mathrm{R}$ (escomento superfician), este tambén foi considera do desprezígel con base no seguinte: en primeixo lugar,as parcelasconm tinham cobertura vegetal, alch da canada de detritos oreanicos que revestiam a superfície das paxcelas florestadas, condicôos estas que fam vorecen melhow infiltrą̧äo da ácua e diminuen a formaçäo de enturradas: em segundo, durante este periobo seco as condiçós de recebinento, ou a oportunicade de recebinento dé água pelo solo é, en geral, maior. En outras palavras, a possibilidade de ocorrência de enxurrada é, normal mente, maior quando o solo se encontra úmido do que quando seco. Din terceiro lugar, foi feita uma análise cuidadosa de todas as chuvas ocon ridas durante os periodos secos considerados, verificando-se que quase todas foram chuvas relativenente pequenas e de baixa intensidade, conforme pode ser observado nas Tabelas 7, 8 e 9 . Nestas, os valores da 6 colura referem-se ao total de chuvas ocorridas no periodo. Destas, por exemplo, o tetal de 7I,2 mm verificados no primeiro período roi, na realidade, a soma de 10 chuvas pequenas; 0 total de $82,6 \mathrm{~mm}$ da 72 Iinha foi, também, a sona de 10 chuvas menores, o mesmo tendo sido verificado para todos os valores maiores que $50 \mathrm{~mm}$ que aparecem na coluna de precipitação destas tabelas. Desta forma, a julsar pelas condições não favoráveis à formação de enxurrada do solo e em virtude das chuvas relativamente pequenas e de baixa intensidade ocorridas, considerou-se desprezivel, para efeitos de estimativa da evapotranspiração, tambémo fatorescoainento superficial.

Os resultados das estinativas do consumo de água. pelas três coberturas vegetais em parte da estação seca de 1973, na es tação seca de 1974, e em parte da estação seca de 1975, são apresentam dos na Tabela 10, onje são dadas, também, as taxas da evapotranspiração em mm/dia, além dos valores da relação $\mathrm{EN} / \mathrm{E}_{0}$ (Evapotranspiração/evaporação medida em tanque classe $A$ ).

Para efeito de comparação do total consumido em to da a estaçao seca de I ano, a iltina linha da rabela lo contém os valo res totais de wi anenas para o período seco de 3974, podendo-se conclu 
Tabela 7: Depleç̃̃o da Agua do bolo, Precipitação e Evaporam ça de Tantue ciesse $A$ medidas em pexiodos isola dos da sstaģão seca de 1973, 197't e 1975. Aucali $\overrightarrow{2}$ to.

\begin{tabular}{|c|c|c|c|c|c|c|}
\hline Período & notas & $\begin{array}{l}\text { \&So } \\
(\mathrm{mm})\end{array}$ & $\begin{array}{l}\sum s \hat{1} \\
(\mathrm{~mm})\end{array}$ & $\begin{array}{c}\text { Depleçäo } \\
\text { (mm) }\end{array}$ & $\begin{array}{l}\text { Precipitacão } \\
\text { no beriodo (m) }\end{array}$ & $\mathrm{E}_{0}$ \\
\hline \multicolumn{7}{|l|}{1923} \\
\hline $1 / 6-5 / 7$ & 35 & 260,5 & 278,4 & $-17,9$ & 71,2 & - \\
\hline $5 / 7-27 / 7$ & 23 & 278,4 & 245,5 & 31,9 & 14,1 & $\ldots$ \\
\hline $27 / 7-24 / 8$ & 29 & 246,5 & 243,4 & 3,1 & 17.7 & - \\
\hline $24 / 8-14 / 9$ & 22 & 243,4 & 248.8 & $-5,4$ & 52,3 & - \\
\hline \multicolumn{7}{|l|}{1974} \\
\hline $24 / 4=10 / 5$ & 17 & 296,0 & 270,4 & 25,6 & 12,5 & 3,0 \\
\hline $10 / 5-29 / 5$ & 20 & 270,4 & 254,6 & 15,8 & 5,7 & 2,9 \\
\hline $29 / 5-18 / 6$ & 21 & 254,6 & 322,5 & -67.9 & 82,6 & 2,1 \\
\hline $18 / 6-29 / 7$ & 42 & 322,5 & 270.5 & 52,0 & 51,9 & 2,5 \\
\hline $29 / 7-14 / 8$ & 17 & 270,5 & 256,3 & 14,2 & 0,6 & $4,0^{\circ}$ \\
\hline $14 / 8-3 / 9$ & 21 & 256,3 & 250,7 & 5,6 & 4,5 & 5,0 \\
\hline $3 / 9-19 / 9$ & 17 & 250,7 & 247.5 & 3.2 & 0,0 & 6,3 \\
\hline \multicolumn{7}{|l|}{1975} \\
\hline $9 / 4=8 / 5$ & 30 & 230,4 & 291,3 & $-10,9$ & 80,8 & 3.5 \\
\hline
\end{tabular}


Tabela 8: Depleç̃o da hena do S elo, Precipitaça e Evaporacâo de Thrue classe a medidas en periodos isola dos da Estaça seca de 1973, 1974 e 1975. Pinus.

\begin{tabular}{|c|c|c|c|c|c|c|}
\hline Deríodo & Modias & $\sum_{\min } \rho$ & $\sum_{(m i n)}$ & $\begin{array}{c}\text { Deplecão } \\
\text { (mis) }\end{array}$ & $\begin{array}{l}\text { Precipitação } \\
\text { no periodo (mm) }\end{array}$ & $\begin{array}{l}E_{0} \\
\mathrm{~mm} / \mathrm{dia}\end{array}$ \\
\hline \multicolumn{7}{|l|}{1973} \\
\hline $1 / 6-5 / 7$ & 35 & 295,9 & 305.6 & -9.7 & 71,2 & $\ldots$ \\
\hline $5 / 7-27 / 7$ & 23 & 305,6 & 267,6 & 38,0 & $14 ; 1$ & - \\
\hline $27 / 7-24 / 8$ & 29 & 267.6 & 257.0 & 10,6 & 17,7 & - \\
\hline $24 / 8-14 / 9$ & 22 & 257,0 & 261,9 & $-4,9$ & 52,3 & - \\
\hline \multicolumn{7}{|l|}{1974} \\
\hline $24 / 4-10 / 5$ & 17 & 298,5 & 233,3 & 15,2 & 12,5 & 3,0 \\
\hline $10 / 5-29 / 5$ & 20 & 283.3 & 263,8 & 19,5 & 5,7 & 2,9 \\
\hline $29 / 5-18 / 6$ & 21 & 263,8 & 306,8 & $-43,0$ & 82,6 & 2,1 \\
\hline $18 / 6-29 / 7$ & 42 & 306,8 & 275,2 & 31,6 & 51,9 & 2,5 \\
\hline $29 / 7-14 / 8$ & 17 & 275,2 & 262.7 & 12,5 & 0,6 & 4,0 \\
\hline $14 / 8-3 / 9$ & 21 & 262,7 & 252,6 & 10,1 & 4,5 & 5,0 \\
\hline $3 / 9-19 / 9$ & 17 & 252,6 & $2 ! 4,8$ & 7,8 & 0,0 & 6.3 \\
\hline \multicolumn{7}{|l|}{.1975} \\
\hline $9 / 4-8 / 5$ & 30 & $291 ; 6$ & 295,0 & $-3,4$ & 80,8 & 3.5 \\
\hline
\end{tabular}


Tabela 9: Deplegĩo da Áua do Solo, Precipitagão e Bvaporam cão de tranque clusse a medidas em perfodos isolados da jotação bece de 1973, 1974 e 1975. Vegetam çäo Hexbécea.

\begin{tabular}{|c|c|c|c|c|c|c|c|}
\hline Periodo & 10 & dins & $\begin{array}{l}\text { Eso } \\
(\mathrm{mn})\end{array}$ & $\sum_{(m p)}$ & $\begin{array}{c}\text { Depleção } \\
(\mathrm{mm})\end{array}$ & $\begin{array}{c}\text { Precipitação } \\
\text { no periodo (mm) }\end{array}$ & Bo \\
\hline \multicolumn{8}{|l|}{1973} \\
\hline$-5 / 7$ & & 35 & 283,2 & 319,0 & $-35,8$ & 71,2 & $\infty$ \\
\hline$-27 / 7$ & & 23 & 319,0 & 275,9 & 43,1 & 14,1 & - \\
\hline$-24 / 8$ & & 29 & 275.9 & 265,7 & 10,2 & 17,7 & . \\
\hline $24 / 0 \quad-1+19$ & & 22 & $265, ?$ & 278,2 & $-12,5$ & 52,3 & 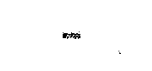 \\
\hline \multicolumn{8}{|l|}{1974} \\
\hline $24 / 4-10 / 5$ & & 17 & 270,9 & 249,0 & 21,9 & 12,5 & 3,0 \\
\hline $10 / 5 \cdots 29 / 5$ & & 20 & 249,0 & 237,2 & 11,8 & 5,7 & 2,9 \\
\hline $29 / 5-13 / 6$ & & 21 & 237,2 & 316.7 & -79.5 & 82,6 & 2,1 \\
\hline $18 / 6=29 / 7$ & & 4.2 & 316,7 & 271,2 & 45,5 & 51,9 & 2,5 \\
\hline $29 / 7-14 / 8$ & & 17 & 271,2 & 257,14 & 13,8 & 0,6 & 4,0 \\
\hline $14 / 8-3 / 9$ & & 21 & 257,4 & 239.4 & 18,0 & 4,5 & 5,0 \\
\hline $3 / 9-19 / 9$ & & 17 & 239.4 & 232,8 & 6,6 & 0,0 & 6.3 \\
\hline \multicolumn{8}{|l|}{.1975} \\
\hline $9 / 4-8 / 5$ & & 30 & 254,6 & 281,0 & $-26,4$ & 80,8 & 3,5 \\
\hline
\end{tabular}


Tanga 10: Concumo de Ána e Taxa de Bvapotranspiração por uncalyotus saluma, por Pinus ceribaea e por ve

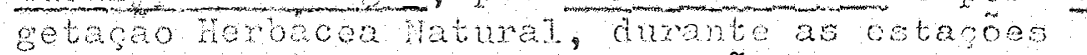
secas de 1974 e parte das estações secas de 1973 e 1975, e valores da razão $\mathrm{NI} / \mathrm{I}_{0}$.

\begin{tabular}{|c|c|c|c|c|c|c|c|c|c|}
\hline \multirow[b]{2}{*}{ Pariodo } & \multicolumn{3}{|c|}{ Eucalipto } & \multicolumn{3}{|c|}{ Pinus } & \multicolumn{3}{|c|}{ Veg. Herbácea } \\
\hline & $\operatorname{IP}$ & $\mathrm{E}$ & \pm & \pm 3 & $Z \mathrm{~T}$ & 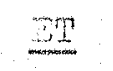 & $\mathrm{BT}$ & 23 & $E I$ \\
\hline 1973 & $(\mathrm{~mm})$ & $(\mathrm{mm} / \mathrm{aia})$ & $\mathrm{B}_{2}$ & $(m+1)$ & $(\mathrm{mm} / \mathrm{dia})$ & $E_{0}$ & $(\mathrm{~min})$ & $(\mathrm{m} / \mathrm{dia})$ & 2) $\mathrm{B}_{0}$ \\
\hline $1 / 6-5 / 7$ & 53,0 & 1,5 & - & 61,5 & 3,8 & - & 35,4 & 1,0 & - \\
\hline $5 / 7-27 / 7$ & 46,0 & 2,0 & $\infty$ & 52,1 & 2,3 & - & 57.2 & 2,5 & - \\
\hline $27 / 7-24 / 8$ & 66,8 & 2,3 & - & 28.3 & 0,9 & - & 27,9 & 1,0 & - \\
\hline $24 / 8-14 / 9$ & 46,9 & 2,1 & - & 47,4 & 2,1 & - & 39,8 & 1,8 & - \\
\hline \multicolumn{10}{|l|}{.1924} \\
\hline $24 / 4-10 / 5$ & 38,1 & $2,2 \quad 0$ & 0.73 & 27,7 & 1,6 & 0,53 & 34.4 & $2,0 \quad 0$ & 0,66 \\
\hline $10 / 5-29 / 5$ & 21,5 & $1,1 \quad 0$ & 0,38 & 25,2 & 1,3 & 0,45 & 17.5 & 0,90 & 0,31 \\
\hline $29 / 5-18 / 6$ & 14,7 & $0,7 \quad 0$ & 0,33 & 39,6 & 1.9 & 0,90 & 3,1 & 0,20 & 0,09 \\
\hline $18 / 6-29 / 7$ & 103,9 & 2,5 & 1,00 & 83,5 & 1,9 & 0,76 & 97,4 & $2,3 \quad 0$ & 0,92 \\
\hline $29 / 7-14 / 8$ & 14,8 & 0,9 & 0,23 & 13,1 & 0,8 & 0,20 & 14,4 & 0,80 & 0,20 \\
\hline $14 / 8-3 / 9$ & 10,1 & 0,5 & 0,10 & 14,6 & 0,7 & 0,14 & 22,5 & $1,1 \quad 0$ & 0,22 \\
\hline $3 / 9-19 / 9$ & 3,2 & $0,2,0$ & 0,03 & 7,8 & 0,4 & 0,06 & 6,6 & $0,4 \quad 0$ & 0,06 \\
\hline \multicolumn{10}{|l|}{1975} \\
\hline $9 / 4-8 / 5$ & 69,9 & $2,3 \quad 0$ & 0,66 & 77,4 & 2,5 & 0,73 & 54,4 & $1,8 \quad 0$ & 0,51 \\
\hline TOPAL & 488,9 & & & $+78,2$ & & & 410,6 & & \\
\hline MEIIA & & 1,50 & 0,43 & & 1,5 & 0,43 & & $1,3 \quad 0$ & 0,37 \\
\hline$\overline{E T}(x)$ & 206,3 & & & 211.5 & & & 195,9 & & \\
\hline
\end{tabular}

(*) Valor de ET apenas rara a estação seca de 1974 
ir pela comparação destes valores que praticamente não houve diferença entre os consumos de água de encalipto, pixus e vegetação horbácea natural naguele períado.

Lstes resultados coletivanonte permiten verificar que os povoumentos de eucaliptos e de pinus não foram, durante o perío do de estudo, responsáveis por nenhun efeito adverso sobre o regine da água do solo, em comparaça con aquele observado em solo revestido por vegetaça herbácea natural. hos periodos secos do ano não foi notada, além disto, diferenca narcente entre o consumo de água pelos três tipos de veretaçäo estudadac. 


\subsection{Crescimento em Area Basel}

A Tabela 1 I contém os valores de DAP médio e de área basal para os povoamentos florestais estudados, obtidos em 8 rediçöes trimestrais realizadas durante o período experimental:

Tabela 11: Vajores de DAP néaio e de Área Dasal do Povomento de sucalipto e de Pinus, durante o periodo experinental.

\begin{tabular}{|c|c|c|c|c|}
\hline \multirow[b]{2}{*}{ Data } & \multicolumn{2}{|c|}{ Ducalipto } & \multicolumn{2}{|c|}{ Pinus } \\
\hline & $D A P(c m)$ & $A B\left(n^{2} / h a\right)$ & $\operatorname{DAP}(\mathrm{cm})$ & $A B\left(m^{2} / h a\right)$ \\
\hline $02 / 07 / 73$ & 11,53 & 15,37 & 10,93 & 13,46 \\
\hline $21 / 09 / 73$ & 11,96 & 16,49 & 11,75 & 25,51 \\
\hline $23 / 12 / 73$ & 12,17 & 17,10 & 13,03 & 19,02 \\
\hline $08 / 04 / 74$ & 12,42 & 17,93 & 13,76 & 21,17 \\
\hline $01 / 07 / 74$ & 12,72 & 18,90 & 14,34 & 23,04 \\
\hline $25 / 09 / 74$ & 12,89 & 19,52 & 24,64 & 24,01 \\
\hline $21 / 12 / 74$ & 13,10 & 20,17 & 15,37 & 26,48 \\
\hline $26 / 03 / 75$ & 13,22 & 20,56 & 15,97 & 28,61 \\
\hline
\end{tabular}

A comparação entre as duas espécies no que diz res peito ao crescimento em área basal pole ser melhor visualizada através da Figura 20. De modo geral, verifica-se que o p. caribaea vax. caribaea apresentou, durante os dois anos observados, taxa de crescimento em áxea basal maior do que a do E. sciligna. Nota-se ainda que em ambos os casos o crescimento foi contínuo durante todo o período.

o objetivo principal destas medições de diâmetro das árvores, todavia, não era o de permitir análise aprofundaca do crescimento e do comportamento dos povoamentos, mas sim o de se poder obter valores comparativos entre taxa de crescimento e água disponivel no solo. Sstas comparações podem ser observadas na Figura 21, que apre senta os valores mensais do total de água armazenada no perfil de 1,80 $m$ do solo.(S), os valores do increnento trimestral de área basal e de DÁ médio para os povoanentos de eucaliptos e de pinus. Pode-se notar que existe uma aparente relação entre a curva de incremento estacional de DAP do povomento de pinus e a maxcha anual da ácua no solo sob este 
62.

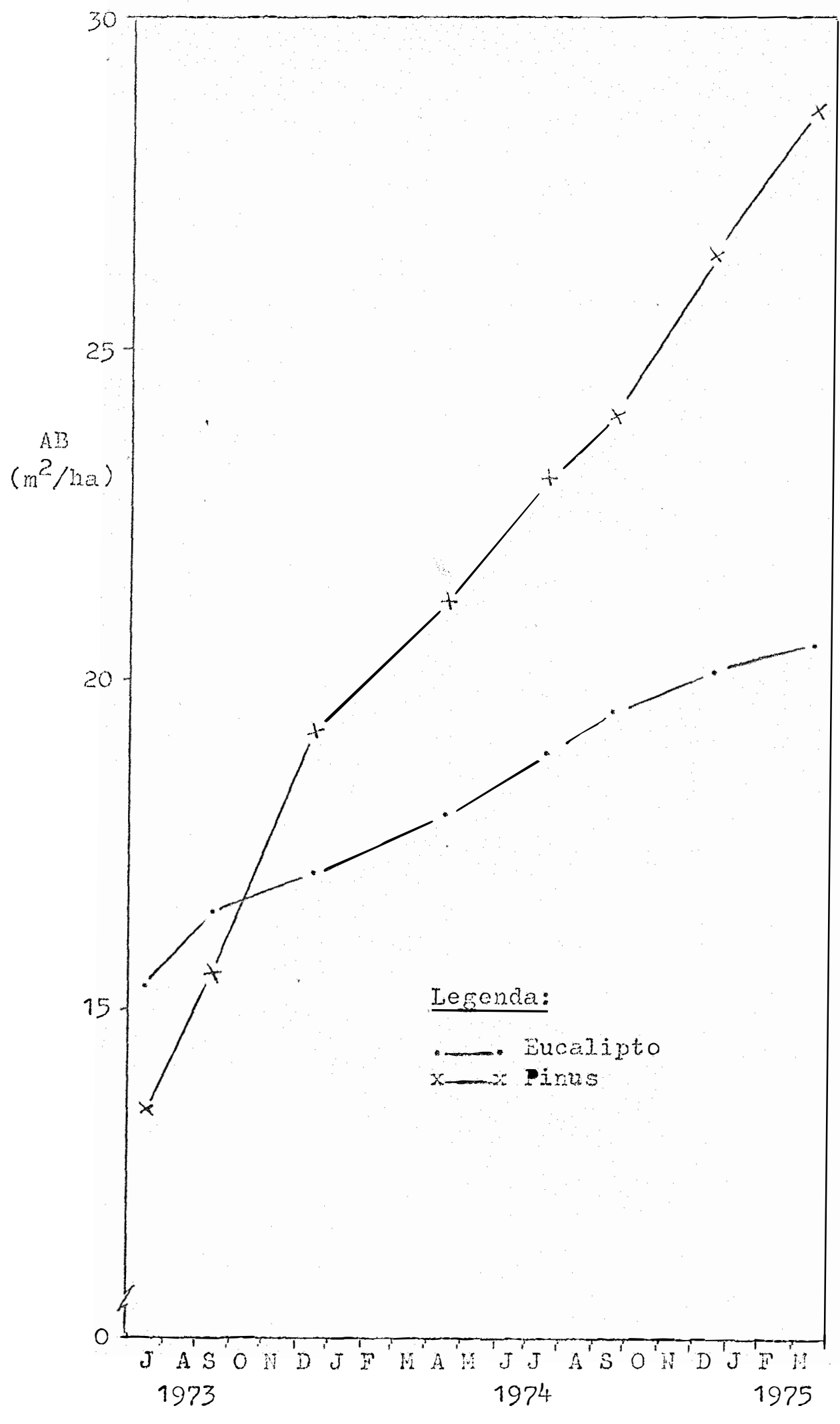

Figura 20: Crescimento da Áea Basal Estacional dos povoamentos de zucaliptos e de pinus. 
70.

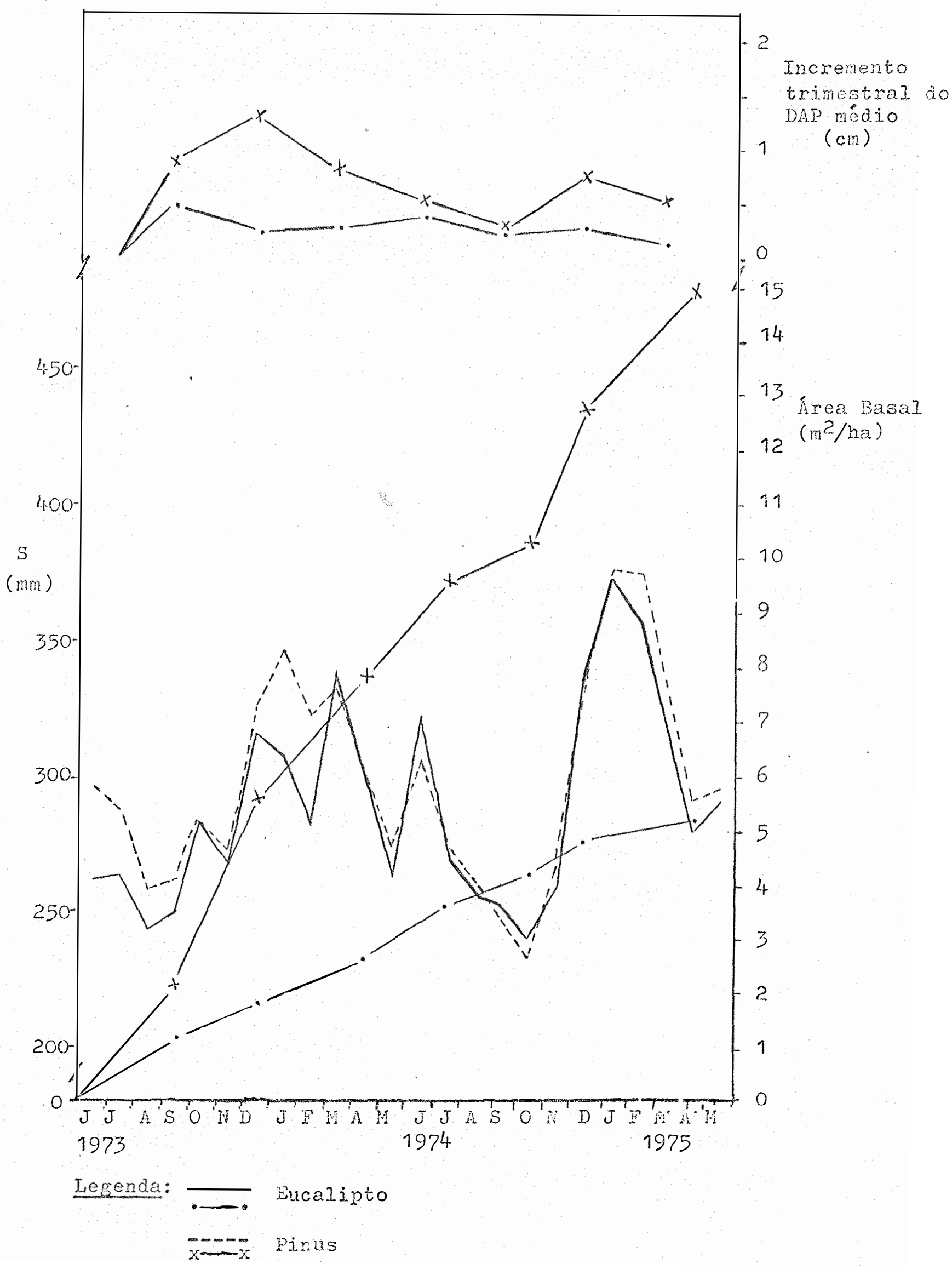

Figura 21: Crescimento Acumulado de Área Basal, Incremento de DAP e higua Armazenada no perfil do solo durante o periolo experimental. 
povoamento, ou seja notan-se incrementos crescentes coincidentes con os perílios de recarga da água do sojo (primavera), e incrementos decrescentes durante o pexíodo de depleção da água do solo (verão e outono).

No caso do eucalipto estas relações não são tão aparentes, a não ser no período de junho de 1974 a março de 1975. Neste mesmo período podemse, tambén, observar alguma semelhança no padrão de crescimento entre as uas espécies. Comparando-se os dois períodos de verão (1973-1974 e 1974-1975), observa-.se que o mês de fevereiro de 1974 foi relativamente seco. Este periodo anormalnente seco refletiuse no regime de áçua do solo sob o povoamento de encalipto, conforme já discutido, observando-se que durante os meses de janeiro e fevereiro de 19\%4 o solo sob eucaliptos se encontrava comparativamente mais seco do que o solo sob pinus. Isto, de certa forma, pode explicar o in cremento decrescente de diâmetro do povoamento de eucalipto observado durante o trimestre setembro-dezembro de 1973. Nota-se que a água do solo sob eucalipto reagiu marcadamente às chuvas pesadas ocorridas em março e em junho de 1974, refletindo num incremento crescente do DAP desde dezembro de 1973 até junho de 1974.

De modo geral, observa-se diminuição, mas näo cessa ção, do crescimento durante o período seco do ano. Aparentemente, ambas as espécies estudadas reassumem o estácjo de crescincnto mais acem lerado a partir do início da primavera, atingindo um máximo por ocasião do início ou meados do verão, decrescendo desta data até fins do in verno. 


\subsection{Efejtos Sobre a Quajidade da Ánua}

Devido a atraso na aquisição dos instrumentos neces sários, os aspectos relativos à qualidade da água só puderam ser estum dados a partir de outubro de 1974. Os resultados aqui apresentidos, portanto, referem-se à media de 18 chuvas medidas no verão $1974-1975$.

As tabelas $12,13,14,15,16,17,18,19,20,21,22,23,24 \mathrm{e}$ 25 contér os dados de pH, turbidez, condutividade, sólidos totais dis.solvidos, cor e alcalinidade dos 5 tratanento catudados, quais sejam, água da chuva, aśua da precipitação interna em eucaliptos e en pinus, e ásua do escoamento pelo tronco, também de eucalipto e de pinus, assim cono as análises da variância respectivas.

A fim de dotector possiveis diferenças entre as duas espécies no que diz respeito a alteração da qualidade da áğua da chuva, bein como testar se esta altcração seria diferente entre os prom cessos "precipitaçäo interna" e "escoanento pelo tronco", inicialmente analisou-se os dados através do csquema fatorial $2 \times 2$. Para as análises de variância com a interação "espécies $x$ processos" significativa, procedeu-se ao desdobramento dos graus de liberdade respectivos.

Para facilitar a comparação entre as médias dos vários tratamentos relativos aos seis aspectos qualitativos estudados, foi elaborada a Tabela 26. Nesta tabela as médias sicnificativamente diferentes ao nível do $5 \%$ de probabilidade encontram-se unidas por um segmento de reta.

O pIf da ağua da chuva gira, em condições normais, ao redor de 5,6 (HEM, 1970). Para a maioxia das aģuas naturais (um rio não poluido, por exemplo) o valor do pli varia de 6,0-8,5 (mph, 1970). pela análicse das Tabelas 12,13,14 e 26, verifica-se que tanto o povoamento de eucalipto como o de pirus causaram alteração significativa no pH da água da chuva que passou por suas copas. Observa-se também que a alteração foi diferente entre o cscoamento pelo tronco de eucalipto e - escoamento pela tronco de pinus, mas não houve diferença entre os va lores médio de pH da precipitação interna nas duas espécies. Para cada espécie houve diferença significativa entrc o pu dos processos escoa... mento pelo tronco e precipitação interna.

A turbidez é una nedida óntica das partículas em 
Mabela 12: Valores de pH paxa chuva, procipitaçäo intorna do sucalipto ( $-P I)$, Pinus ( III) e escoamento pelo tronco em eucalipto ( $\omega-D t)$ e pinus ( $P-E t$ ).

\begin{tabular}{|c|c|c|c|c|c|c|}
\hline \multicolumn{2}{|l|}{ Data } & chuna (x) & $E-E t\left(x_{x}\right)$ & $\operatorname{Pot} \operatorname{st}(\mathrm{x})$ & $\operatorname{Br} P I(\mathrm{X})$ & $\operatorname{DoI}(\mathrm{Xx}$ \\
\hline $1974:$ & $16 / 10$ & 5.5 & 5,2 & 5,3 & 6,0 & 6,0 \\
\hline & $29 / 10$ & 5.6 & 5,5 & 5,4 & 6,1 & 5,8 \\
\hline & $13 / 11$ & 5,1 & 5,0 & 5,2 & 6,4 & 6,1 \\
\hline & $21 / 11$ & 5,0 & 5,0 & 5,2 & 5,8 & 5,8 \\
\hline & $28 / 11$ & 5,4 & 5,6 & 5,4 & 5,9 & 6,0 \\
\hline & $11 / 12$ & 5,5 & 5,3 & 5,0 & 6,1 & 5,9 \\
\hline & $16 / 12$ & 6,2 & 5,4 & 5,4 & 6,2 & 6,1 \\
\hline & $20 / 12$ & 5,3 & 5,2 & 5,1 & 6,2 & 6,1 \\
\hline \multirow[t]{14}{*}{ 1975: } & $06 / 01$ & 5,9 & 6,5 & 5,3 & 7,3 & 7,0 \\
\hline & $10 / 01$ & 6,4 & 6,4 & 5,3 & 6,8 & 6,9 \\
\hline & $13 / 01$ & 5,6 & 6,6 & 5,8 & 6,7 & 6,9 \\
\hline & $03 / 02$ & 4,5 & 5,1 & 4,8 & 6,2 & 6,0 \\
\hline & $06 / 02$ & 5,1 & 6,3 & 5,7 & 6,9 & 6,7 \\
\hline & $19 / 02$ & 4,5 & 5,1 & 4,3 & 6,0 & 6,2 \\
\hline & $24 / 02$ & 4,9 & 5,4 & 4,6 & 5,6 & 5,9 \\
\hline & $26 / 02$ & 4,9 & 5,8 & 5,0 & 6,5 & 6,1 \\
\hline & $03 / 03$ & $4,6$. & 5,3 & 4,5 & 6,4 & 5,9 \\
\hline & $08 / 03$ & 3,9 & $\cdot 4,9$ & 3,8 & 5.5 & 5,2 \\
\hline & $\bar{x}$ & 5,2 & 5,5 & 5,1 & 6,3 & 6,1 \\
\hline & s & 0,62 & 0,56 & 0,50 & 0,46 & 0,46 \\
\hline & $\operatorname{Max}$. & 6,4 & 6,6 & 5,8 & 7,3 & 7,0 \\
\hline & Vin. & 3,9 & 4,9 & 3,8 & 5.5 & 5,2 \\
\hline
\end{tabular}

(*) médias de 2 amostras

(*) médias de 4 amosiras

d.m.s. a 5\% entre datas: 0,4 
Tabela 13: Málise da Variancja para os dados de ph.

\begin{tabular}{|c|c|c|c|c|c|}
\hline Causa de Variasão & C.I. & 5.0 & a.n. & s & \\
\hline Lspécies dentro de lt & 1 & 2,0070 & 2,0070 & 21,5113 & 泟 \\
\hline Bspécies dentro de PI & 1 & 0,1111 & 0,1111 & 1,1908 & H. \\
\hline Processos & 1 & 14,6701 & 14,6701 & 157,2359 & $\pm x$ \\
\hline$(\operatorname{sectan} z)$ & $(3)$ & 16,7882 & 5,5961 & - & \\
\hline Testemune $x$ Tatonial & 1 & 4,0747 & 4,0747 & 43,6731 & 薜范 \\
\hline Tratimentos & $(4)$ & 20,8629 & 5,2157 & 55,9025 & 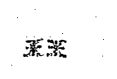 \\
\hline$B 1000 \mathrm{~s}$ & 17 & 17,0716 & 1,0042 & 10,7631 & $x$ \\
\hline Resíduo & 68 & 6,3451 & 0,0933 & - & \\
\hline Total & 89 & 44,2796 & - & - & \\
\hline
\end{tabular}


Tabele 14: Mnálise da variância para os daros de pli.

\begin{tabular}{|c|c|c|c|c|c|}
\hline Causa de Varjagão & G.I. & 5.20 & Q.4. & $\mathrm{F}$ & \\
\hline Processos dentro de $\mathrm{s}$. & 3 & 4,6944 & 4.6944 & 50,3151 & 英澄 \\
\hline Processos dentro de $P$. & 1. & 10,5625 & 10,5625 & 113,2101 & $\mathrm{~s}$ \\
\hline Espécies & 1 & 1,5313 & 1,5313 & 16,4126 & $x \times$ \\
\hline$=$ & $x=$ & & 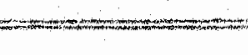 & 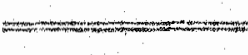 & $y=$ \\
\hline (ratorial) & $(3)$ & 15.7882 & 5,5961 & - & \\
\hline Testemunha x Tatonial & 1. & 4,0747 & 4,0747 & $1+3,6731$ & 35 \\
\hline$=$ & $=$ & 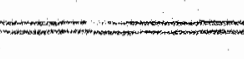 & $=-5$ & $=$ & $=$ \\
\hline Tratamentos & $(4)$ & 20,8629 & 5,2157 & 55,9025 & $E^{*} x_{2}$ \\
\hline 320005 & 27 & 17,0716 & 1,0042 & 10,7631 & 㳭来 \\
\hline Resiouo & 68 & 6,3451 & 0,0933 & - & \\
\hline & & & 5 & $\therefore$ & \\
\hline Total & 89 & 44,2796 & - & - & \\
\hline
\end{tabular}


Tabela 15: Valoré de turbidea para chuva, precipitaçã in.terna en encolipto ( $\mathrm{S}-\mathrm{PI}$ ), pinus (P-PT) e escoamento pelo tronco $(s-3 t)$ e pinus $(P-B t)$.

\begin{tabular}{|c|c|c|c|c|c|c|}
\hline \multicolumn{2}{|c|}{ Data aa amostra } & \multirow{2}{*}{$\frac{\operatorname{covva}(\mathrm{x})}{10,0}$} & \multirow{2}{*}{$\frac{3-2+(x))}{24,8^{\circ}}$} & 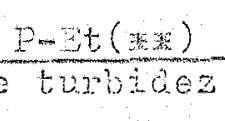 & $\frac{\mathrm{E}-\mathrm{PI}\left(\mathrm{x}_{\mathrm{z}}\right)}{-\mathrm{TNU}}$ & \multirow{2}{*}{$\frac{P-P I(x)}{11,6}$} \\
\hline $1974:$ & $16 / 10$ & & & 11,7 & 17,0 & \\
\hline & $29 / 10$ & 0,7 & 4,6 & 3,1 & 2,9 & 3,5 \\
\hline & $13 / 11$ & 1,8 & 3,1 & 3,0 & 6,0 & 3.3 \\
\hline & $21 / 11$ & 3,6 & 5,4 & 5.7 & 6,0 & 7,8 \\
\hline & $28 / 11$ & 3,6 & 3.3 & 2,5 & 2,5 & 1,9 \\
\hline & $11 / 12$ & 5,6 & 6.7 & 5,9 & 6,6 & 6,6 \\
\hline & $16 / 12$ & 1,3 & 3.1 & 1.8 & 4,1 & 3,2 \\
\hline & $20 / 12$ & 0,26 & 2,0 & 3,9 & 2,3 & 3,5 \\
\hline \multirow[t]{14}{*}{$-1975:$} & $06 / 01$ & 0,35 & 0.6 & 1,6 & 3.8 & 2,1 \\
\hline & $10 / 01$ & 0,53 & 2,6 & 3,2 & 7,3 & 5,0 \\
\hline & $13 / 01$ & 0,42 & 1,3 & 1,8 & 1,6 & 3,1 \\
\hline & $03 / 02$ & 0,84 & 2,9 & 1,9 & 3,4 & 2,9 \\
\hline & $06 / 02$ & 0,34 & 2,9 & 1,9 & 2,7 & 2,2 \\
\hline & $19 / 02$ & 0,9 & 3,4 & 4,2 & 3,5 & 2,2 \\
\hline & $24 / 02$ & 0,61 & 1,2 & 2,0 & 1,9 & 1,1 \\
\hline & $26 / 02$ & 0,57 & 2,2 & 4,3 & 2,2 & 2,1 \\
\hline & $03 / 03$ & 0,98 & 4,9 & 14,4 & 3,0 & 2,8 \\
\hline & $08 / 03$ & 2,2 & 3,6 & 3.2 & 4,8 & 3.7 \\
\hline & $\bar{x}$ & 1,9 & 4,4 & 4,2 & 4,5 & 3,8 \\
\hline & $s$ & 2,5 & 5,3 & 3,5 & 3,5 & 2,6 \\
\hline & Max. & 10,0 & 24,8 & 14,4 & 17,0 & 11,6 \\
\hline & Min. & 0,26 & 0,6 & 1,6 & 1,6 & 1,1 \\
\hline
\end{tabular}

(*) médias de 2 amostras

(x) nédias de 4 amostras

d.m.s. a 5:o entre datas: 2,5 
Tebela 16: Análise da variancia para os dados de Turbider.

\begin{tabular}{|c|c|c|c|c|c|}
\hline Cansa de Variação & G. I. & $S .20$ & Q.\%. & $F$ & \\
\hline Espécies & 1 & 3,3368 & $3,3.368$ & 0,7937 & WS \\
\hline Processos & 1 & 0,2813 & 0,2813 & 0,0669 & ISS \\
\hline Int. E $x P$ & $I$ & 1,5313 & 1,5313 & 0,3642 & is \\
\hline (Patorial) & (3) & 5,1434 & 1,7165 & - & \\
\hline Testemunha $x$ atorial & 1 & 77,0063 & 77.0063 & 18,3170 & $x y$ \\
\hline Tratamentos & $(4)$ & 82,1556 & 20,5389 & 4,8854 & 菜现 \\
\hline BIocos & 17 & 831,7214 & 43,9248 & 11,6374 & s: \\
\hline Resícivo & 68 & 285,8796 & $4,204.1$ & - & \\
\hline Total & 89 & 1.199 .7566 & - & $\ldots$ & \\
\hline
\end{tabular}


Pabela 17: Valoues de Conchtividace sspecifica para Chuva, precipitaça interna en eucalipto ( $(P-I)$, c escoanonto pelo tronco en encalipto $(\mathrm{B}-\mathrm{et})$ e pjous $(\mathrm{p}-\mathrm{Bt})$.

\begin{tabular}{|c|c|c|c|c|c|c|}
\hline Data de & amostra & Chura (x) & $\operatorname{sen}(x)$ & 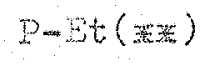 & $\mathrm{E}-\mathrm{PI}\left(\mathrm{x}_{\mathrm{X}} \mathrm{x}\right)$ & $P-P J(x x)$ \\
\hline & & & $-\mathrm{m}=\mathrm{R}$ & 10 & & \\
\hline \multirow[t]{8}{*}{ 1974: } & $16 / 10$ & 24,0 & 362.5 & 76,0 & 61,3 & 30,3 \\
\hline & $29 / 10$ & 11,2 & 228,0 & 54,8 & 30,0 & 17,8 \\
\hline & $13 / 11$ & 36,0 & 206,3 & 05,0 & 72,7 & 35,0 \\
\hline & $21 / 11$ & 12,4 & 59,3 & 20,9 & 27,3 & 17,1 \\
\hline & $28 / 11$ & 12,5 & 21,8 & 22,3 & 18,5 & 11,6 \\
\hline & $11 / 12$ & 25,0 & 27,8 & 28,7 & 29,3 & 20,8 \\
\hline & $16 / 12$ & 14,5 & 28,5 & 17,8 & 21,5 & 13,0 \\
\hline & $20 / 12$ & 17,0 & 56,3 & 42,8 & 22,0 & 13,0 \\
\hline \multirow[t]{10}{*}{ 1975: } & $06 / 01$ & 11,3 & 25,5 & 17,6 & 13,1 & 8,2 \\
\hline & $10 / 01$ & 15,5 & 34,8 & 25,2 & 19,0 & 11,2 \\
\hline & $13 / 01$ & 11,2 & 23,7 & 15,8 & 12,6 & 12,3 \\
\hline & $03 / 02$ & 14,0 & 22,0 & 18,6 & 21,1 & 13,4 \\
\hline & $06 / 02$ & 13,6 & 15,1 & 15,4 & 16,0 & 9,6 \\
\hline & $19 / 02$ & 17,1 & 44,8 & 36,3 & 38,3 & 26,9 \\
\hline & $2.4 / 02$ & 12,6 & 22,2 & 20,2 & 18,5 & 9,7 \\
\hline & $26 / 02$ & 19,0 & 47,5 & 33,3 & 25,3 & 16,1 \\
\hline & $03 / 03$ & 26,0 & 80,5 & 55.5 & 39,0 & 22,3 \\
\hline & $08 / 03$ & 25,0 & 57,8 & 41,3 & 38,8 & 29,3 \\
\hline & $\bar{x}$ & 17,7 & 75,8 & $3 !, 9$ & 29,1 & 17,1 \\
\hline & $s$ & 6,9 & 93,6 & 20,9 & 16,1 & 7.7 \\
\hline & $\operatorname{Max}$ & 36,0 & 362,5 & 85,0 & 72,7 & 35,0 \\
\hline & Min. & 11,2 & 15,1 & 15,4 & 12,6 & 8,2 \\
\hline
\end{tabular}

(*) médias de 2 amostras

(西) médias de 4 amostras

d.m.s. a 5\% entre datas: 46,4 
Tabe1a 18: Mnisise de Variancia para os dados de Conoutividade tspecifica.

\begin{tabular}{|c|c|c|c|c|c|}
\hline Causa de Variaça & $G_{\|} I_{0}$ & 3.2. & 0.10 & $\mathrm{~F}$ & \\
\hline Espécies & 2 & 12.619 .3089 & $12.619,3089$ & 8,5725 & ws \\
\hline Drocessos & 1 & $18.708,2272$ & $18.708,2272$ & 12,7088 & 济糔 \\
\hline Int. $3 \times p$ & 1 & $3.749,7800$ & $3.749,7800$ & 2,5473 & NS \\
\hline (Eatorial) & $(3)$ & $35.077,3161$ & $11.692,4387$ & - & \\
\hline Testomunha $x$ Fatorial & 2 & $6.696,0188$ & $6.696,0188$ & 4,5487 & $x$ \\
\hline Tratamentos & $(4)$ & $41.773,3349$ & 10.443 .3337 & 7,0944 & $* x$ \\
\hline BIocos & 17 & $62.6556,8726$ & $3.679,8160$ & 2,4998 & $x$ \\
\hline Resíano & 68 & $100.100,2891$ & $1.472,0631$ & - & \\
\hline Total & 89 & $204.430,4066$ & - & - & \\
\hline
\end{tabular}


Tabela 19: Valoros de sólidos Motais Dissolvidos pra chuva,

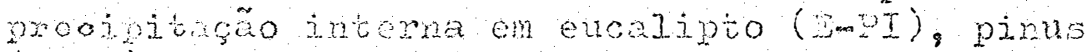
(Dmpt) e escodnonto pelo tronco em eucalipto $(\mathrm{D}-\mathrm{Et})$ e pinus $(p-\mathrm{pt})$.

\begin{tabular}{|c|c|c|c|c|c|c|}
\hline \multicolumn{2}{|c|}{ Data da amostra } & Ghuva(x) & 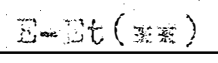 & $D-D t($ 維 $)$ & $\mathrm{B}-\mathrm{PI}\left(\mathrm{K} \mathrm{K}_{\mathrm{K}}\right)$ & $P-P T($ 洪 \\
\hline \multirow[t]{8}{*}{$1974:$} & $16 / 10$ & 9.5 & 147,5 & 30,3 & 24,6 & 12,3 \\
\hline & $29 / 10$ & $4: 5$ & 39,8 & 21.9 & 12,3 & 7,7 \\
\hline & $13 / 11$ & 14,0 & 83,7 & 34,2 & 29,0 & 13,8 \\
\hline & $21 / 11$ & 4,9 & 23,8 & 8,3 & 12,9 & 6,3 \\
\hline & $28 / 11$ & 5,0 & 8,7 & 9,0 & 7,4 & 4,7 \\
\hline & $11 / 12$ & 10,0 & 13,1 & 11,4 & 11,6 & 8,3 \\
\hline & $16 / 12$ & 5,7 & 11,3 & 7,1 & 3,6 & 5,2 \\
\hline & $20 / 12$ & 6,8 & 22,4 & 17,1 & 8,8 & 5,2 \\
\hline \multirow[t]{14}{*}{ 1975: } & $06 / 01$ & 6,2 & 13,9 & 9,9 & 7,5 & 4,4 \\
\hline & $10 / 01$ & 4,5 & 10,2 & 7,0 & 5,2 & 3,3 \\
\hline & $13 / 01$ & 4,2 & 9,4 & 6,3 & 5,0 & 4,9 \\
\hline & $03 / 02$ & 5,6 & 8,8 & 7,3 & 8,4 & 5,3 \\
\hline & $06 / 02$ & 5,4 & 6,0 & 5,9 & 6,5 & 4,1 \\
\hline & $19 / 02$ & 6,3 & 17,8 & 14,4 & 15,3 & 6,8 \\
\hline & $21+102$ & $5 ; 0$ & 8,8 & 8,1 & 7,6 & 3,9 \\
\hline & $26 / 02$ & 7,6 & 19,5 & 13,6 & 10,0 & 6,4 \\
\hline & $03 / 03$ & 10,3 & 32,3 & 22,0 & $1.5,5$ & 8,9 \\
\hline & $08 / 03$ & 10,0 & 23,2 & 16,4 & 15.5 & 11,7 \\
\hline & $\bar{x}$ & 7,0 & 30,6 & 13,9 & 11,8 & 6,8 \\
\hline & $s$ & 2,7 & 37,8 & 8,4 & 5,3 & 3,1 \\
\hline & Max. & 14,0 & 147,5 & 34,2 & 29,0 & 13,8 \\
\hline & Min. & 4,2 & 6,0 & 5,9 & 5,0 & 3,3 \\
\hline
\end{tabular}

(¥) médias de 2 amostras

(x) médias de 4 amostras

d.m.s. a 5\% entre datas: 18,7 
Rabela 20: Anólico da variancie para os daros de sólidos Totais Dissolvidos.

\begin{tabular}{|c|c|c|c|c|c|}
\hline Causa de vaxiagäo & Q.L. & 3.2 & a.t. & $\mathrm{F}$ & \\
\hline Espécies & 1 & 2.097 .36 & 2.097 .36 & 8,72 & s \\
\hline Processos & 3 & $3.010,88$ & $3.010,80$ & 12,52 & 称 \\
\hline Int. $\mathrm{E} \times P$ & 1 & 620,69 & 620,69 & 2,58 & MS \\
\hline (Patorial) & $(3)$ & $5,728,93$ & $1.909,64$ & - & \\
\hline Testemuna $x$ Tratorial & 1 & 1.106 .70 & $1.106,70$ & 4,60 & $3: x_{2}$ \\
\hline Tratamentos & $(4)$ & $6.835,64$ & $1.708,91$ & 7,11 & $x$ \\
\hline B.tocos & $1 ?$ & $10.155,20$ & 597.39 & 2,48 & 琶现 \\
\hline Resíuno & 68 & $16.347,82$ & 240,41 & - & \\
\hline Total & 89 & $33.339,16$ & - & - & \\
\hline
\end{tabular}


Pabela 21: Valorea de cor para chuva, precipitacão interna

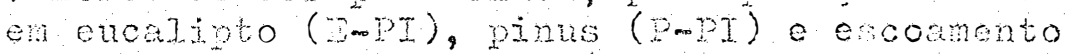
pele tronco on oucalipto ( $-D t)$ e pinus (D-tt).

\begin{tabular}{|c|c|c|c|c|c|c|}
\hline Data a & anostro & Chuva $(x)$ & $2-3 t(x)$ & $p-\operatorname{ct}(z \geq)$ & $2-P I($ 添核) & $D-P I(x)$ \\
\hline & & $-\mathrm{U}$ & dade Platj & $200-c 0 b a \lambda t c$ & de cox & 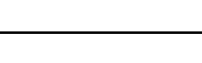 \\
\hline \multirow[t]{8}{*}{ 197\%: } & $16 / 10$ & 50,0 & 2.173 .3 & 136,3 & 171,3 & 75,0 \\
\hline & $23 / 10$ & 0 & 623,8 & 62,5 & 62,5 & 25.0 \\
\hline & $13 / 11$ & 5,0 & 349,2 & 118,3 & 158,3 & 40,0 \\
\hline & $21 / 11$ & 35,0 & 631,3 & 71,3 & 116,3 & 65.0 \\
\hline & $28 / 11$ & 20.0 & 113,8 & 32.5 & 57.5 & 17,5 \\
\hline & $11 / 12$ & 60,0 & 121,3 & 66,7 & 101,3 & 80,0 \\
\hline & $16 / 12$ & 10,0 & 310,0 & 51,3 & 82,5 & 53.3 \\
\hline & $20 / 12$ & 0 & 227,5 & 40,0 & 60,0 & 28,8 \\
\hline \multirow[t]{14}{*}{ 1975: } & $06 / 01$ & 5,0 & 181,3 & 45,0 & 130,0 & 31,3 \\
\hline & $10 / 01$ & 15,0 & 191,3 & 33,3 & 58,8 & 37,5 \\
\hline & $13 / 01$ & 15,0 & 265,0 & 11,3 & 23,8 & 27.5 \\
\hline & $03 / 02$ & 10,0 & $.30,0$ & 32,5 & 76,3 & 42,5 \\
\hline & $06 / 02$ & 5,0 & 76.3 & 31,3 & 77,5 & 48,8 \\
\hline & $19 / 02$ & - & 216,3 & 51,3 & 77.5 & 13,8 \\
\hline & $24 / 02$ & 5,0 & 71,3 & 40,0 & 30,8 & 15,0 \\
\hline & $26 / 02$ & 20,0 & 110,0 & 87,5 & 51,3 & 37,5 \\
\hline & $03 / 03$ & 10,0 & 253,8 & 180,0 & 52,5 & 38,8 \\
\hline & $08 / 03$ & . 5,0 & 206,9 & 30,0 & 51,3 & 20,0 \\
\hline & $\bar{x}$ & 15,0 & 372.7 & 62,3 & 80,4 & 38,8 \\
\hline & $s$ & 17,1 & 499,1 & 43.3 & 100,4 & 19,6 \\
\hline & $\operatorname{Max}$. & 60,0 & $2.173,8$ & 180,0 & 171,3 & 80,0 \\
\hline & Min. & 0 & 71,3 & 11,3 & 23,8 & 13,8 \\
\hline
\end{tabular}

(*) médias de 2 anostras

(x) médias de 4 amostras

d.m.s. a 5\% entre datas: 262,1 
Tobela 22: Mñjise da Vaniânoja para os dados de cor.

\begin{tabular}{|c|c|c|c|c|}
\hline Causa de Variaçáo & G.I. & 3.9. & Q.M. & $\mathrm{F}$ \\
\hline Espécies dentro de to & 1 & 866.854 .1025 & $866.854,1025$ & $18,4383 \times$ \\
\hline Dspécies dentro de pI & 1 & $15.612,5025$ & $15.612,5025$ & $0,3321 \mathrm{iss}$ \\
\hline Processos & 1 & $448.751,8005$ & $448.751,8005$ & 9.5451 现然 \\
\hline (Patorial) & $(3)$ & $1.331 .218,4050$ & $443.739,4683$ & - \\
\hline Testemuna $x$ ratorial & 2 & $219.770,7420$ & $219.770,7420$ & $4,6746 x$ \\
\hline Tratamentos & $(4)$ & $1.550 .989,1480$ & $387.747,2870$ & $8,2475=x$ \\
\hline 131.0cos & 17 & $1.108 .376,9180$ & $65.198,6422$ & $1,3868 \mathrm{~ns}$ \\
\hline Resícuo & 68 & $3.196 .929,4080$ & $47.013,6673$ & - \\
\hline Total. & 89 & 5.856 .295 .4740 & - & - \\
\hline
\end{tabular}


Tabela 23: Anélise da Vaxiância para os dados de Cor.

\begin{tabular}{|c|c|c|c|c|}
\hline Cansa de Variagão & G. I. & $\mathrm{S} . \mathrm{Q}$ & 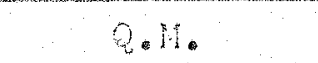 & Ti \\
\hline Hrocessos dentro de $\mathrm{E}$. & 1 & $768.661,3378$ & $763.661,3378$ & 16,3197 积 \\
\hline Processos dentr $\bullet$ de $\mathrm{P}$. & 3 & $4.989,0678$ & 4.989 .0678 & $0,1061 \mathrm{~ms}$ \\
\hline Espécios & 1 & $557.568 \bullet$ & 557.5680 & $11,3600 \mathrm{x}$ \\
\hline (Tatomial) & $(3)$ & $1.331 .218,4050$ & $4,43.739 .4583$ & - \\
\hline Iestenumb a Patorias & 1 & $219.770,7420$ & 219.770 .7420 & $4,6746 \ldots$ \\
\hline Tratanentos & $(4)$ & $1.550 .989,1480$ & $387.747,2870$ & $3,2475 x$ \\
\hline B1000s & 17 & $1.108 .376,9130$ & $65.198,6422$ & $1,3868 \mathrm{Ms}$ \\
\hline Resíauo & 68 & 3.196 .929 .4080 & $47.013,6678$ & - \\
\hline-3 & & & 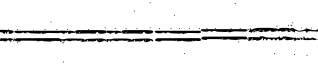 & $=$ \\
\hline Potal & 89 & 5.856 .295 .4740 & - & - \\
\hline
\end{tabular}


Wabela 24: Valores de Alowiniode para a chuva, preciojtaç̃o interna om eucalipto (U-I), pinus (P-I) e escoarento pelo tronco en eucalipto $(L-t)$ e pinus $(p-s t)$.

\begin{tabular}{|c|c|c|c|c|c|c|}
\hline Data do & amostra & Chuve (x) & $E-7 t(y)$ & $P-B t(x)$ & $2-21(a x)$ & $P-P I(x x)$ \\
\hline \multirow[t]{10}{*}{$1975:$} & $06 / 01$ & 34,0 & 114,5 & 47,3 & 126,5 & 63,0 \\
\hline & $10 / 01$ & 41,5 & 12780 & 38,4 & 59,9 & 55,6 \\
\hline & $13 / 01$ & 53,0 & 114,0 & 42,3 & 69,8 & 66,5 \\
\hline & $03 / 02$ & 43,0 & 53,9 & 30,9 & 72,3 & 62,5 \\
\hline & $06 / 02$ & 54,0 & 52.0 & 23,0 & 65.5 & 52,3 \\
\hline & $19 / 02$ & 25,0 & 37,0 & 12,0 & 76.0 & 50,3 \\
\hline & $24 / 02$ & 32,0 & 35,3 & 13,0 & 51,5 & 31,3 \\
\hline & $26 / 02$ & 31.5 & 66,1 & 24,6 & 62,8 & 47,1 \\
\hline & $03 / 03$ & 27.0 & 124,3 & 37,5 & 77.5 & 58,1 \\
\hline & $08 / 03$ & 19,5 & 87.3 & 18,8 & 66,6 & 57.3 \\
\hline & $\bar{x}$ & 36,1 & 81,3 & 28,3 & 72,8 & 55.0 \\
\hline & 5 & 11,6 & 34.5 & 12,4 & 20,4 & 10,8 \\
\hline & Max. & 54,0 & 127,0 & 47,3 & 126,5 & 63,8 \\
\hline & Min. & 19,5 & 35.3 & 12,0 & 51,5 & 31,3 \\
\hline
\end{tabular}

(*) médias de 2 anostras

(अ) módias de 4 anostras

A.m.s. a 5\% entre datas: 26,2 
Mabela 25: Máline da Vuriancia para os dados de Alcalini. dade.

\begin{tabular}{|c|c|c|c|c|c|}
\hline Causa de Variagño & G.I. & 5.8. & Q.1. & $\underline{T}$ & \\
\hline Espécie dentro de $\mathrm{B} t$ & 3 & $13.786,50$ & 13.706 .50 & 52,83 & 现勧 \\
\hline Espécie dontro de P & 1 & $1.591,32$ & $1.591,32$ & 6,10 & $z$ \\
\hline Processos & 1 & 780,57 & 780,57 & 2,99 & n.s. \\
\hline$(\operatorname{atctan})$ & $(3)$ & $16.150,39$ & $5.386,13$ & - & \\
\hline Testemuna $x$ patoria & 1 & $4.400,76$ & $4.400,15$ & 16,86 & 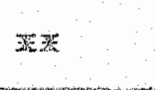 \\
\hline Tratamentos & $(4)$ & 20.558 .56 & 5.139 .64 & 19,69 & 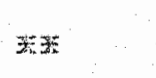 \\
\hline BIOCOS & 9 & $8.682,57$ & 964.73 & 3,70 & 筑签 \\
\hline Resíáno & 36 & 9.395 .13 & 260,98 & - & \\
\hline rotal & 49 & $33.636,26$ & - & - & \\
\hline
\end{tabular}




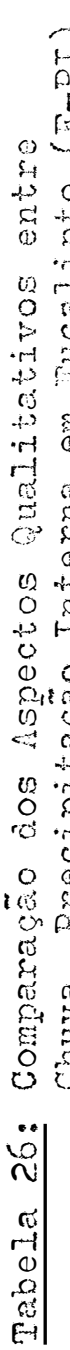

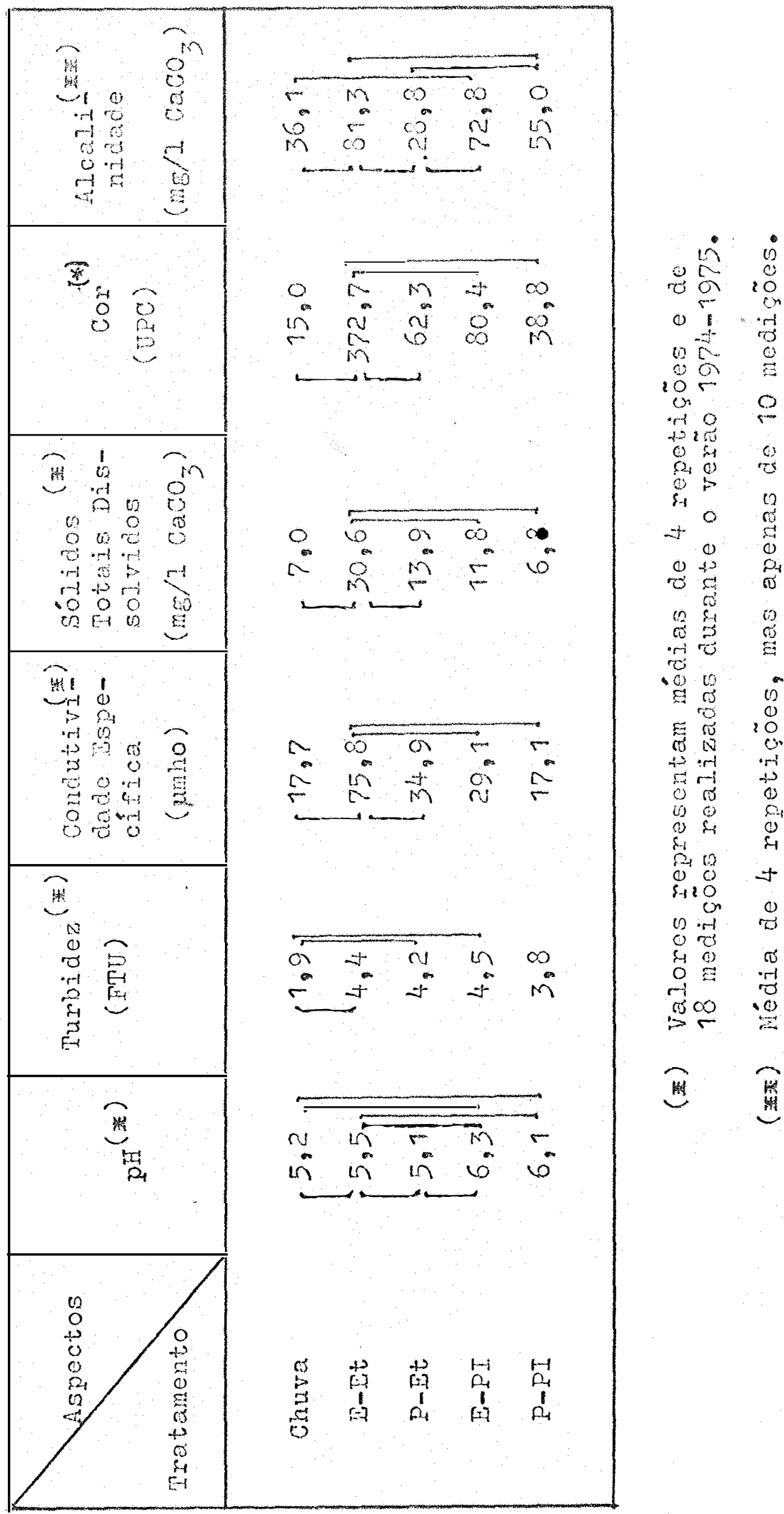


suspensão na ácua, ou soja é una nedia da roduçäo de transparência causada pela presença de matoriats en suspensäo, incluindo panticulas orgâaicas, inorgânicas e mesno ongenisnos vivos. para a agua potávero limite néximo de tuxbidez pemitido é 5 ( U.S. EUBIC HALTH SBRVICE, 1962). De acordo con as tabelas 15,16 e 26 , observa-se que tambén para este fator houve influência significativa causada pelas duas espécies florestais, ou seja tanto o evealipto como o pinus altoraram simisica tivanente a turbidez da a $u$ a da chuve no caso do povoamento de pinus, apenas a ásua do escoanento pelo tronco apresentou major turbidez do que a ácrua de chuva, sendo quo nấo houve diferença signticativa entre a chuva e a precipitaça interna. Os procescos (PT e Et) não diferiran entre si dentro de una mesma espécie, e as ospécies também não se nostraran diferentes em cada processo individualmente. Na labela 15 pode.. - se observar que as prineiras chuvas da estaça chuvosa ou ainda as chuvas que ocorrem após prolongados períodos secos apresentam, en geral, maior quantidade de partículas em suspensão após penetrar pela ve setação.

iTo que dia respeito a condutividade especifica, pode-se entender este fator como seno a capacidade que una solucão apre senta de conduzir a corrente elétrica. Quanto mais concentrada a solum ção, istoé, quanto maior a quantidado de íns presentes, maior é a condutividade. Ista, portanto, representa una medida da concentração ônica da solução. En teoria, a ácua pura apresentaria condutivicade da orden de alguns centésimos de umho. Áśgua da chuva, por conter naturalmente muitos gases e partículas dissolvidas, apresenta condutivjarm de naior que a ásua destilada. A condutividade da áula do mar está 2.0 redor de 50.000 umbo. De modo geral as águas naturais apresentam valores de condutividade específica variando de 10-1000 umb (mbM, 1970). De acordo com os resultados das Tabelas 17,18 e 26 , verifica-se que apenas o eucalipto, particularmente o escoamento pelo tronco nesta cspé cie, apresentou condutivicade nédia sichificativanente maior do que a ácua da chuva. A condutividade da precipitação interna em eucalipto foi sicnificativamente menor do que a condutividade do escoamento pelo tronco. Wo caso dos pinus não houve diferença sicnificativa entre a condutividade média de PI e de Rt. Pelos resultados contidos na Tabela 17, verifica-se ainda que a lavagen (solubilizaça de ions) é sichiricativamente maion pelas primeiras chuvas de outubro, on seja pelas chu vas ocorrias após prolongaio penjodo seco. 
A expressão sólidos Totais Dissolvidos (smo) reforemse à soma de todos os compostos em solução na ácul. De acora con

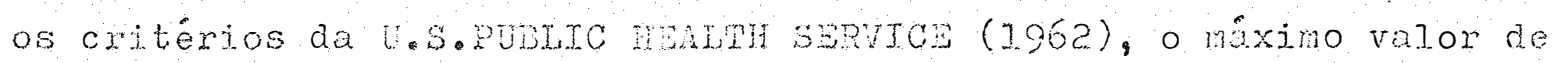
STD permitido en ásua potável é de $500 \mathrm{mg} / \mathrm{I}$. Pelo fato de o GPD neste estudo ter sido obtido a partir dos dados de condutividade (esta dá ayenas uma indicaçäo de STD, (MTH, 1970), era de se esperar que os resultados fossem stmilares, confome pode ser observado has tabelas 19, 20 e 26. As mesmas considexagoes apresentadas para a discussão dos resultados de condutividade valem, consequentemente, também para os re sul.tados de sólidos totais dissolvidos.

Com relação à cors este parâmetro qualitativo serm ve apenas como indicador da presença en solução de compostos principal mente orgânicos que podern produrir coloraçäo. os critérios de potabili dade da U. 3.PUBLIC HEALIH SRRVICE (1962) permitem um náximo de 15 unidades de cor na água. Os resultados das Tabelas 21, 22, 23 e 26 permj..tem concluir que apenas a espécie encalipto, particularmente através do processo de escoamento pelo tronco, apresentou valor médio de cor significativanente naior que a água da chuva. A cor média da água de escomento pelo tronco en eucalipto foi também sicnificativamente maior do que a cor da água da precipitaçäo interna nesta espécje, e airda significativamente maior que a cor do escoamento pelo tronco e da pren cipitação interna registradas para a espécie pirus. os valores de cor do escoamento pelo tronco e da precipitação interna em pinus não foran diferentes entre si, nem tampouco diferentes daquele verificado para a chuva. Merece destaque neste particular os valores altos de cor registrados para o processo de escoamento pelo tronco ein eucalipto (Tabela 21), indicando que este processo nesta espécie parece estar associado à lavagen acentuada de componentes orgânicos responsáveis pela coloram ção forte da água.

A alcalinidade, do ponto de vista químico, diz res peito à capacidade que a solução anresenta de neutralizar ácidos. Nuitos compostos podem contribuir para a alcalinidade da água. Bm condições naturais, a maior parte da alcolinidade resulta do equilíbrio com - $\mathrm{CO}_{2}$ atmosférico. Im condiçöes particulares, após a interação con a vegetação, por exemplo, poße haver também contribuição de ácidos or ̧ânicos e vários tijes de materiais ajssolvidos ou em suspensão. pelo exame das Tabejas 24,25 e 26, veritica-se que apenas a espécie enca- 
lipto apresentou, tanto a precipitação interna como escoamento pelo tronco, valores de alcalinidade significativamente majores que a alcalinj.dade média da água da chuva. Não houve diferença significativa entre os processos na espécie evcalipto. Para o caso dos pinus, a alcali nidade média da precipitação interna foi significativamente maior que a do escoamento pelo tronco, mas ambas não diferiram da alcalinidade média da chuva.

Estes resultados, coletivamente, permitem afirmar que o povoamento de eucaliptos causou, de modo geral, alterasão qualim tativa dáácua da chuva ligeiramente major do que o povoamento de pinus, no que diz respeito aos parâmetros estudados. Dsta alteraçăo foi mais acentuada para o processo escoamento pelo tronco do que para a precipitação interna. O pH do escoamento pelo tronco em pinus foi lim geiramente, mas não significativamente menor do que o pII da água da chuva. Os resultados, ainda, confirmam as referências na literatura de que as confiferas, em geral, são melhores recomendadas para plantio em locais once a vegetação gode contribuir para a deterioraçäo estética de superfícies jiquidas (na orla de reservatórios, por exemplo). 


\section{RESUMO E CONCIUSOES}

o presente trabalho se refere ao estudo de alguns aspectos do balanco hídrico realizado en três tipos de cobertura vegem tal: una plantação de Eucalyptus saliggna, Snith de 5-6 anos de idade, uma plaritação de Pinus caribaea, Horelet var. caribaea, também com ida de de 5 m6 anos, e u̧ma parcela contendo vegetação herbácea natural, todas situadas no campus da Escola superior de figricultura "Luiz de Que roz", en Piracicaba, são Paulo.

Nestes três diferentes ecossistemas, os seguintes componentes do ciclo da água foram medidos durante 2 anos consecutivos, de junho de 1973 a naio de 1975: a) precipitação; b) evaporação en tan que Classe $A$; c) precipitação interna; d) escoamento pelo tronco; e) á gua do solo; f) DAP estacional das árvores. Estes parâmetros quantitam tivos pemitiran o cálculo das perdas por interceptação nas florestas de eucaliptos e de pinus, do consumo de água pelas três diferentes vegetaçōes durante a estação seca do anos a determinação do regime anua? da água do solo nos três sistenas, e a verificação das relações entre - crescimento radial e os povoamentos florestais e a quantidade de água disponível no solo. Além disto, en amostras de água da chuva, da água da precipitaçäo interma nos povoamentos florestais, e em água resultante do processo de escomerto pelo tronco, foram, também, realiza. das análises dos seguintes parâmetros de qualidade da água: pH, turbidez, condutividade, cor, sólidos totais dissolvidos e alcalinidade.

A precipitação foi medida em um pluviógrafo e um pluviômetro instalados na parcela com vegetação herbácea. Também nesta parcela foi instalado o tanque classe A para a medição da evaporação. A precipitação interna foi medida utilizando-se interceptômetros com área de captação de $127 \mathrm{~cm}^{2}$. o escoamento pelo tronco foi medido por meio de dispositivos colocados ao redor do tronco das árvores. A água do solo foi medida através do nétodo de moderação de neutrons, em três tubos de alumínio em cada tipo de vegetação, até a profundidade de 2 metros. Os parâmetros qualitativos foram determinados em laboratório, de acordo com os procedimentos padronizados da AHERICAN PUBLIC HBATH Assoctation (1949). A estimativa do consumo de ácua foi restrita apenas aos períodos secos co ano, e foi baseada na equaço: Evapotranspi- 
ração = Precipitação + variaçäo do armazenamento da água do solo (ET = $P+\Delta S)$.

De acordo com os resultados obtidos, e consideran-do as condições de clima e de solo da área experimentả, bem como as condjgões dos povoamentos florestais e da veģetação herbácea estudados, as sequintes conclusões podem ser estabelecidas:

1. A interceptação média dá água da chuva causada pelo povoamento de eucaliptos foi, de $12,4 \%$, enquanto que o povoamento de pirus apresen tou interceptação nédia de 7,2\%.

2. O escomento pelo tronco foi quantitativamente maior no eucalipto do que no pinus ( $4,2 \%$ e $3,0 \%$ respectivamente).

3. A precipitação interna, por outro lado, foi maior no povoanento de pinus $(90,4 \%)$, do que no povoanento de eucaljpto $(83,6 \%)$.

4. As equações de regressäo que permitem a estimativa da precipitação intema (PI), do escoamento pelo tronco (Et) e da precipitaçẫo efe-m tiva (PE) a partir da medição da precipitação no aberto (PT), para eucalipto ( $\mathrm{E}$ ) e para pinus ( $P$ ) são as seguintes:

$$
\begin{aligned}
& P I_{E_{P}}=0,890(\mathrm{PT})-0,530 \\
& P I_{P}=0,938(\mathrm{PT})-0,570 \\
& P t_{E}=0,053(\mathrm{PT})-0,060 \\
& E t_{P}=0,025(\mathrm{PT})+0,139 \\
& P E_{E}=0,939(\mathrm{PT})-0,629 \\
& P E_{P}=0,978(\mathrm{PT})-0,596
\end{aligned}
$$

5. Considerando a precipitação média anual verificada no período experimental, os valores de interceptação média determinados para os po voamentos filorestais correspondem a uma perda média anual de $174 \mathrm{~mm}$ de água pelo eucalipto, e $101 \mathrm{~mm}$ pelo povoanento de pinus.

6. De modo geral, sempre houve água disponível no solo nas três condições de vegetação estudadas, a não ser nos meses de agosto e setembro, quando o conteúdo de umidade esteve próximo ou abaixo do conteúdo correspondente a 15 atmosferas de pressão.

7. A análise do regime anual, ou da marcha anual da água do solo sob eucalipto, sob pinus e sob vegetação herbácea natural mostrou que 
praticamente não houve diferenças maxcantes no regime da água do so Io entre estas três coberturas vegetajs.

8. En termos médios, o solo sob eucalipto apresentoumse ligeiramente mais seco do que o solo sob vegetação herbácea natural durante as épocas de alta umidade no solo, ao passo que para os períodos nos quais o solo apresentou-se mais seco, o reverso foi verificado.

9. Já o solo sob o povoamento de pinus apresentoumse, em geral, ligejramente mais úmido do que o solo sob vegetação hexbácea, e também lifeiramente mais úmido do que o solo sob eucalipto.

10. Comparando o regime anual médio da água do solo, notoumse que o som lo sob vegetação herbácea apresentou-se mais úmido do que os outros dois durante o período de recarga da água do solo (setembro-feverei ro); durante o período de depleção da ácua do solo (março-agosto) o reverso parece ser verdadeiro.

11. A maior diferença verificada entre os conteúdos médios de água no solo nos três sistemas estudados ocorreu nos meses de verão, quando - solo sob eucalipto se apresentou bem mais seco do que os demais.

12. A comparação dos regimes anuajis nas diferentes camadas do solo mos-. trou que as camadas superficiais $(0-90 \mathrm{~cm})$ foram as que apresentam ram maior flutuação mensal de conteúdo de umidade. Nas camadas mais profundas (90 até $280 \mathrm{~cm}$ ) estas flutuaçôes foram significativamente menos acentuadas.

13. O povoamento de pinus causou, em geral, maior denleção da água do solo apenas nas camadas de $90-120 \mathrm{~cm}$, dando alguma indicação de uma maior concentração de raizes nesta profundidade. Já o povoamento de eucalipto e a vegetação herbácea natural causaram maior depleção nas camadas mais profundas, depleção esta liğeiramente maior para o eucalipto.

14. Pela análise da amplitude máxima de variação da água do solo nas três parcelas estudadas, verificou-se que a recarga da água do solo foi maior na vegetação herbácea, depois em pinus, depois em eucalip to. Estas diferenças de recarga da ázua do solo foram proporcionais às diferentes perdas médias por interceptação nos povoamentos florestais.

15. As estimativas do consumo de água dos dois povoamentos florestais, 
assim como da vegetação hexbácea natural deram como resultados para a estação seca (maio a setembro) de 1974 os seguintes valores: eucalipto: $206,3 \mathrm{~mm}$; pinus: $211,5 \mathrm{~mm}$; vegetação herbácea: $195,9 \mathrm{~mm}$. Os valores da taxa de evapotranspiração $\mathrm{em} \mathrm{mm} / \mathrm{dia}$ foram, respectivamente: 1,5, 1,5 e 1,3. 2 os valores da relação $\mathrm{ET} / \mathrm{E}_{0}$ foram, respectivamente: $0,43,0,43$ e 0,37 .

16. Os resultados, coletivamente, permitem afirmar que não houve efeito adverso sobre o regine da ácua do solo como decorrência do plan tio de eucalipto ou de pinus, em comparaçäo con o regime observado em solo revestido por vegetaçẫo herbácea natural.

17. Durante o período experimental, a área basal do povoamento de euca liptos passou de $15,37 \mathrm{~m}^{2} / \mathrm{ha}$, no início do experimento, para $20,5 \overline{6}$ $\mathrm{m}^{2} /$ ha ao fim do periodo. Para o povoamento de pinus, o crescimento observado foi de $13,46 \mathrm{~m}^{2} /$ ha para $28,61 \mathrm{~m}^{2} / \mathrm{ha}$. pode ser notada une aparente correspondencia entre os acréscimos estacionais do DAP né dio dos povoamentos e as variações da água disponível no solo, notando ise incrementos crescentes durante o período de recarga da . água do solo, e incrementos decrescentes durante o período de depleção, principalmente para o caso dos pins.

18. A análise estatística dos parâmetros de qualidade da água estudados, revelou, de modo feral, que o povoamento ce eucalipto foi res ponsável por uma alteração maior da qualidade da água da chuva do que o de pinus. Esta alteração foi principalmente devida a interam ção da água da chuva com a vergetação através do processo de escoamento pelo tronco.

19. Tanto o pH da precipitação interna como o do escoamento pelo tronco em eucalipto foran maiores que o pil da água da chuva. No caso do pirus; o pH do escoamento pelo tronco foi significativamente menor do que o pH da á:ua da chuva, mas o pH da precipitação interna foi significativamente maior.

20. Quanto aos parâmetros turbidez, condutividade, cor, sólidos totais dissolvidos e alcalinidade, apenas os valores medidos no povoamento de eucalipto foram significativamente maiores que aqueles medidos na ácua da chuva. Os valores destes parânetros no povoamento de pinus não diferiran estatisticamente daqueles observados na água da chuva. 


\section{SUMMRY}

This thesis is related to a vater balance study carried out in three different vesetations: a plantation of Bucalyotus salima, Smith, a plantation of pinus caribea Morelot var. caribaea, both 5-6-year old, and a plot with natural herbaceous vecetation, all Iocated on the canpus of the Escola superior de Acricultura "tujz de Quejroz", in Piracicaba, Gtate of são paulo.

In those ecosyotens the foll wing conponents of the water cycle have been measured during two consecutive years, from june 1973 to may 1975: a) Gross mecipitation; b) Class A pan evaporaw tion; c) throughall; d) stenflow; e) sojl water; $f$ ) seasonal variam tion of trees d.b.h. These neasuroments were used for the calculation of the interception loss by the forest stands, and the vater consumption by each of the three vegetation covers curing the dry season; they also served to exanine the relationships between the stands radial grovth and the water available in the soil, and to determine the annul range of soil moisture as related to the three diferent veretations. Besides these quatitative measurenents, samples of water of eross precipitation, througheall and stenflow were taken after each rajn and anajysed for pr, turbidity, conductivity, color, total dissol ved solids, and alkalinity.

Gross precipitation was sampled in a recording rain gauge and a standard, non-recording rain guse, both installed in the open (at the natural herbaceous vegetation plot). Also in this plot was placed the class $\Lambda$ pan evaporimeter. Throughfall was measured in each stand by randonly locating twelve $127 \mathrm{~cm}^{2}$ gages. These gages were relocated periodically during the study period. Stemflow was measured by sealing narrow rubber collars to tree trunks, which caucht downflowing water and conducted it to storage, plastic containers. Soil va ter was measurement monthly using the neutron scattenine techrique, to a depth of 1,80 meters. The water quality parmeters vere analysed

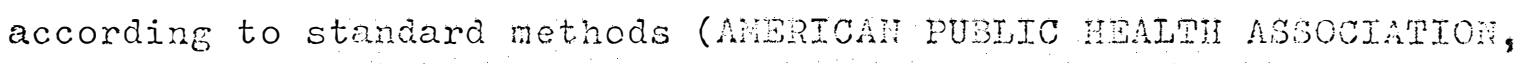
1949). The vater consumption as estimated only during the dry season, according to the simplified equation avapotranspiration = Precipitation + soil vater depletion $(n=P+\Delta s)$. 
1. Interception Joss in the eacelyphs stand amounted to 12, 4s, as an average value for the priod studed. For the pine rtand interection loss was $7,2 \%$

2. Stenflow was quentitatively kighen in the oucalyphs stand than in the pine (4,2\% against $3,0 \%$ respectively).

3. Throughelj, on the other hend, wes hichen th pine than in eucalyptus $(90,4 \%$ and 33,6, respectively).

4. Regression equations relating eross precipitation (PG) rith through fall (T) stemflon ( $(\bar{B})$ and net prectitation (PN) for both eucolyn-

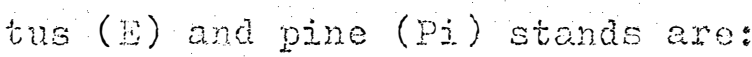

$$
\begin{aligned}
& T_{\mathrm{D}}=0,890(\mathrm{po})-0,530 \\
& T_{P_{j}}=0,938(P G)-0,570 \\
& S_{\mathrm{Ii}}=0,053(\mathrm{PG})-0,060 \\
& S_{P i}=0,025(P G)+0,139 \\
& \mathrm{PH}_{\mathrm{P},}=0,939(\mathrm{PG})=0,629 \\
& \mathrm{PN}_{\mathrm{Pi}}=0,978(\mathrm{PC})-0,596
\end{aligned}
$$

5. Taking into account the anount of the average annual precipitation. measured during the study perjod, interception loss in eucalyptus was equivalent to a joss of $174 \mathrm{~mm}$ of water, and in pine, to a loss of $101 \mathrm{~mm}$ of water.

6. In general there was water avajable in the soil over the entire pe riod jn all three vegetation conditions; only during the months of august and september did the water in the soill reach tension below 15 atm.

7. The analysis of the annual range of soil water in eucalyptus, pine, and in natural herbaceous vegetation did not show any significant difference in the soil water regime anong the vegetation covers stu died.

8. On the averace the soil under encalyptus was slightly drier than the soil under herbaceous vegetation during the periods of nomaly hich water content; on the contrary, during those pants of the year. wen the soil is nomally ary, the opposite was true.

9. The soil wher pines was, in general, nore und than those undex eucalyptus, and under horbacous vecotation. 
10. The andyses of the data anout the average soil water regine for the year showed that the soil maer herbaceous vecetation was, in general, more unid than the soils under eucalyptus and pine during the period of soil water recharge (september through february); du ring the period of soil vater depletion, the oposite vas true.

11. The greater difference in soil mointure content anong the three co ver conditions occurred during the summer months, when the soil un der eucalyptus vas arier than the others.

12. Consjdering the noisture regine in each of the soil layers studied, higher fluctuations of moisture occurred minly in the upper soil leyers $(0-90 \mathrm{~cm})$.

13. The pine stands caused constarebly higher depletion of moisture in the layers of 90-120 cm, indicating an apparent root concentram tion in this depth. Whe eucalyptus stand and also the herbaceous vegetation caused greater depletion of nojeture in deeper layers, this depletion being highor for the forest stand.

14. Soil water recharge in herbaceous vegetation was higher than in 1 . ne, and both were higher than in eucalyptus. These differences in sojl watex recharge vere proportionate to the interception losses in the forest stands.

15. For the dry period of may through september, 1974, the estimated. values of evapotranspiration were as follows: eucalyptus: $206,3 \mathrm{~mm}$; pine: $211,5 \mathrm{~mm}$; herbaceous veretation: $195,9 \mathrm{~mm}$. The values of eva potranspiration rates (mm/day) vere $1,5,1,5$ and 1,3 , and the ratios $\mathbb{Z l} / \mathbb{E}_{0}$ (evapotranspiration/Class A pan evaporation) were 0,43 , 0,43 and 0,37 , for eucalyptus, pine and herbaceous vegetation.

26. These results collectively permit the conclusion that there vere no adverse effects on the soil vator regime which could be ascribed to the plantation of eucalyptus or pine, as compared with that observed for the natural herbaceous vegetation.

17. During the study period, basal area of the eucalyptus stand changed from $15,37 \mathrm{~m}^{2} / \mathrm{ha}$, in the beginning, to $20,56 \mathrm{~m}^{2} / \mathrm{ha}$ at the end. Basal area in pire changed from $13,4.6 \mathrm{~m}^{2} / \mathrm{ha}$ to $28,61 \mathrm{~m}^{2} / \mathrm{ha}$ during the same period. An apparent corregpondence was observed between seasonal d.b.h. incroments and seasonal variation of soil moisture, the incremonts increasing auring the period of soit vator rechure, and decreasing during the period of soin water depletion. 
18. Sktistical analyses of the vatex quajty porameters showed that the oncalyptus stand was, in general, responolole for a hiser albextion of the quenty of water than the pine stand, as the rain was penetrated through these forest canomes This ateration wo particulary haber in stenflow water than in throughall wa tos.

19. Por the eladyptus, the wH of thoughall water and that of stemthow veter were significhty hjoher than the pH of ratn water. Fon the pines the pH of stemiow water was sjoniticantly smaller twan that of ran water, wut the pt of throughall water was higho.

20. As to turbidtsy, conauctivity, colot, total atssolved solids, and andalinty ony the eucalyptus stand presented ralues of these pa rameters stotjoticaliy hither that those observed in rain vater. The sane valnos neasured in tho nine stand were not statistically ditherent from of the rain. 


\section{IITERATURA CITADA}

ALDRIDGE, R. \& JACKSON, R.T., 1973. Interception of Rainfall by Hard Beech (Notnoragus trincata) at Taita, hew Zealand. N. Zealand Jour. of Science, 16(1): 185-198. In: Forestry Abstracts, 35(4): $1235,1974$.

AMPRICAN PUBLIC HEALTI ABSOCIATIOA, 1949. Standard Methods for the Exa mination of Vater and sevage. Oth Jaition. 286 p.

ArônIHO, 1969. A Preliminary Study of the Stem Plow Leachates of Pinus pinaster and their affect on Soiz properties. Ext. from Repe Foxa Dep. Australia. In: Forestry Abstracts, 31(4) 6060, 1970.

ASSOCIAGAO PAULISTA DOS FABRICATMPS DE CELULOSE B PAPEI, 1973. Relatório Estatístico. Sãa Paulo. $246 \mathrm{p}$.

ATTIILI, P.M., 1966. The Chemial Composition of Rainwater in Relation to Cycling of Nutrients in nature Bucalyptus torest. Plant ard Soil, 24(3): 390-406.

AUSSEAAC, G., 1972. The Actnal Evapotranspiration of pour Forest Stands in the Last of Prance. Ann. Sci. For., 29(3): 369-389. In: Selecm ted Jater Res. Abstracts, 7(11): 5, 1974 .

AUSSZMAC, G.; BOMNAU, $H_{0}$ i L IT TACOH, F., 1972. Restitution of Hineral Ilements to the Soil, Through the Li.tter and Through Precipitation, in Three Forest Stands of Bastern France. Oecologia Plant., 7 (1): 1-21. In: Forestry Abstracts, 34(2): 733,1974 .

BABALOLA, O. \& SAMIE, A.G., 1972. The Use of a Neutron Technique in Stu dying Soil Moisture Profiles under Forest Veretation in the Horthern Guinea Zone of Nigeria. Tropical Science, 14(2): 159-168.

BALDY, C.; POUFON, H. \& SCHOEHENBERGER, A., 1970. Variations in Soil Moisture Content as a Function of Stand Type in Northern Tunisia. Anr. Inst. Nat. Rech. For. Tunis., 4(3). In: Forestry Abstracts, $33(1): 318,1972$.

BANERJIEE, A.K., 1973. Computing Transpiration and Soil Evaporation from Periodic Soil Moisture Measurements and other Physical Data. Indian Forester, 99(2): 82-91.

BAUMGARTIR, A., 1967. Inergetic Bases for Differential Vaporization from Forest and AGricultural Lands. In: Intern. Symp. on Forest. Hydrolosy. Persamon Press, N. York. p. 381-389.

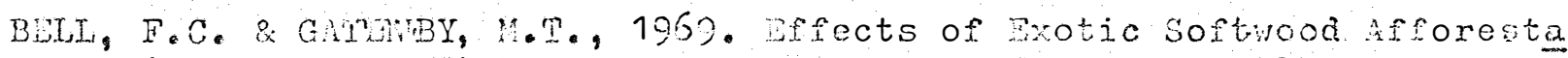
tion on Vater Yield. Vater Res. Found. of Aust., Bull. n.s. I. no 15, 93 p. In: Forestry Abstracts, 32: 77, 1971. 
BLACK, C.A., 1968. Soil-plant Relationships. John Wiley \& Sons, Inc. New York. 792 p. Chap. 2: Soil Water, p. 70-152.

BROWN, Jr., J.H. \& BOURN, T.G., 1973. Patterns of Soil Moisture Deplem tion in a hixed Oak Stund. Forest science, 19(1): 23-30.

BRUCKERT, S. a TOUTAIK, F., 1971. The Effects of Rainfall penetrating the Canopy of Beech and Scots Pine on the Process of Humification. Ecol. Plant., 6(4): 329-339. In: Forestry Abstracts, 33(4): 5930, 1972 .

BUBLINEC, E., 1972. Influence of Pine Monocultures on Momentary Soil Moisture. Acta Inst. Forestalis Zvolen., 3: 125-160. In: Forestry Abstracts, $35(7): 3470,1974$.

BURGY, R.H. ¿ POMBROY, C.R., 1958. Interception Iosses in Grassy Vege-tation. Trans. Amer. Geoph. Union, 39(6): 1095-1100.

BURROUGHS, Jr., E.R. \& SCHULRZ, J.D., 1964. Evapotranspiration and soil Moisture Depletion. Soc. of Amer. Foresters, Proc., Denver, Colorado: $98-101$.

BYRIDS, H.R., 1967. Limitine Site Factors in the Development of Forest Watershed Plantations. In: Int. Symp. on Forest Hydrology. Pergamon Press. it. York. p. 629-637.

CAMARGO, O.N., 1968. nbsorção Foliar e Lavagem de Nutrientes nas Plantas. USP-ESALQ, Bol. Didático ne 20. $123 \mathrm{p}$.

CERVELINI, A.; REICHARDT, K.; SALATI, I. \& ZUR, B., 1972. Preliminary Studies on the Water Economy in "Cerrados". CWNA, ESALQ, Bol. Cien tifico BC-003. $18 \mathrm{p}$.

COHBN, O.P.; KAPLAN, J. \& SHARABANI, N., 1966. Hater Balance Under Pine Plantations and liatural Herbaceous Vegetation in the Judean Foothills. 6th World Forestry Congress. Madrid. p.: 3811-3814.

COstIN, A.B., 1961. Forest Hydrology of Australian Subalpine Catchments. 2nd World Eucalyptus Conference. FAO. São Paulo. p.: 883-395.

CROFT, A.R. \& MONINGER, L.V., 1953. Evapotranspiration and other Water Losses on Some Aspen Forest Types in Relation to Vater Available for Stream Flov. Trans. Amer. Geoph. Union, 34(4): 563-574.

CROUSE, R.P.; CORBETT, E.S. \& SEEGRIST, D.W., 1966. Methods of Measuring and Analyzing Rainfall Interception by Grass. Bull. I.A.S.H., $11(2): 110-120$.

CRUCIAnI, D. :., 1972. Balanço Hídrico em solo Cultivado com Cana-deaquear. CSMA, WALA. BOL. Cient. BC-006. $35 \mathrm{p}$. 
CDRRHOWSKI, M.S. \& OLSZRUSKT, J.I., 1968. Rainfall Interception by a Fo rest Canopy. Oikos, 19(2): 345-350. In: Forestry Abstracts, 30(3): $3480,1969$.

DECKER, J.P. \& WIEN, J.D.: 1960. Tranopirational Surges in Tamarix and Eucalyptus as Measure with an Infrared Gas Analyzer. Plant Physi ology, 35(3): 340-343.

DILES, J., 1967. Interception and Stemflow in stands of Norway Spruce and Beech in West Germany. In: Int. Symp. on Forest Iydrolow, Pergamon Press. Hew York: 179-185.

DEMALLE, D.R. \& PAULSELL, L.F., 1969. Canopy Interception, Stemflow and. Streanflow on a small Drainage in the Missouri Ozarks. Res. Bull. Ho. Agric. Exp. Sta. no 951, 26 p. In: Forestry Abstracts, 31(2): $1854,1970$.

DOR5T, J., 1973. Antes que a Natureza Morra. Editora Edgard Blucher Ltha. São Pauro. 394 p.

DREIBELBIS, F.R., 1962. Some Aspects of Watershed Hydrology as Determi ned from Soil Moisture Data. Jour. of Geophysical Research, 67(9): $3425-3435$.

DREIBELBIS, F.R., 1963. Land Use and soil Type Effects on the Soil Hois ture Regimen in Lysimeters and small Vatersheds. Soil sci. Soc. of America Proce, 27(4): 455-460.

DRIBELBIS, F.R. \& AMERMAT, C.R., 1964. Land Use, Soil Type, and Practi ce Effects on the Water Budget. Jour. of Geophysical Research, $69^{-}$ (16): 3387-3393.

EATON, J.S.; LIKENS, G.Z. \& BOPMANN, F.H., 1973. Throughfall and stemflow Chemistry in a Northern Hardwood Forest. Jour. of Bcology, 61(2): 495-508. In: Forestry Abstracts, 35(3): 717, 1974.

ESCHNER, A.R., 1967. Interception and Soil hoisture Distribution. In: Int. Symp. on Forest Iydrology. Pergamon Press. N. York. p. 191200 .

FEDERER, C.A., 1970. Heasuring Forest Evapotranspiration - Theory and Problems. USDA, Forest Service Research Paper NE-165. 25 p.

FERRAZ, E.S.B., 1972. Estudo da Evapotranspiração Real Através da liedi da de Umidade do Solo por hoderação de Neutrons. CDHA, Bol. Cientifico BC-005. ESALQ-USP. $40 \mathrm{p}$.

FERRI, H.G. 1957. O Consumo d'água dos Bucaliptos. An. Bras. de Econ. Florestal, $9(9)$ : 207-210. 
FERRI, H.G., 1961. Aspects of the Soll-Water-Plant Relatinships in Conexion with some Brazizian Types of Vegetation. Tropical Soils and Vegetation Proc., Abidjan Symp., UNisCO. p.: 103-109.

FISCHER, D.U.; GAMBEL, A.W.; LIMENS, G.R. B BOHANH, F.H., 1968. Atmos pheric Contributions to Vater quality of Streams in the Hubbard Brook Wxperimental Forest, Hev Hampshire. Water Resour. Res., 4(5): $1115-1126$.

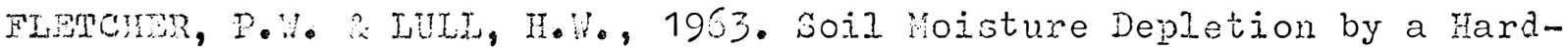
wood Forest During Drouth Years.Soil Sci. Soc. of Amer. Proc., 27 (1): $94-98$.

FRANCO, C.M. \& IMPRZnTo, R., 1950. Mranspiração de Eucalyptus saligna Sn. Ciencia e Cultura, 2(1): 29-30.

FRECHETRE, J.G., 1969. Interception of Rainfall by a Laurentian Balsam Fir Forest. Naturaliste Canadian, 96(4): 523-529. In: Forestry Abstracts, 32: 66, 1971.

GAISIR, R.N., 1952. Readily Available Vater in Forest Soils. Soil Scien ce Proc., 16(4): 33!r-338.

GEIGER, R., 1966. The Clinate Near the Ground. Harvard University Press. Cambridge, Mass. 611 p.

GESPER, P.I. Q IIOLOHAYCIUK, N., 1971. Some Efects of Stem Flov from FO rest Canopy Trees on Chemical Properties of Soils. Ecology, 52(4): $691-702$.

GIPFORD, G.F. \& SHAV, C.B., 1973. Soil Moisture patterns on two Chained Pinyon-Juniper Sites in Utah. Jour. of Range Management, 26(6): $436-440$.

GINDEL, I., 1964. Seasonal Pluctuations in Soil Hoisture under the Canopy of Xerophytes and in Open Areas. Commonw. Tor. Rev., 43(3): $219-234$.

GOODELI, B.C., 1963. A Reapraisal of Precipitation Interception by Plants and ittendant vater Loss. Jour. of Soil and Vater Conserva tion, $18(6)$ : 231-234.

HACH CHDHCAL COMPANY, $1973^{\circ}$. Manual Laboratory Instrumentation. Conductivity lieters. $16 \mathrm{p}$.

mACH CHBICAL COMPATY, $1973^{\mathrm{b}}$. HACH DR Colorimeter Methods Manual. 9th Ed. 166 p. 


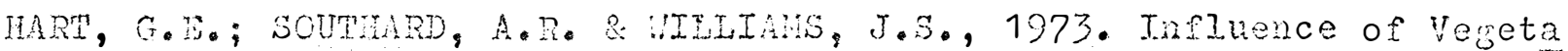
tion and substrate on stremvater chemistry in forthern Utah. UNDI, Off. of Water Res. Pesearch, Project OMn-017. $53 \mathrm{p}$.

IIULVEY, J.D., 1964. Nainfall Interception by Marcivood Forest Ititter in the Southern Appalachians. Southeast. Forest Bxpt. Sta., U.S. Forest Sexv. Res. paper S-3,8 p.

HELVE, J.D., 1967. Interceptjon by Bastern White Pine. Water Resour. Research, 3(3): 723-720.

HELVEY, J.D. 'ix IILULETS, J.D., 1962. The Annual Range of Soil Moisture under Iigh Rainfall in the Bouthern Appalachians. Jour. of Forestry, 60(7): $485-436$.

HIELVI, J.D. \& PARRIC, J.I., 1965 . Canopy and Litter Interception of Rainfall by IIardwood of Zastexn United States. Hater Resour. nese arch, 1(2): 193-206.

HELVIS, J.D. \& PATRIC, J.I., 1965b. Design Criteria for Interception Studies. Int. Ass. Sci. Hydrolocy. Bull. 67: 131-137.

HUY, J.D., 1970. Study and Interpretation of the Chemical Characteristics of Natural fater. Ceol. Survey later-Supply Paper no 1473. U.S. Govern. Print. Office. $363 \mathrm{p}$.

HERRING, H.C., 1970. Soil Hoisture Trends under three Different Cover Conditions. U.S. Porest Serv. Research Note Pill-114. In: Forestry Abstracts, 32: 29, 1971.

HEVLITI, J.D.; DOUGLASis, J.J. \& CLUTTER, J.I., 1964. Instrumental and Soil hoisture Variance Using the Neutron Scattering Method. Soil Sci., 97: 19-24.

HILI, R.D., 1972. Soil Moisture Under Forest, Bukit Timah Nature Reser ve, Singapore. Gard Bull., 26(1): 85-93. In: Selected Vater Res. Abstracts, 7(11): 9, 1974 .

HONNBCK, J.W., 1970. The Radiant Energy Budget of Clearcut and Forested sites in Vest Virginia. Forest Science, 16(2): 139-145.

IVATSUBO, G. \& TSUTSUMI, T., 1968. On the Amount of Plant Nutrients Sup plied to the Ground by Rainwater in Adjacent open Plot and Forests. (III). On the Amount of plant sutrients Contained in Run-off Water. Bull. Kyoto univ. no 40: 140-156. In: Forestry Abstracts, 32 (4), 1971.

JACKson, I.J., 1971. Problems of Bhroughrall and Interception Assesment Under Tropical Forest. Jour, of Iydrolosy, 12:234-254. 
JOMNSON, P.L. \& SHNK, H.T., 1973. Studies of Cation Budgets in the so uthern Apralachians on rour Bxperinchtal Vatersheds with Contrasting Vegetation. Ecolosy, 54(1): 70-80.

JOHNSTON, R.S.; TEW, R.K. \& DOTY, R.D., 1969. Soil Hoisture Depletion and Estimated Rvapotranspiration on Utah Mountain Watersheds. USDA Forest Service, Research Pajer Int.-67. 13 p.

JohNSTON, R.S., 1970. Bvapotranspiration from Bare, Herbaceous, and As pen Plots: A Check on a Pormer study. Water Res. Research, 6(1): $324-327$.

JORDAH, C.F. \& KITN, J.R., 1972. Mineral Cycling: Some Basjc Concepts and their Application in a rropical Rain Forest. Annual Review of Ecolosy and Systematics, 3: 33-50.

KAPLAN, J., 1961. Water Relations in Wucalypts. 2nd World Eucalyptus Conference. RÁ. São Paulo. p.: 1008-1012.

KARSCHOn, R., 1971. The Effect of Coppice Cutting on the Water Balance of Bucalyptus camalciulensis Dehn. The Israel Jour. of Arric. Rese $\operatorname{arch,~21(3):115-12ú.~}$

KARSCHOH, R•, 1973. Comunicação pessoal.

KARGCHOH, R. \& HETH, D., 1967. The Vater Balance of a Plantation of Eucalyptus camaldulensis, Dehn. Contrib. on Eucalypts in Israel, III: $7-34$.

KAUI, O.H. \& BILIINGS, W.D., 1965. Cation Content of Stemflo: in Some Forest Trees in North Carolina. The Indian Forester, 91(6): 367370.

KEREISKI, S., 1970. Interception of Rainfall by the Crown and Litter of Pinus nigra. Gorskostop. Nauka, 7(5): 39-52. In: Forestry Abstracts, 32(4), 1971 .

KIMMIS, J.P., 1973. Some Statistical Aspects of Sampling Throughfall Precipitation in Nutrient Cycling Studies in British Columbian Coastal Forests. Ecolosy, 54(5): 1008-1019.

KITCHIIG, R., 1967. Water Use by Tree Plantations. Jour. of Hyarolosy, 5: $206-213$.

KITTREDGE, J.; LOUGHSAD, H.J. \& MAZURAK, A., 1941. Interception and Sternflow in a Pine Plantation. Jour. of Forestry, 39: 505-522.

KOLRR, K.R., 1967. Wxponential Depletion of Soil Moisture by Evapotranspiration at Forest Sites in the Sierra Nevada, as Related to 
Available Soil lloisture and Vapor Pressure Deficit. Dissor. Abstr., 27-B(10): 3364. In: Forestry Abstracts, 29(11): 62, 1968.

KUnkL, S.H., 1974. Agua - su Calidade suele Depender del Forestal. Unasylva, 26(105): 10-16.

LEOHAD, R. S., 1961. Net Precipitation in a Northern Hardwood Rorest. Jour. of Geoph. Research, 66 (8): $2417-2421$.

LiNOARD, R. R., 1967. Mathematical Theory of Intercention. In: Int. syme. on Porest inyrolom. Percanon Press. Nev York. 131-136.

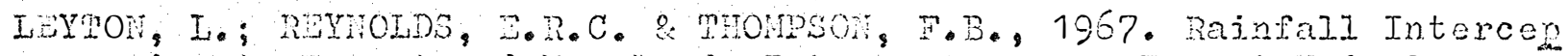
tion in Forest and Hoorland. Tntern. Symp. on Forest Mydrolocy. Pergenon press, New York. 163-170.

LIGON, J.T. 2 VIJSON, T.V., 1972. Doep Seepage on piedmont vatersheds. Werter Resources Rescarch Institute, Clemson University, Report no 29. $66 \mathrm{p}$.

LIMDN, G. B. \& BATON, J.S., 1970. A Polyurethane stemflow Collector for Trees and Shrubs. Ecoloey, 51(5): 938-939.

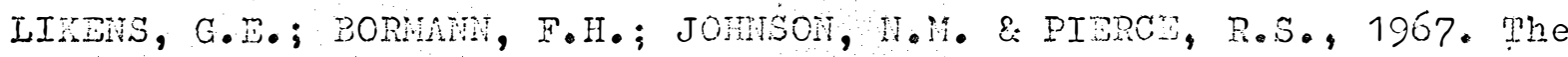
Calcium, Vagresiun, Totassiun, and sodium Buagets for a smali Foreste Ecosystem. Bcolosy, 48(5): 772-735.

LINSLEY, Jr., R.K.; KOHIJR, H.A. \& DNULHUA, J.I.H., 1949. Applied Hydrom IoGJ. McGraw-Jill Book Co., Hew York, 689 p.

LOH, K.S., 1972. Intercention Joss in the Humid. Forested Breas (with es pecial reference to Sungai Lui Catchement, West Malaysia). Malayan Nature Jour., 25(2): 10\%-111. In: Forestry Abstracts, 35(3): 615, 1974.

MAHENDRAPPA, M.K., 197\%. Chemical Composition of Stemflow from Sone Eas tern Canadian Tree Species. Canadian Jour. of Forest Research, 4 (1): 1-7. In: Forestry Abstracts, 35(10): 5772, 1974 .

MCCLURKIH, D.C., 1958. Soil Moisture Content and Shortleaf Eine Radial Grovth in North Mississipi. Forest Science, 4(3): 232-238.

McCOLI, J.G., 1970. Properties of Some Natural haters in a Tropical Het Forest of Costa Rica. Bio-Science, 20(20): 1096-1100. In: Forestry Abstracts, 32(4); 1971.

MCKEE, J.J. \& VOJF, H. H., 1963. Water hality Criteria. California Sta te hater Resources Control Boara, $2 u b \cdot 3-1 \cdot 540$. 
HomuGHen, K.G. B BIACH, T.A., 1973. A Study of Evopotranspiration From a Douglas Fir Forost Using the Dnersy Balance Approach. Water Resour. Research, 9(6): 1579-1590.

MaLLo, H.Aa, 1960. Contribuiçẽo ao Pstudo do Consuno de Água por Eucalyptus alba Rein, Piptadonia rinjda Benth e Astronium urundevve

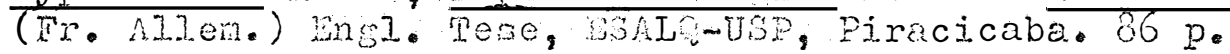

MITZ, L.J. \& DOUGLASS, J.R., 1959. Soil Mojsture Depletion Under Several Piedmont Cover Types. USDA, Forest Service, Techn. Bulzetin no 1207. 23 j.

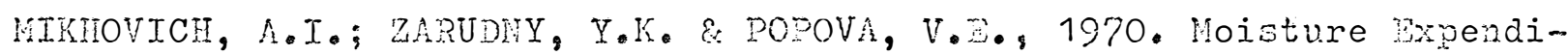
ture by Forest and Fields in the Protective Afforestation Regions. Les. Agroles. Resp. Mezhved Temat Nauch 56(20): 113-119. In: Selected Vater Res. Abstracts, (7):2: 30, 1974.

MTHA, V.N., 1967. The Effect of Stem-flo: on the Soil. Pocroved, 10: 44-52. In: Forestry Abstracts, 309/: : 3687, 1969.

MOBHRIMG, D.K. \& RALSTON, C.W., 1967. Diameter Growth of Lobloliy Pine Related to Available Soil Yoisture and Rate of Soil Hoisture Loss. Soil Sci. Soc. of Antar. Proc., 31(4): 560-562.

MOLCHANOV, A.A., 1963. The Hydrolopical Role of Forests. Transl. from Russian. USDh, Nat. Sci. Foundation. l.07 p.

HURPHY, Jr., C.ت. \& KNOERR, K.R., 1975. The Evaporation of Intercepted Rainfall from a Forest Stand: An Analysis by Simulation. Water Res. Research, 11(2): 273-280.

NICOLSON, J.A.; THORUD, D.B. \& SUCOFT, E.I., 1968. The InterceptionTranspiration Relationships of thite spruce and thite Pine. Jour. of Soil and Vater Conservation, 23(5): 181-184.

NIULGARD, B., 1969. Distribution of Rainfall in Beech and spruce Fom rest, a Comparison. Abst. in Bot. Notiser, 122(2): 308-309. In Fo restry Abstracts, 31(1): 70, 1970.

MIHLGAD, 3., 1970. Precipitation, its Chemical Composition and Effect on Soil Vater in a Beech and a Spruce Forest in south Sweden. Oikos, 21(2): 203-217. In: Forestry Abstracts, 32(4), 1971.

HISHIMURA, T., 1973. Hovement of Nutrients in a Small Kountainous and Forested Watershed. Jour. of the Japan. For. Soc., 55(11): 323333. In: Forestry Abstracts, 35(10): 5906, 1974.

ORR, H.K., 1968. Soil-roisture Tronds After phinning and Clearcutting in a second-Growth Ponderosa Pine stand in the Black Hills. U.S. Forest Service Research llote Ril-99. $8 \mathrm{p}$. 


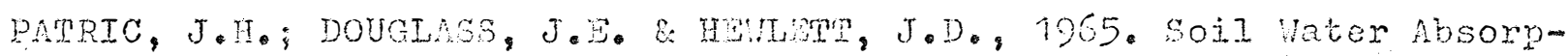
tion by Homtain and piedmont Forests. Soil Sci. Soc. of Amer. Proc., 29: 303-303.

PMMAN, Hete, 1967. Fvaporation from Roxests: a Comparison of Theory and Obcervation. In: Int. Symp on Rorest Hydrolow. Pexganon press, N. Yoxk. p.: $373-300$.

PIERCE, R.S., 1965. Water - Prality Probejms Related to Timber Culture and Harvesting. In: Proc. Mun. Vatershed Manag. Symp. Publ. 446, Univ. of Hassachusetts and U.S. Dept. of Agriculture. 45-43.

POZDrYMoV, L.K., 1956. The role of Rain Penetrating Beneath the Forest Canopy in the Process of the Dxchange of laterial Betweon Forest and soil. Dolsl. Akad. Nauk, 107: 753-756. In: Soij and Tertilizers, 19, 1956.

RAKHMnNOV, V.V., 1953. Are the Precintations Intercepted by the Iree Croms a toss to the Forest? Botanicheskii Rhumal, 43: 1630-1633. Transl. from Russian. Israel Proge for scient. Translations, PST' Cat. $n 293$.

RAHZANI, G., 1956́. Ievantanento da Carta de Solos da Seção réenica "Qujuica Acrícola" da Dscola Suerior de Agricultura "Iuiz de ouei roz". Tese de Livre-Docência. 36 p. + tabelas e mapas.

PAINANI, G. ; PREIRE, O. \& KINJO, T., 1966. Carta de Solos do Município de Pinacicaba. Centro de Mstudos de Solos. MSAln-UgP. 85 p.

RAPP, H. \& ROMANS, F., 1968. The Vater Balance in the Mediterranean $\mathrm{Sm}$ cosystems. I. Throushell of precipitation in stands of enercus ilex and Dinus halepensis. Ncol. Olant., 3(4): 271-284. In: Pores try Abstracts, 31(1): 68, 1970.

REICHARDT, Ko, 1972. Rvaporação da Ácua do Solo. CBNA, ISAIO, Bol. Cien tífico BC-0O4. 30 p.

REICHART, $K_{\text {e }}$ 1973. Física dos Processos de Transferencia mo Sistema Solo-Planta-Atmosfera. Vol. III. Publ. Especial no CZnA, BSALUSP.

REPNEVSKA A, H., 1969. Soil Moisture Regine in the scots pine rorests of the Kola Peninsula. Lesoved., Moshva, 3: 78-82. In: Forestry Astracts, 31(2): 2143, 1970 .

REYHOLS, S.G., 1970. The Gravimetric lethod of sojl Noisture Determina tion. Dart I: A study of Bquipnent and Nethodolocical problcms. Jour. of Hydrology, 11: 258-273. 


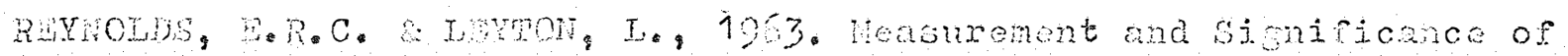
Throughell tin Forost stands. Fn: The thter Rolations of plonts. Blachell sciont. Publications. Nolard e Gon tita. Bngland. p. $127-1 / 1$.

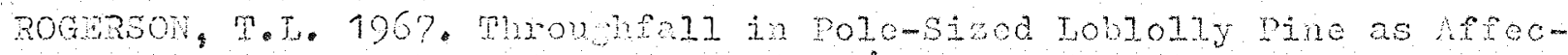
ted by stand Density. In Tht. Symo on Porest Hydrolon. Percamon Press. H. York: 187-190.

Rogupon, T.I., 1968. Mnining Incroases Throughell in Loblolly pine Plantations. Tour. of soil and vater Consorvation, $23(4): 141-$ 142.

ROGERSOH, T.I. \& BYZMES, H.R., 1960. Net Rainfall Under Hardwoods and Red Pine in Central Ponoylvania. Wher Resour. Research, 4(1): $55-57$.

Ronycher, Je, 1963. Net Precipitation Uader a Douslas-Pir Forest. Horest science, $9(4): 423-423$.

RUnTrR, A.J., 1963. Studies in the Water Relations of Pinus Sylvegtris in plantation Conditions. I - Heasurements of Rainfall and Intexception. Jour. of Fcolosy, 51: 191-203.

Rurren, A.J., 1967. An Anoyyisis of Wvaporation from a stand of Scots Pine. In: Int. Sym. on Forest Hydroloy. Percamon Press. H.York. p.: $403-477$.

RUTTPR, A.J., 1968. Vater Consunption by Forests. In: Water Deficits

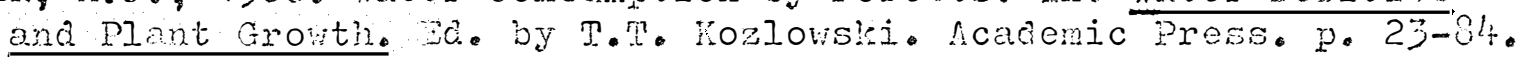

SARTZ, R.S., 1972 . Soil Water Depletion by a Hardwood Porest in South vestern Visconsin. Soil Sci. Foc. of hmer. Proc., 36(6): 961-964.

SARTZ, R.S., 1972 . Anomalies and Sampling Vaxiation in Porest Soil Va. ter Measurenent by the ileutron hethod. Soil Sci. Soc. of hmer. Proc., 36(1): 148-153.

SCHRODER, R., 1956. Distribuição e Curso Amul das Precipitações no DS tado de são Paulo. Braçantia, 15(18): 193-249.

SCHULTE, J.D., 1967. Current Status of Boil-Hoisture Heasurement by the lieutron Hethod. In: Tnt. Bymp. on Forest Hyorolocy. Percamon Press. 1. York. p: 791-796.

SECRETARIA DA ACRICUTHUA, 197\%. Programação PIurianual de Reflorestam meato de são paulo. S.A., Instituto Florestal, são paulo. 2o p. 6 arpas. 


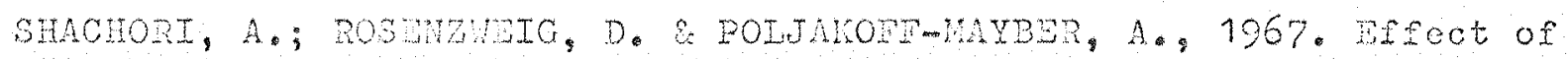
Heditexranom Vegetation on the nototure Regime. In: Int. Syra. on rorest ilydrolocy. Pexganon Press. Hork. p.: 231-311.

SHPAK, I.S., 1971. Whe Erects of Torests on the fater Balance of Drai nace Dasins. Translated from Rusian. Israel Prog. for Scientific Translations L.ta. $258 \mathrm{p}$.

StM, I.K., 1972. Interception Joss in the Iumia Porestod Areas. Malay Nat. Jo, 25(2): 104-111. In: Selected Vater Res. Abstracts, $7(13)$ : 7. 1974 .

SKAU, C.Y., 1964. Interception, Throughfall, and Stemflow in vtah and Allicator Junipor Cover Types of Northern hrizona. Forest Science, $10(3): 283-287$.

SHITI, M.K., 1973. mhroughfall, Stemflow, and Interception in pine and - Bucalypt rorest. Australian Foxestry, 36(3): 190-197.

SOERIANEGARA, I., 1970. The Role of Rainfall in the Recycling of Nutri ents in Terrestrial Ecosystems. Rimba Indonesia, 15(1/2): 36-41.In: Forestry Abstracts, $32(4), 1971$.

STAMHER, H.N.; IGHE, O.C. \& WHITBISY, H.R., 1973. Calculation of Evam poration from leasurenent of Soil vater and the soil Water Charac teristic. Canadian Agric. Fngineering, 15(1): 2-5.

SWANK, U.T.; GOEBII, N.B. \& HELVEY, J.D. 1972. Interception Loss in Loblolly Pine Stands on the South Carolina Piedmont. Jour. of So il and Water Conservation, 27(4): 160-164.

TAmid, C.B., 1968. Evaporation of Water from Plants and Soil. In: Water Deficits and Plant Growth. Ed. by T.T. Kozlowski. Academic Press. p.: 73-106.

TARRATT, R.F., 1968. Nutrient Cycling by Throughiall and Stemflow Precipitation in Three Coastal Oregon Forest rypes. USDA Forest Service Research Paper'ne PNH-54. In: Forestry Abstracts, 30(3): $3686,1969$.

TAYLOR, A.W०; EDHARS, W.Y. E SIMPSON, B.C., 1971. Wutrients in streams Drainin voodland and Farmland Near Coshocton, Ohio. Vater Resour. Res., $7(1)$ : 81-89.

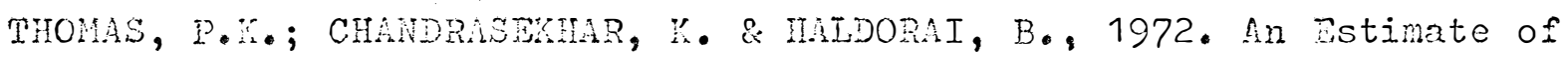
Transpiration by Ducalyptus riobulus from lilgiris Vatersheds. In dian Forester, 98(3): 168-172. 
IHOMPSON, T.B., 1970. Seasonal Painfall Interception by Oak Coppice (cuercus robur $\mathrm{D}_{0}$ ) in the Leafy anci Leafless state in Southern Encland. In: Aspects of Porost climates (Aberystwyth Symp. in Acric. Heteorology no 13). In: Forestry Abstracts, 32(4), 1971.

THORITHAITE, C.H. \& MAjHeR, J.R., 1955. The Water Balance. Drexel Inst. of Technolocy. Dubl. in Climatolosy, Vol. VIII, no 1. $86 \mathrm{p}$.

PHORUD, D.3., 1963. Effects of Pruning on Rainfall Interception in a Minnesota Red Pine Stand. Forest Science, 9(4): 452-455.

TOLLANAR, P. R RYCHBORST, H., 1975. The Effect of Conifers on the Che mistry and hass Balance of wo Large Lysimeters in Castricum (The Netherlands). Jour. of Ifydrology, $24(1 / 2): 77-87$.

TRIMBLE, Jr., G.R., 1969. Dianeter Growth of Individual Hardwood Tress. USDA Forest Service Research Paper Ni-145. $25 \mathrm{p}$.

TRIMBDE, Jr., G.R. \& UITZMA, S., 1954. Effect of a Hardwood Forest Canopy on Rainfall Intensities. Trans. Amer. Geoph. Union, 35(2): $226-234$.

TROENDLE, C.A., 1970. A Comparison of Soilmoisture Loss from Forested and Clearcut Areas in Vest Virginia. USDA Forest Service Research Note No-120. $8 \mathrm{p}$.

U.S. PUBJIC MAITH SERVICD, 1962. Drinking Water Standards. U.S. Gov. Print. •ffice. 61 p.

VALEHZIANO, S. \& SCARAMUZZI, G., 1967. Preliminary Observations on the Seasonal Diameter Growth of Bucalyptus camaldulensis and T. Viminalis. Fio, World symp on lan-ilade Forests and their Industrial Importance. Canverra: 1923-1939.

VOit ARX, W.S., 1974. Energy: Natural Linits and Abundances. E.0.S. prans. Amer. Geoph. Union, 55(9): 828-832.

VEIHMEYER, F.J., 1953. Use of Water by Native Vegetation versus Grasses and Forbs on Vatershedis. Trans. Amer. Geoph. Union, 34(2): 201212.

VOIGT, G.K., 1960. Distribution of Rainfall Under Forest Stands. Forest Science, 6(1): 2-10.

HRD, R.C., 1971. Heasuring Bvapotranspiration: a Review. Jour. of Hydrolosy, 13: 1-21.

WEIIL, J., 1973. Whe Reaction of Reech and spruce stands to Rain. AII¿enl. Forstzeitschrift, 28(42): 956-957. In: Forestry nbstracts, 35 (8): 4101, 1974. 


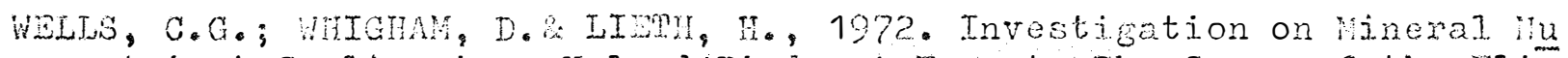
trient Cycling in a Upland piedmont porest. The Jour of the EI $=$ sha Hitchell Bcient. Boc., 88(2): 66-78.

VILI, G.H., 1955. Renoval of Mineral nutrients from tree Croms by Rain. vature, 176: 1180 .

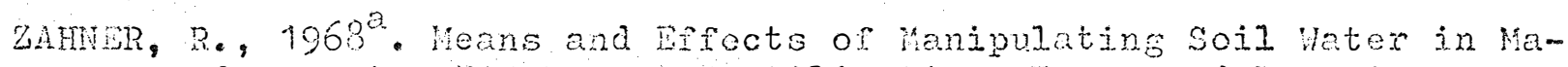
nased Forests. In: Forest pertilization, Peory and Practice. T.V.A., 10-14.

ZAmpr, R. 1968 ' vater Deficits and Growth of Trees. In: Water Deficits and plant crowth. Ba. by M. Wozlowski. Acedemic Press. $\mathrm{p} \cdot \mathrm{:} 191-254$.

ZINKE, P.J., 1967. Porest Interception studies in the united states. Intern. Symp. on Porest Hydrolocy. Percamen press. If. York. p. $137-161$.

2ON, R., 1927. Forests and Hater in the Jisht of Scientific Investigam tion. USDA Forest Service. U.S. Gov. Print. Orfice, Vashington. $106 \mathrm{pp}$. 